University of South Florida

DIGITAL COMMONS

@ UNIVERSITY OF SOUTH FLORIDA
Digital Commons @ University of

South Florida

8-1-2008

\title{
Travel Assistant Device (TAD) to Aid Transit Riders with Special Needs
}

CUTR

Follow this and additional works at: https://digitalcommons.usf.edu/cutr_nctr

\section{Recommended Citation}

"Travel Assistant Device (TAD) to Aid Transit Riders with Special Needs," National Center for Transit Research (NCTR) Report No. CUTR-NCTR-RR-2006-06, Center for Urban Transportation Research, University of South Florida, 2008.

DOI: https://doi.org/10.5038/CUTR-NCTR-RR-2006-06

Available at: https://scholarcommons.usf.edu/cutr_nctr/156

This Technical Report is brought to you for free and open access by the National Center for Transit Research (NCTR) Archive (2000-2020) at Digital Commons @ University of South Florida. It has been accepted for inclusion in Research Reports by an authorized administrator of Digital Commons @ University of South Florida. For more information, please contact digitalcommons@usf.edu. 


\title{
Travel Assistant Device (TAD) to Aid Transit Riders with Special Needs
}

Final Report

FDOT BD549 WO 33

\author{
Prepared for \\ Florida Department of Transportation
}

605 Suwannee Street, MS 30

Tallahassee FL 32399

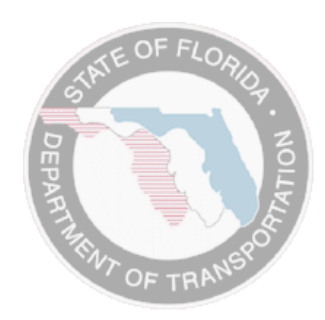

Prepared by

National Center for Transit Research

at the Center for Urban Transportation Research

University of South Florida

4202 E. Fowler Ave. CUT100

Tampa FL 33620-5375

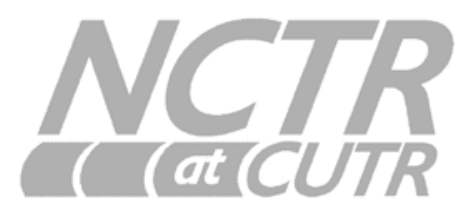

August 2008 


\section{Disclaimer}

The opinions, findings, and conclusions expressed in this publication are those of the author(s) who are responsible for the facts and accuracy of the data presented herein. The contents do not necessarily reflect the views or policies of the Florida Department of Transportation or the Research and Special Programs Administration. This report does not constitute a standard, specification, or regulation.

The report is prepared in cooperation with the State of Florida Department of Transportation and the U.S. Department of Transportation.

\section{Patents Pending}

Multiple patents on the TAD system and components are pending, USF 2008. 


\begin{tabular}{|c|c|c|c|c|}
\hline \multicolumn{2}{|l|}{$\begin{array}{l}\text { 1. Report No. } \\
\text { FDOT-BD } 549 W O \# 33\end{array}$} & \multicolumn{2}{|c|}{ 2. Government Accession No. } & 3. Recipient's Catalog No. \\
\hline \multirow{2}{*}{\multicolumn{4}{|c|}{$\begin{array}{l}\text { 4. Title and Subtitle } \\
\text { Travel Assistant Device (TAD) to Aid Transit Riders with Special Needs }\end{array}$}} & $\begin{array}{l}\text { 5. Report Date } \\
\text { August } 2008\end{array}$ \\
\hline & & & & 6. Performing Organization Code \\
\hline \multicolumn{4}{|c|}{$\begin{array}{l}\text { 7. Author(s) } \\
\text { Sean Barbeau, Phil Winters, and Nevine Georggi }\end{array}$} & $\begin{array}{l}\text { 8. Performing Organization Report No. } \\
\text { NCTR-77609-00 }\end{array}$ \\
\hline \multirow{2}{*}{\multicolumn{4}{|c|}{$\begin{array}{l}\text { 9. Performing Organization Name and Address } \\
\text { National Center for Transit Research at the Center for Urban Transportation } \\
\text { Research, University of South Florida } \\
\text { 4202 E. Fowler Ave. CUT100 } \\
\text { Tampa FL 33620-5375 }\end{array}$}} & 10. Work Unit No. (TRAIS) \\
\hline & & & & $\begin{array}{l}\text { 11. Contract or Grant No. } \\
\text { FDOT-BD 549WO\#33 }\end{array}$ \\
\hline \multirow{2}{*}{\multicolumn{2}{|c|}{$\begin{array}{l}\text { 12. Sponsoring Agency Name and Address } \\
\text { Florida Department of Transportation } \\
605 \text { Suwannee Street, MS } 30 \\
\text { Tallahassee FL } 32399\end{array}$}} & & & $\begin{array}{l}\text { 13. Type of Report and Period Covered } \\
\text { FINAL Report }\end{array}$ \\
\hline & & & & 14. Sponsoring Agency Code \\
\hline \multicolumn{5}{|c|}{$\begin{array}{l}\text { 15. Supplementary Notes } \\
\text { Sponsored by a grant from the Florida Department of Transportation and the U.S. Department of Transportation }\end{array}$} \\
\hline \multicolumn{5}{|c|}{ 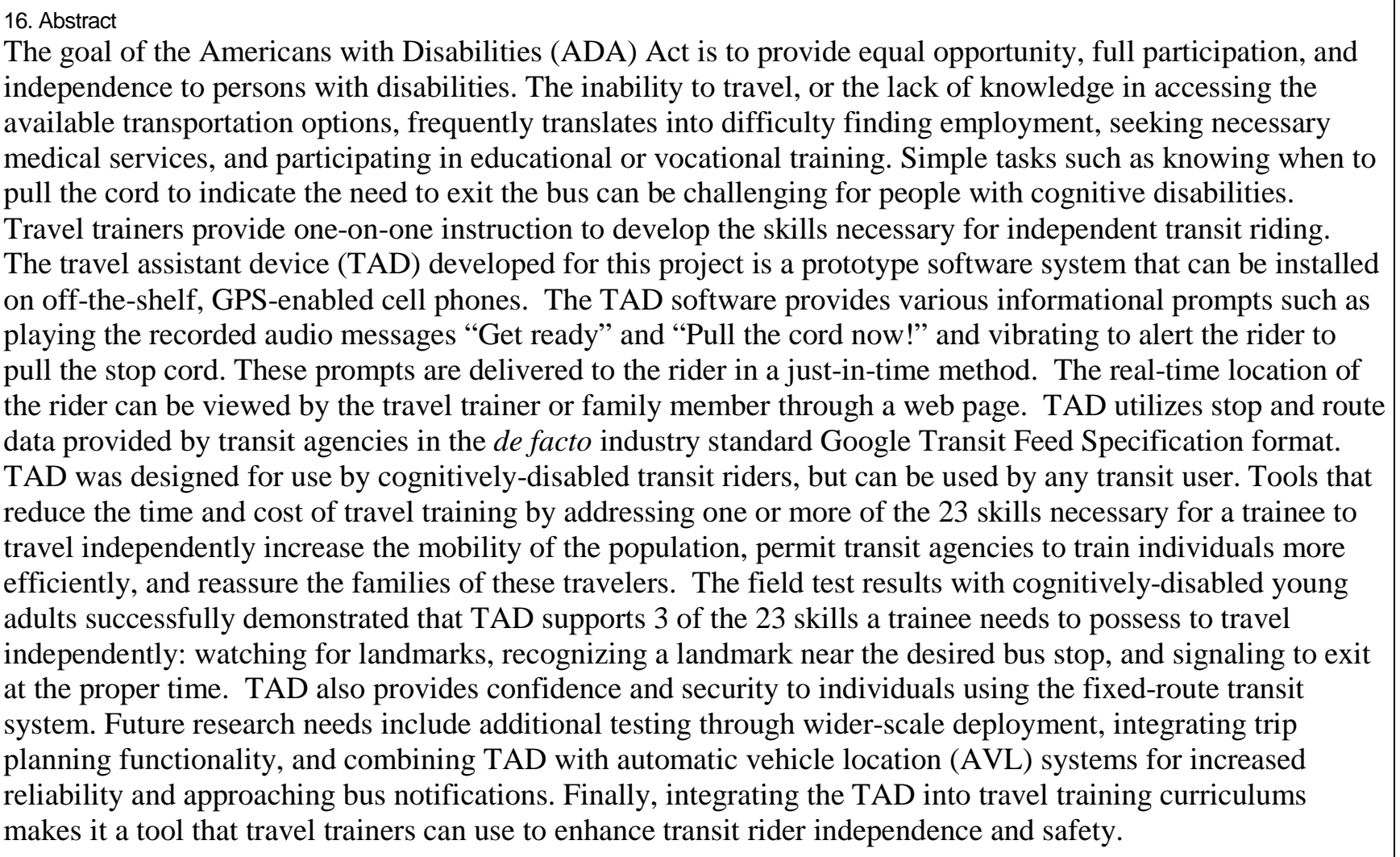 } \\
\hline \multirow{2}{*}{\multicolumn{2}{|c|}{$\begin{array}{l}\text { 17. Key Word } \\
\text { Travel training, cognitive disabilities, location based systems, } \\
\text { LBS, public transportation, paratransit, global positioning } \\
\text { system, GPS, special needs, cellular, mobile }\end{array}$}} & \multirow{2}{*}{\multicolumn{3}{|c|}{$\begin{array}{l}\text { 18. Distribution Statement } \\
\text { Available to the public through the National Technical Information Service } \\
\text { (NTIS), } 5285 \text { Port Royal Road, Springfield VA 22161, (703) 487-4650, } \\
\text { http://www.ntis.gov/, and through the NCTR website at http://www.nctr.usf.edu }\end{array}$}} \\
\hline & & & & \\
\hline $\begin{array}{l}\text { 19. Security Classif. (of this rer } \\
\text { Unclassified }\end{array}$ & 20. Security $\mathrm{Cla}$ & is page) & 21. No. of Pages & 22. Price \\
\hline
\end{tabular}




\section{Acknowledgements}

This report is prepared by the National Center for Transit Research through the sponsorship of the Florida Department of Transportation (FDOT) and the U.S. Department of Transportation.

The authors appreciate the efforts of Mr. Mark Sheppard, Travel Trainer at Hillsborough Area Regional Transit (HART), and Ms. Gigi Gonzalez, Transition Facilitator, Exceptional Student Education, School Board of Hillsborough County, USF Department of Special Education.

FDOT Project Manager:

Amy Datz, FDOT Public Transit Office

Project Team:

Sean Barbeau, Principal Investigator and Research Associate, CUTR

Philip L. Winters, TDM Program Director, CUTR

Nevine Labib Georggi, Research Associate, CUTR

Miguel Labrador, PhD, College of Engineering, USF

Rafael Perez, PhD, College of Engineering, USF

Computer Science and Engineering Students Team:

Alfredo Perez

Dmitry Belov

Milena Sarmiento

The research team thanks the Sprint-Nextel Application Developer Program for its cooperation and the donation of phones and cellular service that were tested as part of this research project. 


\section{Executive Summary}

A 2001 NCTR study of barriers to transit use involved field testing that collected information on how well participants could plan transit trips by determining bus routes, bus stops, and schedule times. A total of 57 percent of the responses received from field test participants were negative in relation to how they would feel about using the transit information materials to plan an actual bus trip. Many participants expressed that the transit trip planning tasks were difficult, even with the extensive instruction provided by the observers/interviewers. Participants described feeling frustrated, irritated, and confused as a result of the trip planning tasks they were asked to complete. A number of the field test participants were so flustered by the transit trip planning experience that they indicated they would not attempt to take the bus trip if the transit information materials presented were the only resources available. The responses received from these participants suggest that the task of planning a transit trip using only the printed materials presents so great a challenge that it discourages individuals from trying public bus service. This situation is magnified for many of the 50 million Americans with disabilities who depend on transit as their primary means to and from school, work, doctor appointments, and other essential activities.

The goal of the 1990 Americans with Disabilities (ADA) is to provide equal opportunity, full participation, and independence to persons with disabilities. For many people, transit is a travel option for jobs, schools, shopping, or other destinations. For persons with disabilities, transit is often the sole means of mobility. The inability to travel, or the lack of knowledge in accessing the range of transportation options in the community, frequently translates into difficulties finding employment, seeking necessary medical services, participating in educational or vocational training, recreation, leisure, and other community activities. Travel training began as a mandate by the ADA to instruct children with disabilities on how to move safely from one place to another. It then expanded into a service available to any individual new to transit in general or to a community in particular. Transit trainers invest time and labor in providing one-on-one instruction to develop the skills necessary for independent transit riding. Any and all tools that increase the efficiency of the training process should be used by transit agencies to redirect resources better used to train more individuals in utilizing fixed-route transit. The latest figures indicate that the operating cost per trip for complementary paratransit service is $\$ 22.14$, compared to $\$ 2.75$ for fixed route transit.

Travel training is short-term, comprehensive, individualized instruction provided by qualified personnel to individuals with disabilities other than blindness or visual impairments. Travel trainers teach the skills and techniques necessary for individuals with disabilities to negotiate public environments, including public transportation when appropriate, in a safe and independent manner. The instruction is customized to the person's needs and abilities and is taught in the environment in which the individual is expected to travel. To travel independently, a trainee must demonstrate 23 skills that include reading the bus schedule and/or finding routes; leaving the place of origin and arriving at the bus stop on time; demonstrating appropriate street crossing skills; carrying a bus pass; paying the correct fee; identifying the correct bus through number, color, style, or 
asking the driver for a bus transfer if needed; watching for landmarks and recognizing a landmark near the desired bus stop; and signaling to exit at the proper time, among others. The travel assistant device developed for this project is a prototype software system that can be installed on off-the-shelf, GPS-enabled cell phones. The Travel Assistant Device (TAD) software provides various informational prompts such as playing the recorded audio messages "Get ready" and "Pull the cord now!" and vibrating to alert the rider to pull the stop cord. These prompts are delivered to the rider in a just-in-time method. The realtime location of the rider can be viewed by the travel trainer or family member through a web page. TAD utilizes stop and route data provided by transit agencies in the de facto industry standard Google Transit Feed Specification format. TAD was designed for use by cognitively-disabled transit riders, but can be used by any transit user.

Previous research using mobile devices to aid persons with disabilities has been performed by various institutions and companies to prompt the initiation of tasks, such as taking medications or remembering appointments. An off-the-shelf, Pocket PC-based navigation system has been modified to allow simple communication with the visually impaired but does not allow real-time communication with the Internet. Therefore, it does not provide tracking services or remote monitoring by a travel trainer or caretaker. Additionally, the high cost of the system, almost $\$ 2,000$, represents a significant financial burden for the user. In a 2003 research project, the University of Colorado's Coleman Institute used an off-the-shelf device to create a prototype transportation guidance device but concluded that "no hardware platform exists yet with all needed capabilities" for creating an all-in-one mobility assistant device. Another prototype, Opportunity Knocks, showed significant promise for automatically detecting when an individual is lost based on GPS data recorded from a cell phone coupled with a modular GPS unit. However, while the system provides alerts when it senses the individual is lost, it does not provide proactive cues to the user to indicate when they should exit the transit vehicle. Additionally, the system must have prior travel learning behavior in its memory to benchmark normal performance, and thus cannot provide alerts for new riders. Combining separate cell phone and GPS units drives up total system costs and has a design that may be awkward for the disabled user to carry.

Existing literature on navigation skills for those with cognitive impairments was consulted as part of the TAD design process. Recent research suggests that the task of real-time navigation is most successful when guided by auditory prompts. One study found that auditory alerts are not only the most effective type of prompts for real-time navigation for cognitively impaired individuals, but they are also the most preferred by participants. The authors attribute these findings to the cognitive process of navigation, which occupies the visual processing components of the brain. Prompts that require visual attention such as maps, images, or written directions can conflict with the visual component of navigation itself. Therefore, the auditory processing of directives does not directly conflict with the visual information that the individual is receiving and allows the subject to handle both tasks simultaneously.

TAD was designed primarily to deliver an auditory prompt that alerts the individual to exit the bus. Additional visual and tactile (i.e., vibration) prompting also were implemented as secondary prompting methods. The research team conducted an extensive analysis of 
mobile phone technology to evaluate the feasibility of using mobile phones as a travel assistant device. This investigation included an analysis of positioning methods available for cellular networks and devices, methods of software development to gain access to position data, software standardization and compatibilities for mobile phones, and the current status of positioning techniques. The TAD system is a software communication architecture that enables GPS-enabled mobile phones to provide end-user travel services to the person carrying the phone. For the initial phase of TAD development, three main services were targeted for implementation: the delivery of real-time auditory prompts to the transit rider via the cell phone, informing them when they should request a stop; the delivery of an alert to the rider, caretaker, and travel trainer if the rider deviates from his or her expected route; and a web page that allows travel trainers and caretakers to create new itineraries for transit riders as well as allow monitoring of real-time rider location.

In the TAD system design, there were three primary goals:

1) Make the system low-cost and widely accessible.

This involves using off-the-shelf, consumer-grade, GPS-enabled cell phones for a compact, inexpensive, all-in-one solution. Standards-based solutions also were used to allow interoperability on multiple platforms (i.e., different cell phones and cellular carriers). In addition, open-source solutions were used when possible to reduce implementation and management costs to transit agencies. Finally, to minimize future development costs, the software is forward-compatible with future mobile devices.

2) Make the architecture modular, allowing system components to be reused when possible; new features can easily be added in future versions.

Web services were used to allow the TAD systems to operate in heterogeneous computing environments on multiple platforms and operating systems. System entities were designed so that elements (i.e., database server) may be exchanged without disrupting the entire system

3) Provide a reliable service tailored to transit riders with special needs.

A simple, uncluttered user interface is provided for the user. To avoid confusion, only two auditory announcements ("Get ready” and "Pull the cord now!") are used. The phone vibrates to alert the user when to request a stop.

For over one year, TAD was continuously tested by project staff through iterative testing, development, re-testing, and debugging processes while resolving technical and software issues encountered during the testing period. To date, qualitative results indicate that TAD works precisely and is able to deliver notifications to the user in the exact location chosen by the travel trainer via the web page. Limited field tests with six cognitively-disabled young adults successfully demonstrated the proof-of-concept of the TAD system after overcoming institutional barriers and putting research subject protections in place. 
Ultimately, an efficient stop detection algorithm on the mobile phone was developed to address both limitations of computing resources on the mobile phone--that which prevents advanced spatial calculations, and the lack of complex spatial data from the Google Transit Feed defining the actual bus path. Testing revealed problems with the accuracy of the bus route and stop information obtained from the transit agency's Google Transit Feed. These data problems resulted in occasional missed or false alerts, demonstrating the importance of TAD's automated alarms for path deviation. The data problems can likely be minimized through improved quality control efforts on the part of the transit agency. The most frequently reoccurring errors encountered during TAD testing were related to inaccurate bus stop locations in HART's bus stop inventory. Recently, HART updated the bus stop inventory by re-geocoding all bus stop using GPS surveying units. Future TAD field tests utilizing the new inventory may find that the bus stop inaccuracy error is resolved.

The initial design, implementation, and field testing of the TAD software application running on commercially-available, GPS-enabled mobile phones that announce upcoming bus stops to the transit rider have been successful. The device with the proof-of-concept TAD software has been field tested in the Tampa area on HART transit bus routes with very promising results. However, several improvements remain to be researched, designed, tested, and implemented.

Several areas of the TAD software system can be improved. For example, improvements to the TAD mobile phone application user interface may help riders be less conspicuous when utilizing the TAD. Field-test participants stated their preference for a more discreet notification method to alert them of upcoming stops, as opposed to the alerts being announced via the device's speaker phone. Future versions of TAD could utilize Bluetooth ${ }^{\mathrm{TM}}$ wireless headsets so that the audio prompt for "Get ready" and "Pull the cord now!” would be heard privately by the rider through a headset.

Another function that could be added to the TAD system is trip inference. It may be possible to automatically predict which transit trip the rider currently wants to take by using his or her real-time position and past travel behavior. This feature could remove the requirement for the rider to select his or her trip from a list displayed on the phone and make the user experience simpler.

Trip planning functionality also could be integrated into the TAD website. Currently, the website user must have knowledge of the bus system's routes and schedule to set up a trip for a TAD user. Trip planning software such as Google Transit potentially could be integrated into the TAD system. Using a source and destination address, this software would be able to automatically plan a trip and set up the proper routes and schedules for download by the TAD mobile application.

While, for the majority of transit trips, TAD is able to alert the rider at the appropriate time, both bus stop detection and alert triggering algorithms should be enhanced to avoid giving alerts in very close proximity to the desired stop. The current algorithm provides some alerts in locations that require very fast rider reaction time in requesting a stop before 
the bus passes the destination stop. Advanced bus stop detection algorithms should give the rider notification earlier without giving the alert too soon.

The current requirement to detect the first stop for each segment should be removed to prevent possible failures due to an incorrectly geo-coded starting bus stop location. By removing this requirement, TAD will still alert the rider of his or her approaching destination stop even if the user was never detected as being near his or her starting stop. To further increase the reliability of TAD, it will be desirable to simultaneously monitor several segments ahead of the current segment instead of monitoring only the segment that is currently being traveled. Currently, if TAD doe not detect the ending stop of a segment, it will continuously search for the stop even if the rider has successfully exited the bus and is traveling on the next segment. By monitoring several segments ahead, TAD will move on to the remaining segments of a trip in case an intermediate bus stop joining two segments was not properly detected.

Future work should also focus on creating a tool that allows administrators to move bus stop locations in the database via the user interface. It is likely that many transit agencies will have inaccuracies in their bus stop inventory. Therefore, allowing the travel trainer to move the stop to the correct location would ensure that TAD functions correctly for that segment, while removing from the TAD system administrators the burden of manually updating datasets. Allowing direct placement by the travel trainer through a website tool also reduces errors in communicating information between parties and reduces the potential for human error during direct data manipulations in the database. Once a bus stop is manually moved, automatic updates via the Google Transit Feed should continue to take place, but the manually-adjusted bus stops would remain untouched during the update process. In the future, tools such as Google Earth ${ }^{\mathrm{TM}}$ 's Streetview, which provide a firstperson perspective of the street at the bus stop location, should prove very useful to travel trainers in remotely viewing the potential destination of a transit rider's planned trip.

Transit Automatic Vehicle Location (AVL) systems should also be studied to see what additional services can be provided to the user, such as providing the estimated time until arrival and ensuring that the rider boarded the correct bus. AVL should also be investigated as a potential backup positioning system when the mobile phone cannot calculate a GPS fix based on its embedded GPS hardware. Since AVL utilizes GPS antennas that are located on the exterior of the bus, it may be able to calculate position information in environments where a mobile phone cannot. While lack of an accurate GPS signal does not present a significant problem for newer phones with high-sensitivity assisted GPS technology, AVL may serve as an important backup for older mobile phones with less sensitive GPS. AVL may also be utilized to provide location-aware services to transit riders with mobile phones without GPS function. However, the quality of such a service would have to be researched and evaluated.

Further testing with other transit agencies is essential for the research team to observe the results of TAD functioning on a different transit system. Provided that a transit agency has an accurate and up-to-date bus stop inventory and that data are placed in the Google 
Transit Feed Specification format, the TAD system should be able to read the data and instantly add that agency to the system.

The task of integrating the TAD into travel training curricula is an open issue that will require input from multiple parties including special education professionals and travel trainers. Guidance for the training the trainers on TAD should be developed to ensure they utilize it properly during training sessions. Trainers should also be educated to assess that a rider is adequately prepared to independently use TAD to complete a trip. Further studies into defining the capabilities and skills needed for a rider to use this and future TAD applications are needed with input from parents, trainers, riders, and others to assure the user-friendliness and functionality of the application to riders with specific disabilities. Although field tests with special needs population proved rather challenging logistically, more is needed to refine TAD making it more applicable to different needs. For example, for the hearing impaired, in addition to alerting the rider by vibration of the phone, more visual alerts on the phone screen can be considered instead of current audio prompts.

Lastly, since no software system is 100 percent reliable, travel trainers should provide clients with fallback plans in case the TAD software is not able to alert the rider at the appropriate time. Both the tracking feature and the automated route deviation alert of the TAD software, along with general utility features of a cell phone, are designed to aid the travel trainer and/or guardian in case the rider becomes lost. However, in general, with or without TAD's assistance, different scenarios should be prepared and field tested for a particular rider according to his/her specific needs. Keeping in mind that TAD is designed to be a used as a tool, to aid in travel training and to enhance the rider's independence and safety, trainees should have ample opportunities to practice with their guardians and trainers so that some level of familiarity and confidence is attained before riding independently. 


\section{Table of Contents}

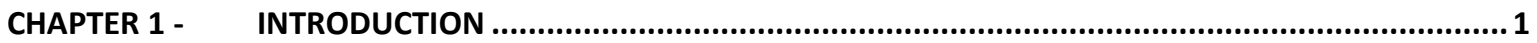

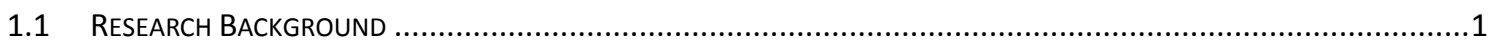

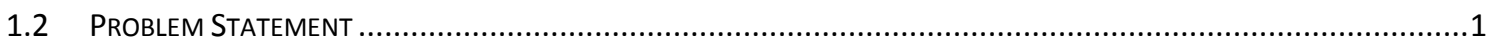

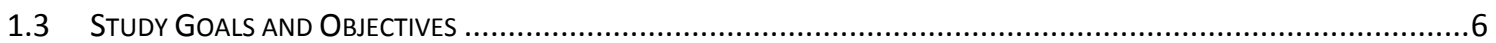

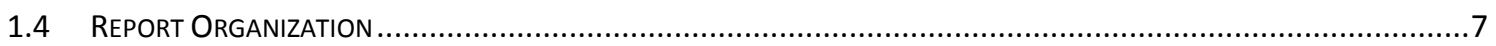

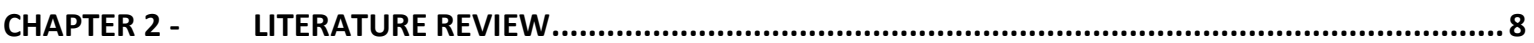

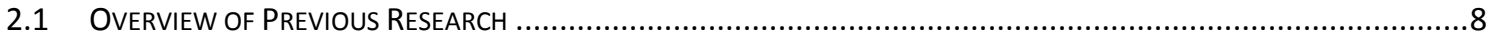

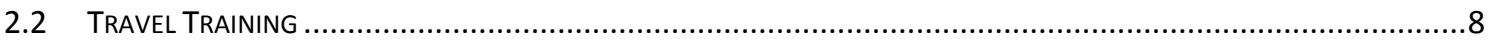

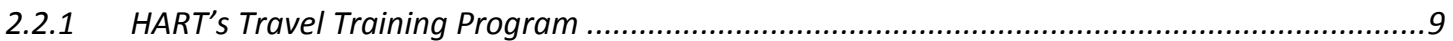

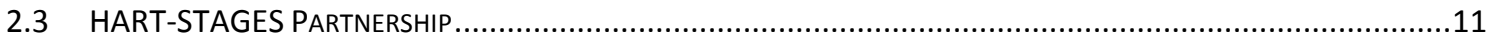

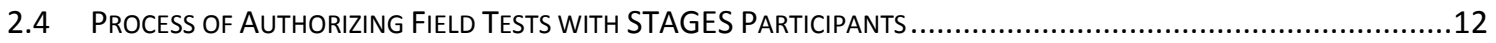

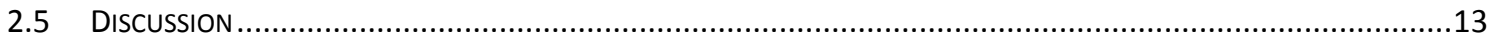

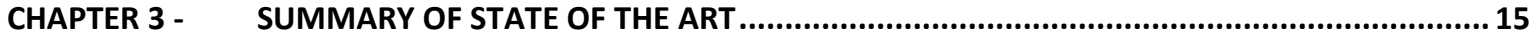

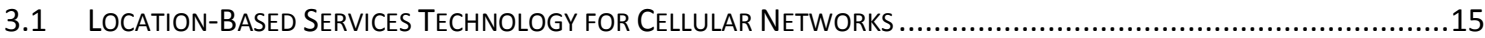

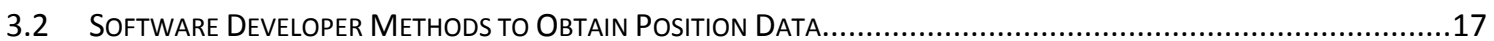

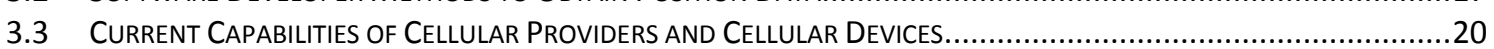

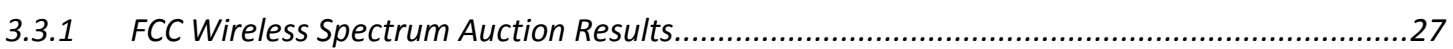

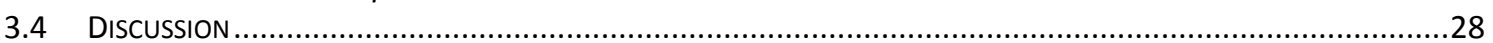

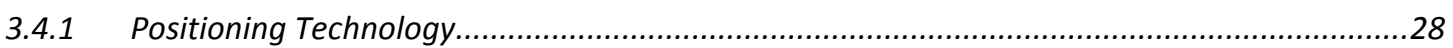

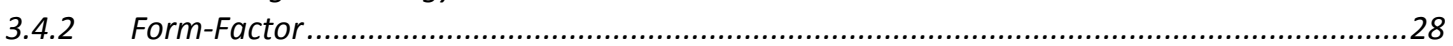

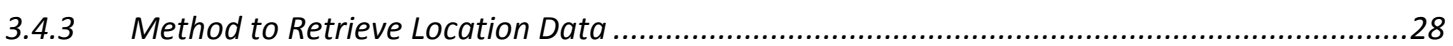

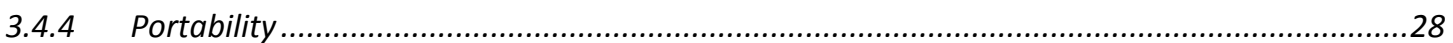

3.4.5 Coexistence of TAD with Mobile Phone Functionality ..........................................................28

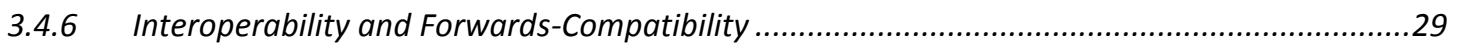

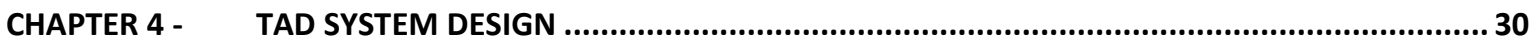

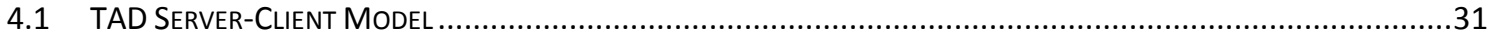

4.2 TAD WEB PAGE

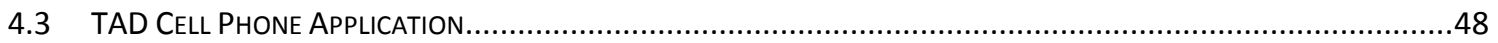

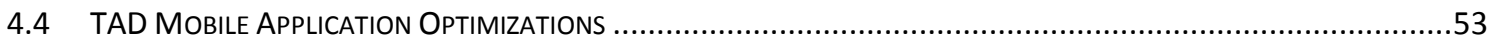

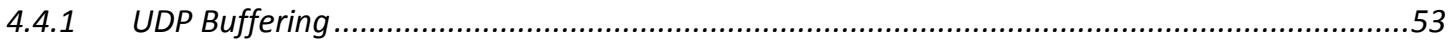

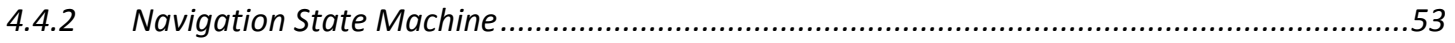

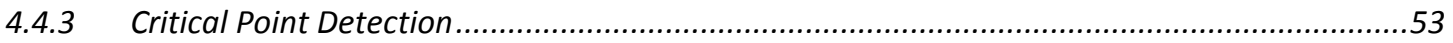

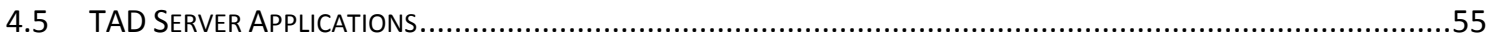

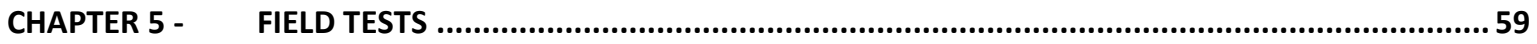

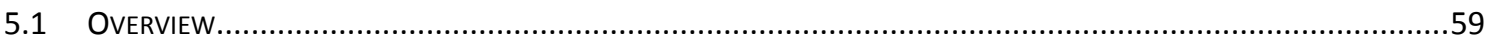

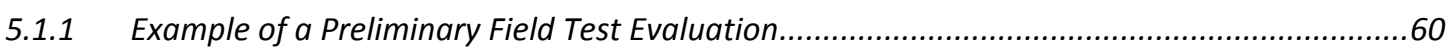

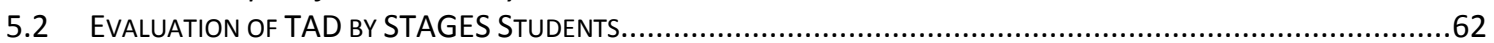

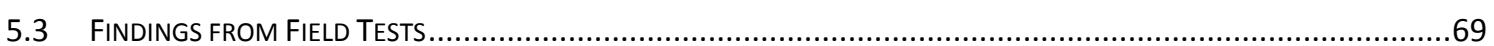

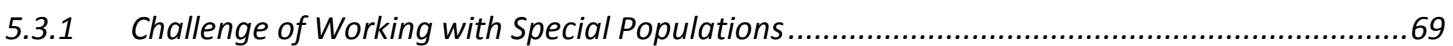

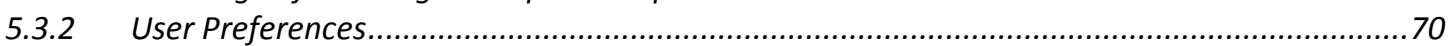

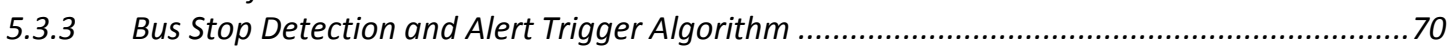

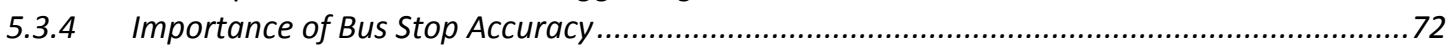

CHAPTER 6 - CONCLUSIONS AND FUTURE RESEARCH.................................................................. 74 


\section{List of Figures}

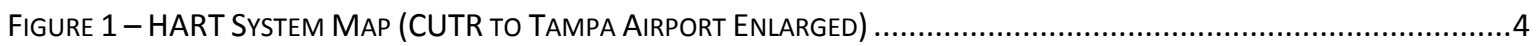

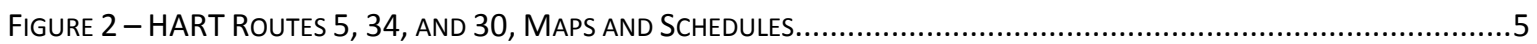

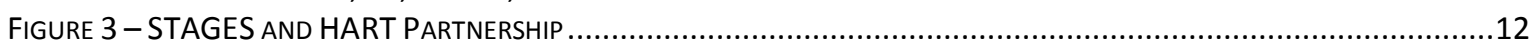

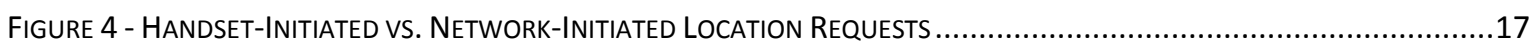

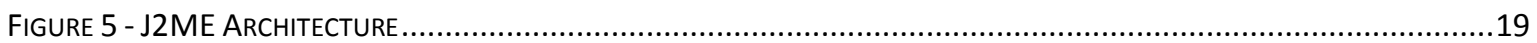

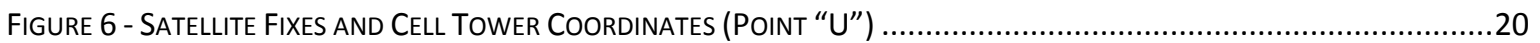

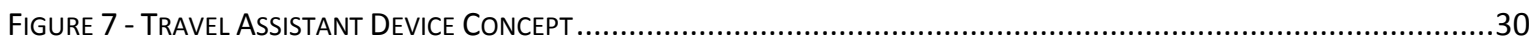

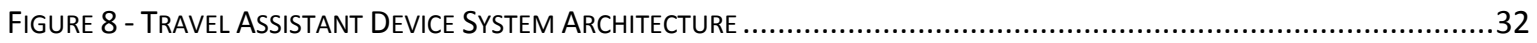

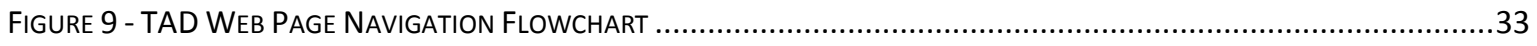

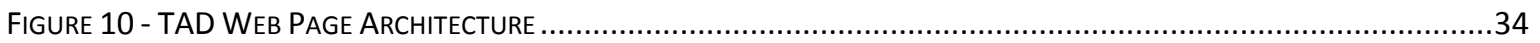

Figure 11 - tad Communication Protocol between the Webpage Client and the Server..................................35

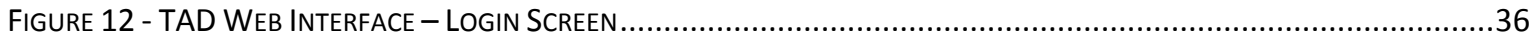

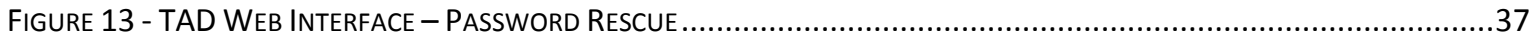

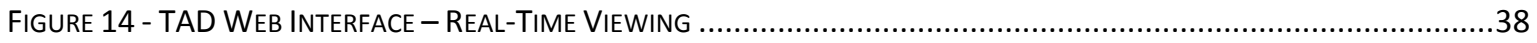

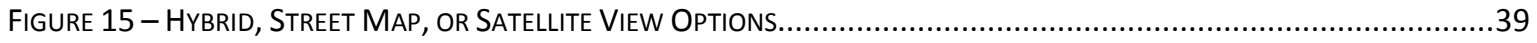

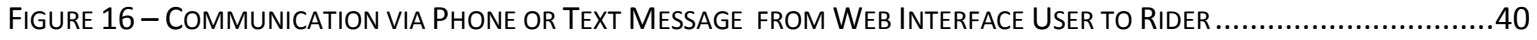

FIgURE 17 - TAD WEB INTERFACE - NEW TRIP ITINERARIES CAN BE CREATED FOR A PARTICULAR USER ...............................42

FIGURE 18 - TAD WEB INTERFACE - EXISTING TRIP ITINERARIES CAN BE EDITED USING THE WEBSITE ...............................43

FIGURE 19 - TAD WEB INTERFACE - SEGMENTS CAN BE ADDED TO AN EXISTING TRIP...........................................44

FIGURE 20 - TAD WEB INTERFACE - TAD WEB PAGE ALLOWS THE CREATION OF NEW USERS..........................................45

FIGURE 21 - TAD WEB INTERFACE - ACCOUNT INFORMATION CAN BE UPDATED.....................................................46

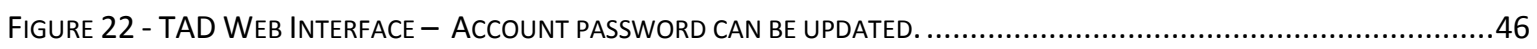

FIGURE 23 - TAD WEB INTERFACE - POSSIBLE ROLES ASSIGNED TO USERS. .......................................................47

FIGURE 24 - TAD WEB INTERFACE - USERS CAN BE ASSIGNED TO A SUPERVISOR. ...............................................48

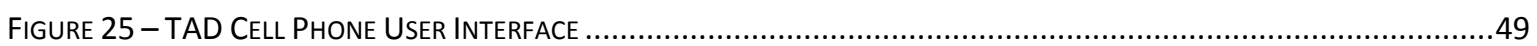

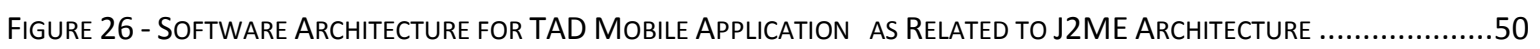

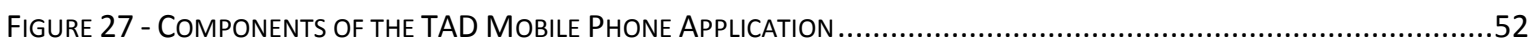

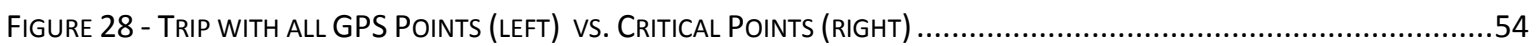

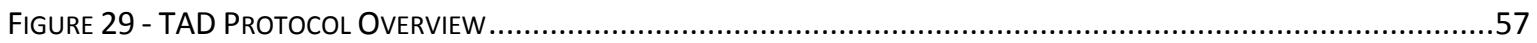

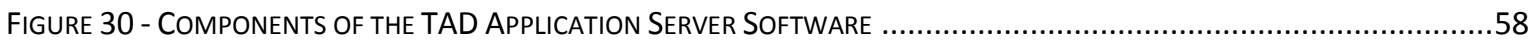

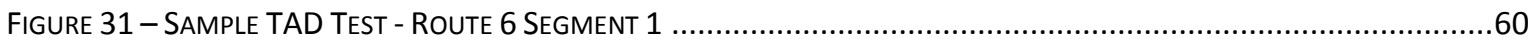

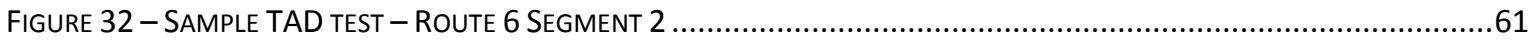

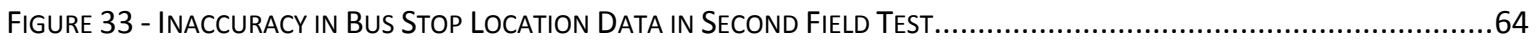

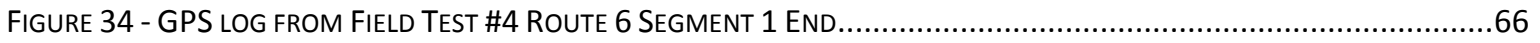

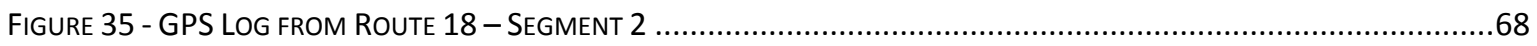

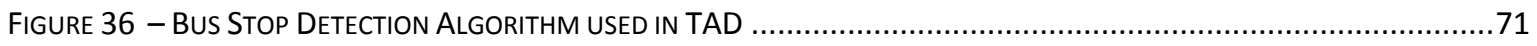

FiguRE 37 - ILLUSTRATION Of INACCURACIES IN BUS STOP INVENTORY DATASETS ..............................................73 


\section{List of Tables}

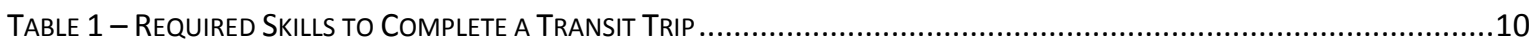

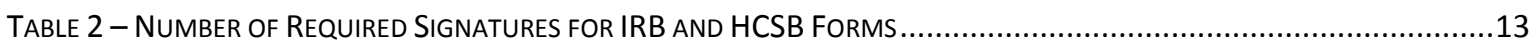

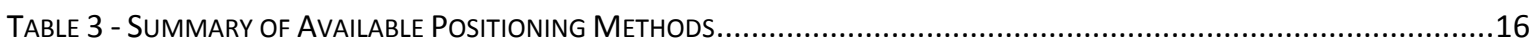

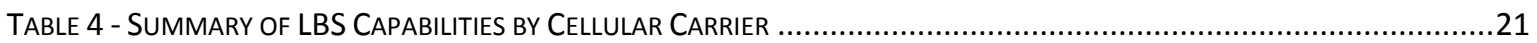

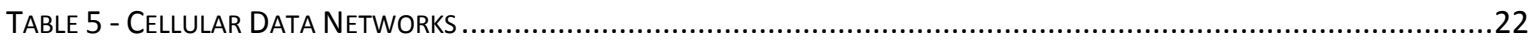

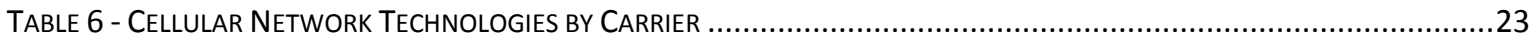

TABLE 7 - SUMMARY OF RESULTS FROM TAD TESTING CONDUCTED ON RANDOM BUS STOPS ........................................6.

TABLE 8 - RESULT OF TAD EVALUATION WITH STAGES STUDENTS ...............................................................63 


\section{CHAPTER 1 - INTRODUCTION}

The Center for Urban Transportation Research (CUTR) and the Department of Computer Science and Engineering (CSE) at the University of South Florida (USF) with funding from the Florida Department of Transportation (FDOT) and the United States Department of Transportation (USDOT) have established an ongoing partnership over the past several years that focuses on the development of cutting-edge community applications utilizing locationaware and mobile technologies in transportation applications. The next sections of this chapter present the research background, goals and objectives, and an illustrated example of the problem/need this research is addressing.

\subsection{Research Background}

The Florida Department of Transportation through the National Center for Transit Research (NCTR) funded research focused on the use of mobile devices and the development of location-aware artificial intelligence software systems. To date, several prototypes have been developed for use by the transportation industry but have not yet deployed. For example, TRAC-IT is an application that utilizes GPS-enabled phones to collect travel survey data including trip start and end times, trip duration and distance, origin and destination coordinates, travel route, and speed. Another prototype is the Personal Travel Coach that uses TRAC-IT to pattern the travel behavior of participating households. An intelligent travel feedback advisory system (also known as an expert system) proposes tailored suggestions to reduce vehicle miles traveled by the household and the individual. Suggestions are generated based on a set of rules that analyze trip characteristics. For example, if different household members made separate trips to a grocery store on the same day, the advice would be to combine trips. Another Personal Travel Coach application is the path prediction algorithm designed to alert the user of any real-time incidents that would require postponing, canceling, or re-routing trips on the previously-used paths recorded and recalled by the phone. Future developments envisioned for this application would make all traveler information resources such as those used for 511 available to a traveler's cell phone to bring timely information to the trip decision-making process.

The knowledge gathered from these projects, along with recent advances in mobile communications technology, led the research team to envision the GPS-enabled mobile phone as a personalized travel assistant device (TAD).

\subsection{Problem Statement}

A 2001 NCTR study into barriers to transit use conducted field testing that collected information on how well participants could actually plan transit trips by determining bus route(s), bus stop(s), and schedule time(s) (1). Information was collected from 17 pilot study and 80 final study participants, and qualitative data were collected from participants pertaining to their perceptions of the trip planning tasks and the transit information materials used. A majority of the participant responses received in relation to the least understandable and/or most difficult aspects of the trip planning tasks pertained to the layout and use of the 
transit information materials. More than half (57 percent) of the responses received from field test participants related to how they would feel if they had to use the transit information materials presented to plan an actual trip on the bus were negative. Many participants expressed that the transit trip planning tasks were difficult, even with extensive instruction provided by the observer/interviewers. Participants described feeling frustrated, irritated, and confused as a result of the trip-planning tasks they were asked to complete. Taken together, there were more than 100 separate comments made related to the printed transit materials being confusing, difficult to understand, or just plain frustrating. At least 20 of the field test participants were so flustered by the transit trip planning experience that they indicated they would not even try to make the bus trip if they had to use only the transit information materials presented to them. The responses received from these participants suggest that the task of planning a transit trip using only the printed materials presented poses so great a challenge that it discourages individuals from trying out public bus service.

According to a 2004 NCTR study, approximately half of a general population survey sample could not successfully plan an entire trip on a fixed-route transit system using the printed materials provided (2). Several studies have documented route-finding difficulties in elderly populations over 70 years old regardless of cognitive ability (3),(4),(5). As the baby-boomer generation ages, their number is forecasted to grow nearly four times faster than the population as a whole in the two decades from 2010 to 2030 (6). In 2001, approximately 26 percent of state units on aging surveyed by the Aging States Project identified transportation as a top health issue for seniors, and 38 percent identified inadequate transportation as a barrier to promoting health among this age group (7). More than one in five (21 percent) of seniors do not drive. Half of those - 3.6 million Americans - stay home on any given day partially because they lack transportation options (8). This situation is magnified for many of the 50 million Americans with disabilities who depend on transit as their primary means to and from school, work, doctor appointments, and other essential activities.

Research conducted under Transit Cooperative research Program (TCRP) Project B-5 to identify the characteristics of paratransit riders with and without disabilities who could be attracted to ride fixed-route service, the features they value in fixed-route services, and the physical and institutional barriers that hinder such efforts (9). The research was based on consumer surveys of people with disabilities who did not use fixed route services as well as those who did. On-board surveys, telephone surveys, and focus groups were conducted at transit agencies around the country to obtain data on passenger preferences and abilities. Survey results indicate that the top four features that can make fixed-route transit attractive to paratransit users are, in order from 1 to 4 : low fares, easy access (i.e., no big roads to cross) to the bus stop, drivers who announce all stops, and no transfers. According to the TCRP Report 24, individuals with disabilities surveyed indicated that they do not ride accessible, fixedroute services for a variety of reasons, including, but not necessarily limited to (9):

- lack of knowledge about the availability of accessible fixed-route services

- the need to cross wide roads to use the service

- ineffective policies on the part of the transit system

- inadequate training of drivers regarding the announcement of bus stops

- the need to make transfers between modes or among vehicles 
- inadequate seating

- lack of large, covered shelters at bus stops

- the perceived lack of security

An example of how complex it is to plan a transit trip is illustrated in Figures 1 and 2 . Planning a transit trip from CUTR on the USF campus to the Tampa International Airport may involve selecting appropriate routes from the HART system map (Figure 1), leading to three routes and then looking at three brochures with route schedules (Figure 2).

For those who have Internet access, a search using Google transit trip planning would have yielded the following steps:

1. Begin by walking to Leroy Collins Blvd @ Fowler Ave (takes about 1 min)

2. Bus \#5 - 40th St, direction: Marion St @ Laurel St

Service run by Hillsborough Area Regional Transit, 6:10pm

Leave from Leroy Collins Blvd @ Fowler Ave, 6:26pm

Arrive at 40th St @ Hillsborough Ave

3. Bus \#34 - Hillsborough Avenue, direction: Hanley - Waters Transfer Ctr 11 mins to make transfer; 6:37pm, leave from Hillsborough Av@ 40th St 7:06pm, arrive at Hillsborough Av@ Ambassador Dr

4. Bus \#30 - Town N Country, direction: Fortune St @ Marion St

6 mins to make transfer

7:12pm, leave from Kelly Rd @ Hillsborough Av

7:28pm, arrive at Tpa Intl Airport Post Office

5. Walk to Tampa Intl Airport (takes about 12 minutes)

Even the most aware individual might need assistance to be assured they will complete the trip correctly. For the cognitively disabled, the complex task of completing a transit trip may successfully be accomplished through assistance from the transit agency. For the same population group, transit is the sole means of providing transportation, and the dependency on transit is a lifetime commitment. 


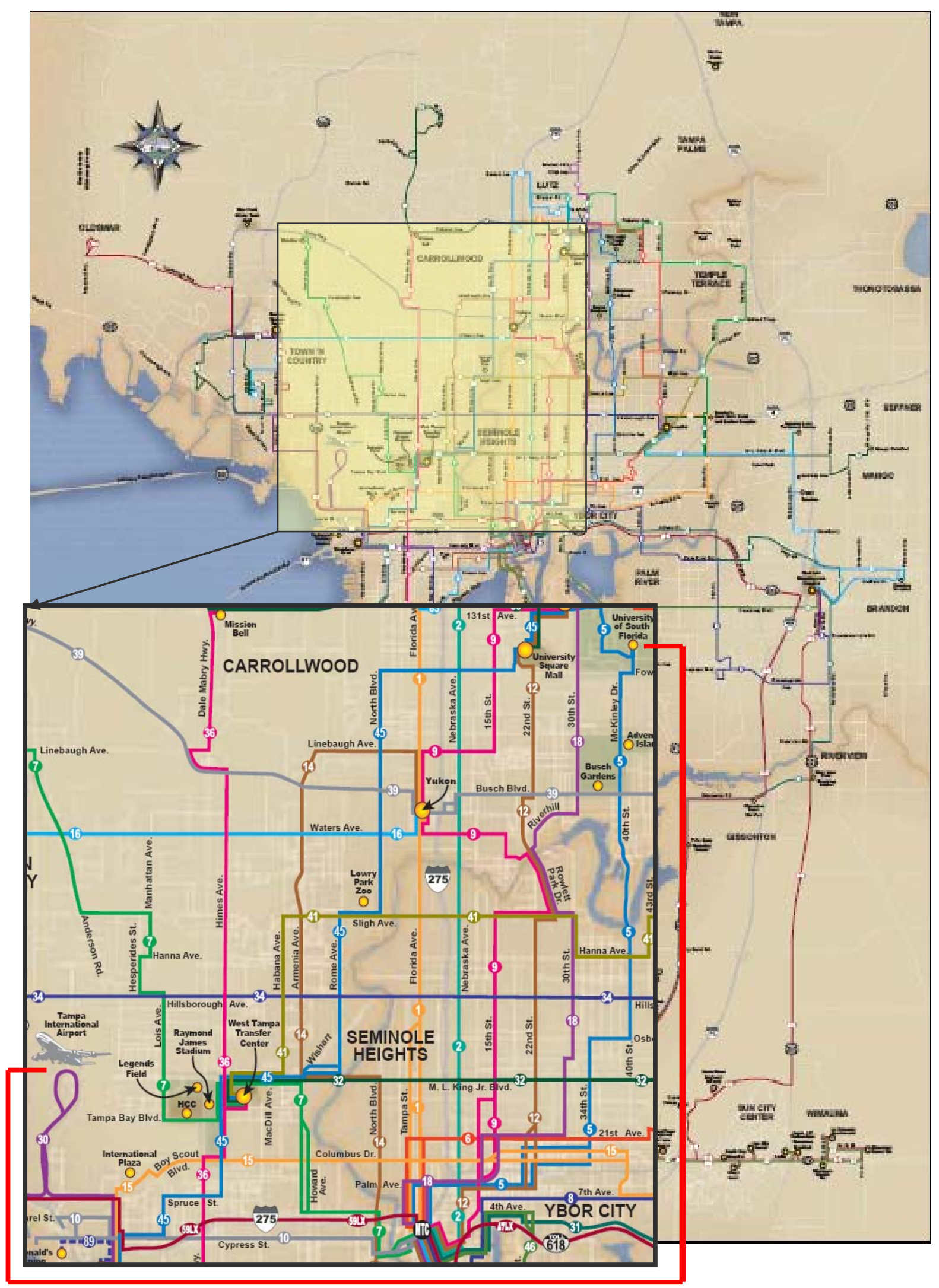

Figure 1 - HART System Map (CUTR to Tampa Airport Enlarged) 


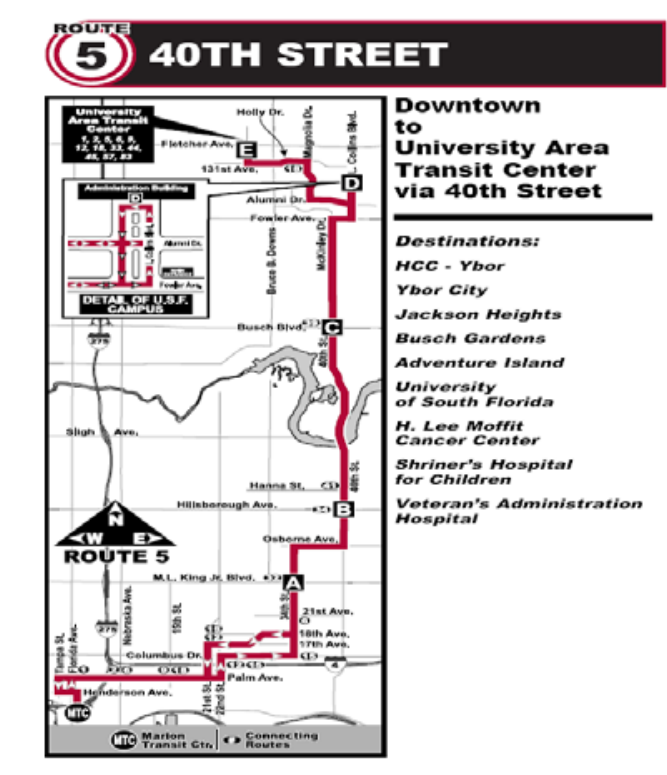

(34) HILLSBOROUGH AVE.

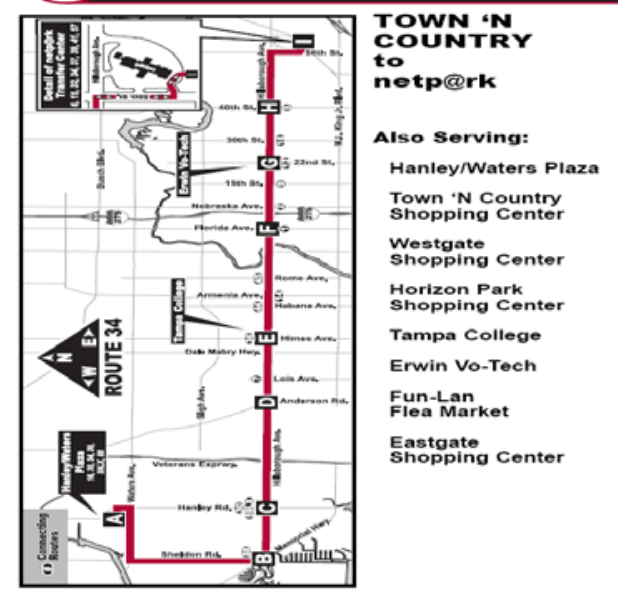

(30) TOWN ‘N COUNTRY

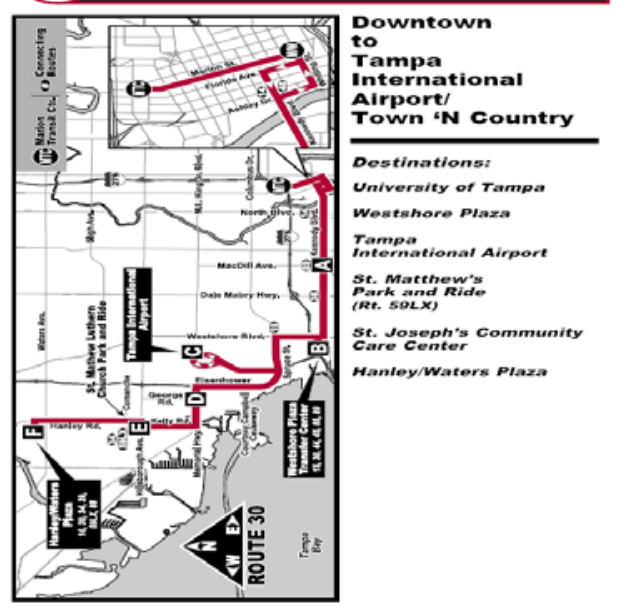

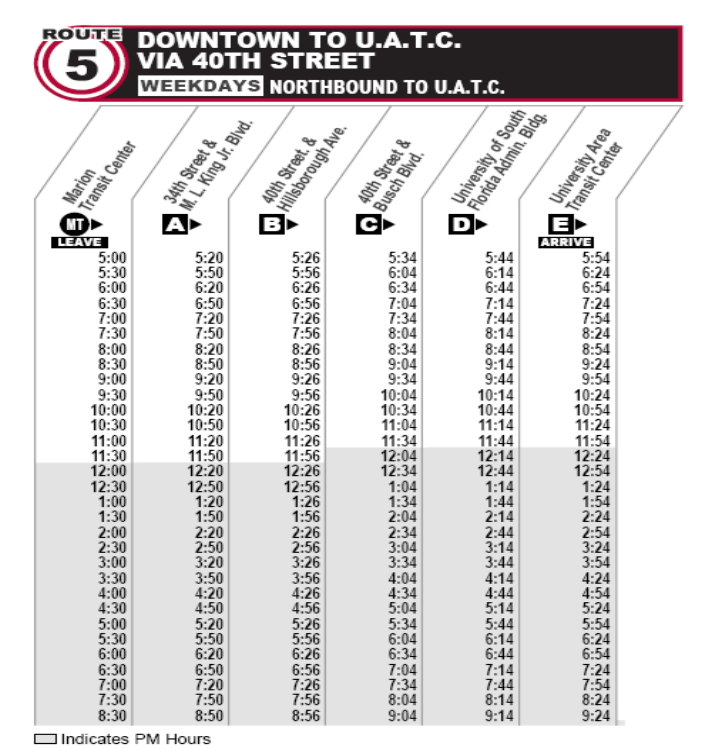

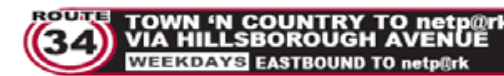

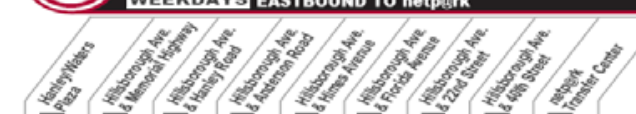

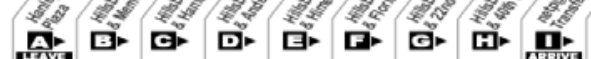

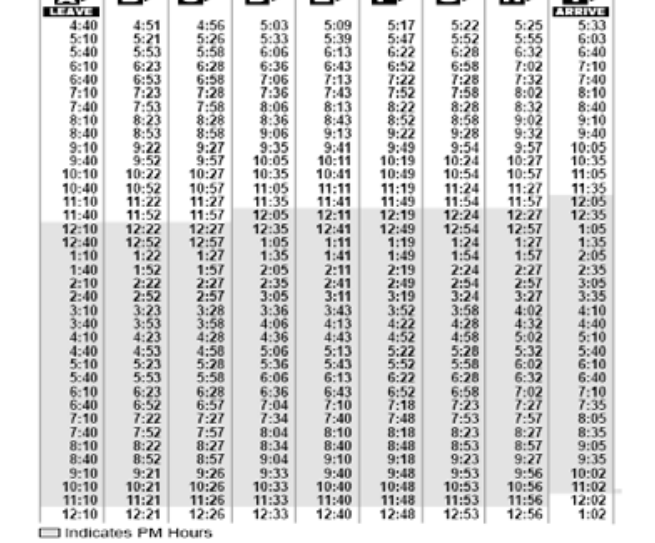

(30)

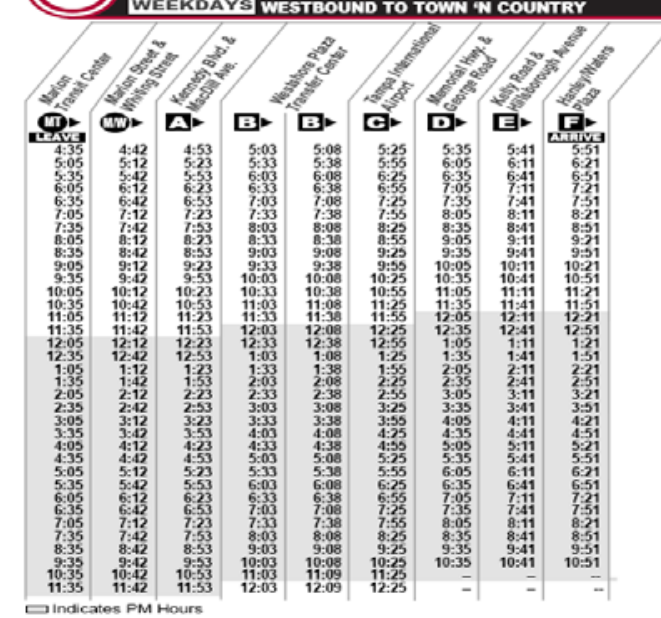

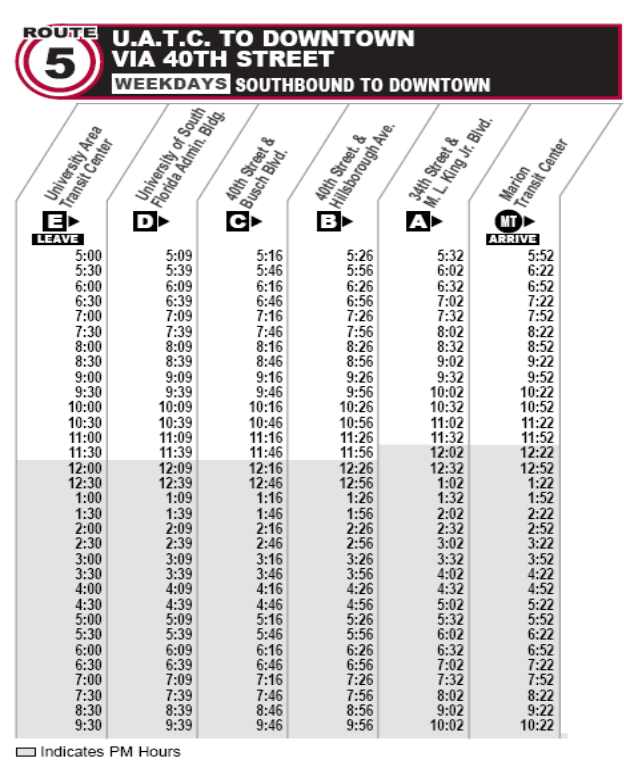
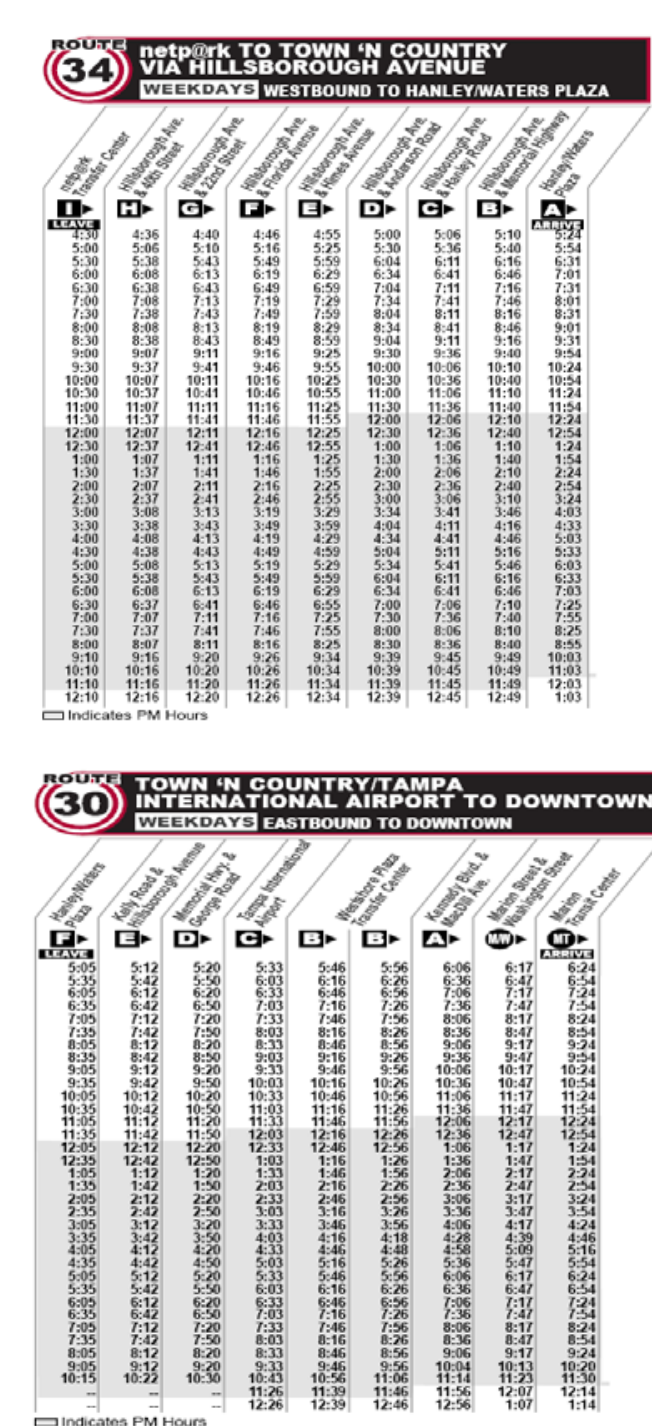
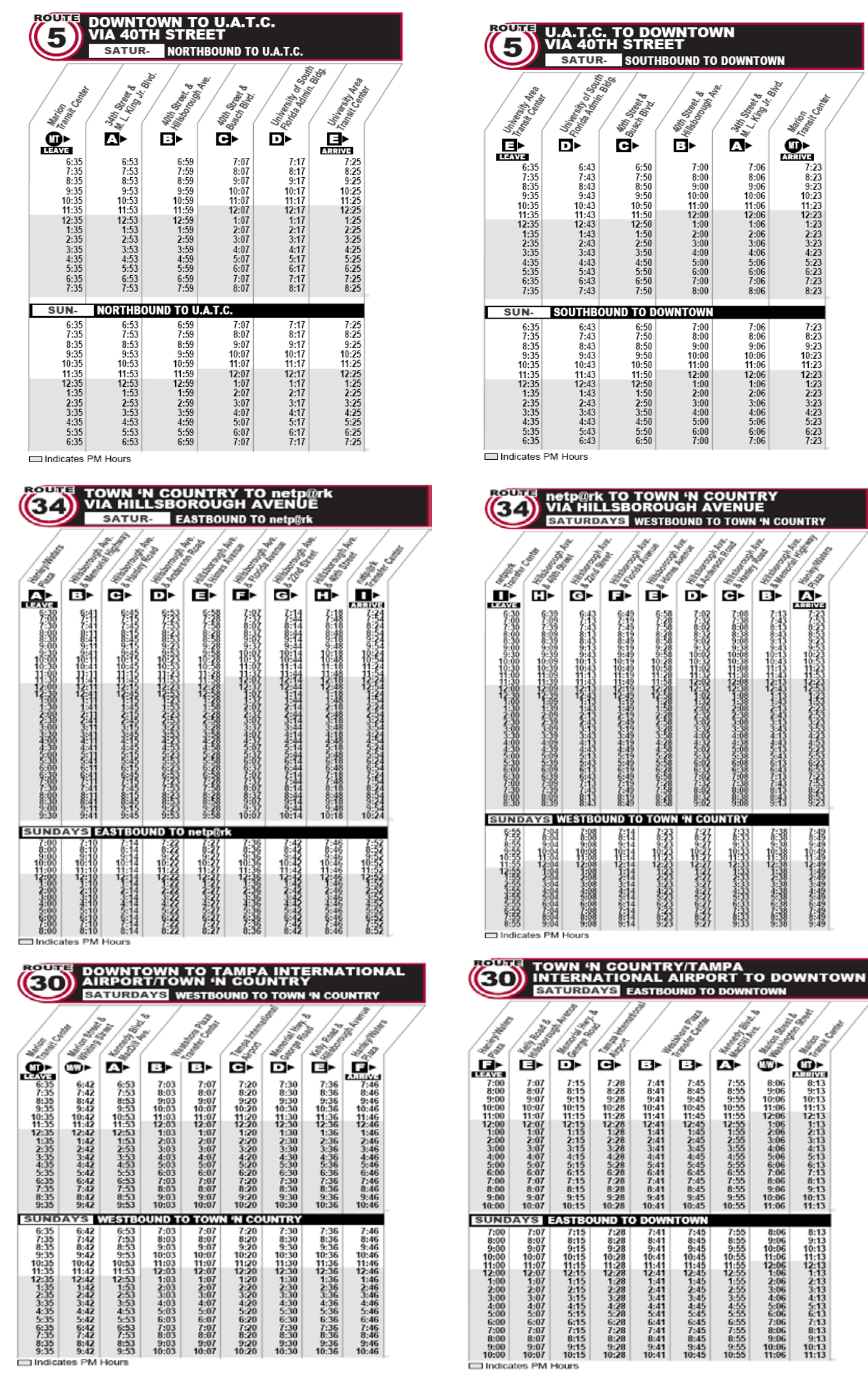
According to the Census Bureau, people with limitations in cognitive functioning or a mental or emotional illness that interfered with their daily activities accounted for 6.4 percent of the population, or 19 million people. A cognitive impairment is defined as "any disorder requiring special attention to or alternate methods for communicating concepts and instructions” (10). For those with cognitive disabilities, planning and executing a trip may be a daunting task. Individuals with cognitive impairments may have difficulty acquiring, storing, or retrieving information. Some examples include reading and understanding directions, accessing the correct vehicle, exiting from the correct station or stop, and understanding announcements. The literature suggests that orientation training is the key to enable a passenger with a cognitive impairment to travel within a transit environment. Such passengers should be trained not only to use the transit system, but also to understand all aspects of a transit trip. Information and/or assistance may be obtained from local human service agencies (10).

Compounding the difficulty faced by the traveler, transit agencies are struggling to support expensive and specialized on-demand services (i.e., paratransit) for riders who cannot use normal public transportation. According to the American Public Transportation Association, the average cost of paratransit is $\$ 17$ per trip versus an equivalent fixed-route transit cost of $\$ 1.70$ per trip (11). The Americans with Disabilities Act (ADA) requires that paratransit services be provided to all persons who are unable to use fixed-route bus service. Since transit agencies are not allowed to pass the majority of the additional costs of a paratransit trip to the rider, they must either absorb the costs or find ways to transfer able riders from paratransit to fixed-route services.

\subsection{Study Goals and Objectives}

This research project seeks to develop a software application that uses cell phones with built-in GPS to overcome the challenges facing new transit riders, especially those who are cognitively disabled. This device could increase fixed-route transit use among the cognitively disabled to increase mobility and reduce paratransit costs for transit agencies. While riders with cognitive disabilities are the initial target market for this application, TAD could be used by many different types of travelers, such as tourists who are unfamiliar with a region and its transit system. TAD, in conjunction with automated transit trip planners, could enable a large number of users to independently and successfully travel using public transportation.

The project team designed and developed a software system based on GPS-enabled cell phones to act as a travel assistant device (TAD) for transit riders. Various forms of informational prompts are delivered to the rider in a just-in-time method, such as triggering the phone to ring and vibrate when the rider should pull the stop cord to arrive at the correct stop. Other, more complex communications include delivering an audio message from the phone to give instructions based on the passenger's current location. For the sight-or hearing-impaired, the phone's vibrate feature could alert them to an approaching stop. Automated alarms can also be triggered and the travel trainer remotely alerted if a rider wanders off his or her pre-determined path. Traditional phone communication is possible between the rider and the trainer, which would allow a lost rider to be guided to 
the correct location. More advanced information, such as directions or maps based on the current location of the rider, can also be accessed by the trainer or family members at any point.

The primary purpose of this project was to create a software system for GPS-enabled mobile phones that would prompt transit riders to request a stop when they are approaching their destination. Research goals included:

1) Design and develop TAD prototype software for GPS-enabled cell phones that guides transit riders with mental/cognitive disabilities in utilizing the transit system.

2) Create an online, map-based web page that provides a caretaker and travel trainer with the means to remotely monitor the transit rider's location when desired.

Additionally, tasks included triggering alarms when the rider deviates from his/her planned route, as well as providing the travel trainer and caretakers with the ability to view via website the real-time location of the rider.

\subsection{Report Organization}

The next chapter presents a literature review on mobile devices to aid the disabled and an insight into travel training, highlighting the partnership between Hillsborough Area Regional Transit (HART) Travel Training program and the Successful Transition After Graduation for Exceptional Students (STAGES) program at USF. Chapter Three summarizes the state-of-the-art, location-based services in cellular networks, the different methods of obtaining position data and the capabilities of cellular providers and devices. Chapter 4 describes the TAD system design, including the server, user, and webpage modules. Chapter Five documents the field-testing process and findings. The last chapter presents the study conclusions and future research direction. 


\section{CHAPTER 2 - LITERATURE REVIEW}

\subsection{Overview of Previous Research}

Previous research using mobile devices to aid persons with disabilities has been performed by various institutions and companies. Past research using mobile devices for prompting the initiation of tasks such as taking medications or remembering appointments has been successful (12), (13). Currently, Humanware, Inc. sells a product for the visually impaired called the Trekker, which combines a personal digital assistant (PDA) with Global Positioning System (GPS) and Braille input devices (14). This product resembles an offthe-shelf, Pocket PC-based navigation system but has been modified to allow simple communication with the visually impaired. However, it does not allow real-time communication with the Internet, and, therefore, does not provide tracking services or remote monitoring by a travel trainer or caretaker. Additionally, the high cost of the system, almost \$2,000, represents a significant financial burden for the user. Most important, the device is tailored for those with visual impairments and cannot be customized for those with cognitive disabilities.

The application of mobile devices specifically to help cognitively disabled persons use public transportation is not unprecedented. In several papers, researchers at the University of Illinois at Chicago, the Coleman Institute for Cognitive Disabilities, and the Center for Lifelong Learning and Design, both at the University of Colorado, speculated that a mobile computing device (PDA), when coupled with a GPS system, could successfully assist the cognitively-disabled in riding transit (15), (16), (17),(18). In a 2003 research project, the University of Colorado's Coleman Institute and partner software company AgentSheets used off-the-shelf PDAs and GPS devices to create a prototype transportation guidance device (19). They concluded, "no hardware platform exists yet with all needed capabilities” for creating an all-in-one mobility assistant device (20). Liao et al. presented a novel hierarchical Markov model that can detect abnormal travel behaviors, which lead to the creation of a subsequent system called Opportunity Knocks (21). Opportunity Knocks shows significant promise for automatically detecting when an individual is lost based on GPS data recorded from a cell phone coupled with a modular GPS unit (21). However, while the system provides alerts when it senses the individual is lost, it does not provide pro-active cues to the user regarding when he/she should exit the transit vehicle. Additionally, the system must have prior travel learning behavior in its memory to benchmark normal performance and thus cannot provide alerts for new riders. Combining separate cell phone and GPS units drives up total system costs and has a design that may be awkward for the disabled user to carry.

\subsection{Travel Training}

The Individuals with Disabilities Education Act (IDEA) was originally enacted by Congress in 1975 to ensure that children with disabilities, like all children, have the opportunity to receive a free and suitable public education. Over the years, the law has been revised many times. The most recent amendments were passed by Congress in 
December 2004, with final regulations published in August 2006 (23). In 1999, federal regulations included a provision on travel training:

Travel training means providing instruction, as appropriate, to children with significant cognitive disabilities, and any other children with disabilities who require this instruction, to enable them to (i) develop an awareness of the environment in which they live, and (ii) learn the skills necessary to move effectively and safely from place to place within that environment (e.g., in school, at home, at work, and in the community.

(NICHCY Transition Summary, 1996)

Travel training is short-term, comprehensive, individualized instruction provided by qualified personnel to individuals with disabilities other than blindness or visual impairments. Travel trainers teach the skills and techniques necessary for individuals with disabilities to negotiate public environments, including public transportation when appropriate, in a safe and independent manner. The instruction is individualized to the person's needs and abilities and is taught in the actual environment in which the individual is expected to travel.

Independent travel instruction is a comprehensive training program designed to teach individuals with disabilities how to establish and maintain orientation in their environment as they travel safely and effectively on public transportation from their current location to a known destination. It includes travel in indoor areas and residential neighborhoods as well as rural, business, and downtown areas. While some people require instruction only for specific routes, others learn to develop cognitive or mental maps of street patterns and are able to travel widely throughout the environment.

Travel training and travel instruction have shown success in several studies and a professional organization for travel instructors, the Association of Travel Instruction (ATI), has been established in the United States (24), (25), (26). ATI is a national professional association that exists to develop the relatively new professions of travel training instructor and travel trainer for seniors and persons with disabilities other than those with blindness. The goal of ATI is to serve the practitioners who teach persons with disabilities and seniors to use public transit safely and independently. Table 1 includes the 23 skills a trainee needs to possess to travel independently. The research team identified several travel training skills where TAD may potentially play a role in further developing these skills. Note that the NCTR project successfully tested TAD for skills that appear shaded in the table.

\subsubsection{HART's Travel Training Program}

HART offers the Travel Training Program, which is designed to properly train any resident or visitor to Hillsborough County on how to use the HART system. A HART representative gives step-by-step instructions on how to use the transit guide, read a passenger schedule, and how to ride the bus. Trainees receive route schedules, a transit guide, and informational brochures to get them acquainted with HART. Additional training trips can be arranged. Disabled persons also are eligible, provided their disability does not 
require special assistance or specifically trained personnel. Advertised as an added bonus, the first ride on HART with the Travel Training program is free

\section{Table 1 - Required Skills to Complete a Transit Trip}

\begin{tabular}{|c|c|c|}
\hline & Skill & Potential TAD Application \\
\hline 1 & $\begin{array}{l}\text { Leave the place of origin and arrive at the bus } \\
\text { stop on time. }\end{array}$ & $\begin{array}{l}\text { TAD could be used to alert rider to leave origin } \\
\text { in time to catch next bus. }\end{array}$ \\
\hline 2 & Demonstrate appropriate street crossing skills. & \\
\hline 3 & $\begin{array}{l}\text { Travel to and from the bus stop using his/her } \\
\text { route of choice. }\end{array}$ & $\begin{array}{l}\text { TAD could be used as a pedestrian navigation } \\
\text { tool. }\end{array}$ \\
\hline 4 & $\begin{array}{l}\text { Stand at the bus stop or terminal in an } \\
\text { appropriate place. }\end{array}$ & \\
\hline 5 & Look in the direction of bus travel. & \\
\hline 6 & Carry a bus pass and take out the correct fee. & $\begin{array}{l}\text { TAD could be used in junction with Near Field } \\
\text { Communication (NFC) to swipe phone as means } \\
\text { of payment. }\end{array}$ \\
\hline 7 & $\begin{array}{l}\text { Identify the correct bus (through number, color, } \\
\text { style, inquiry). }\end{array}$ & $\begin{array}{l}\text { TAD could be used to show image of bus with } \\
\text { route number displayed and alert rider as bus } \\
\text { approaches stop/station. }\end{array}$ \\
\hline 8 & Signal to the driver the desire to board. & \\
\hline 9 & Board the front entrance in consecutive turn. & \\
\hline 10 & $\begin{array}{l}\text { Show the driver the bus pass or transfer and } \\
\text { deposit the correct fare in the box. }\end{array}$ & $\begin{array}{l}\text { TAD could be used in junction with NFC to } \\
\text { swipe phone as means of payment. }\end{array}$ \\
\hline 11 & Communicate any special needs to the driver. & \\
\hline 12 & Know how to board the lift and be secure. & \\
\hline 13 & Ask the driver for a bus transfer, if needed. & $\begin{array}{l}\text { TAD could be used to alert rider to remember to } \\
\text { ask for a transfer before exiting the bus. }\end{array}$ \\
\hline 14 & Select a seat or a proper place to stand. & \\
\hline 15 & Watch for landmarks. & TAD can be used to sound alert to "Get ready." \\
\hline 16 & $\begin{array}{l}\text { Obey the rules of the bus and exhibit } \\
\text { appropriate bus behavior. }\end{array}$ & \\
\hline 17 & Recognize a landmark near the desired bus stop. & TAD can be used to sound alert to "Get ready." \\
\hline 18 & Signal for exiting at the proper time. & $\begin{array}{l}\text { TAD can be used to alert driver to "pull the cord } \\
\text { now!" }\end{array}$ \\
\hline 19 & Exit the bus through the proper door. & \\
\hline 20 & $\begin{array}{l}\text { Travel to any necessary transfer points or } \\
\text { destinations through the most direct or the safest } \\
\text { route. }\end{array}$ & $\begin{array}{l}\text { TAD could be used as a pedestrian navigation } \\
\text { tool. }\end{array}$ \\
\hline 21 & $\begin{array}{l}\text { Dial or ask for assistance when utilizing the } \\
\text { phone. }\end{array}$ & $\begin{array}{l}\text { TAD could be pre-programmed to presets to } \\
\text { contact parent/guardian (e.g., press } 1 \text { to call } \\
\text { mom). }\end{array}$ \\
\hline 22 & Respond and act correctly in emergencies. & \\
\hline 23 & Read the bus schedule and/or find routes. & $\begin{array}{l}\text { TAD could be used with Google Transit } \\
\text { (http://www.google.com/transit) planner to } \\
\text { automatically plan trips when given an origin and } \\
\text { destination. }\end{array}$ \\
\hline
\end{tabular}


To create a design for TAD that was appropriate for the target population, Mark Sheppard, Travel Trainer for Hillsborough Area Regional Transit (HART), and Gigi Gonzalez, Transition Facilitator for Exceptional Student Education for the Successful Transition After Graduation for Exceptional Students (STAGES) program at USF, were included as members of the research team. In addition, an advisory group was created and briefed on the TAD concept to obtain further feedback from those involved in travel training or special education. This group includes individuals from the Louis de la Parte Florida Mental Health Institute (FMHI) at USF, the Florida Department of Transportation, MacDonald Training Center, and the Hillsborough County School District. Additional travel instructors were also consulted through a presentation and dialogue at the 2005 Association for Travel Instruction (ATI) National Conference.

The collaboration of Mr. Sheppard of HART and Ms. Gonzalez of STAGES with the research team was essential for the success of this research. The following sections highlight the HART and STAGES partnership.

\subsection{HART-STAGES Partnership}

Successful Transition After Graduation for Exceptional Students (STAGES) is a school district of Hillsborough County Transition Program at the University of South Florida (USF) College of Education that provides training and support to young adults with disabilities. STAGES, in partnership with the Department of Special Education, offers each student an opportunity to experience college life, explore career options, utilize public transportation, learn self-advocacy skills, interact with age appropriate peers, and reach their potential as an independent member of the community. In close association with the STAGES Program at USF, HART has offered its expertise to the task of introducing, instructing, and developing each STAGES student in becoming a travel independent individual in using the Hillsborough County public transit system (Figure 3).

HART stands ready to assist in the ongoing training of each STAGES student in successfully utilizing the public bus system to new destinations, such as new residences or future employment opportunities. HART knows the importance of gaining confidence in the daily use of public transportation. The element of transportation is one of the most important needs for successful, independent living. The best work-skill training remains unused if they cannot get to the work place.

Mark Sheppard HART Travel Trainer 


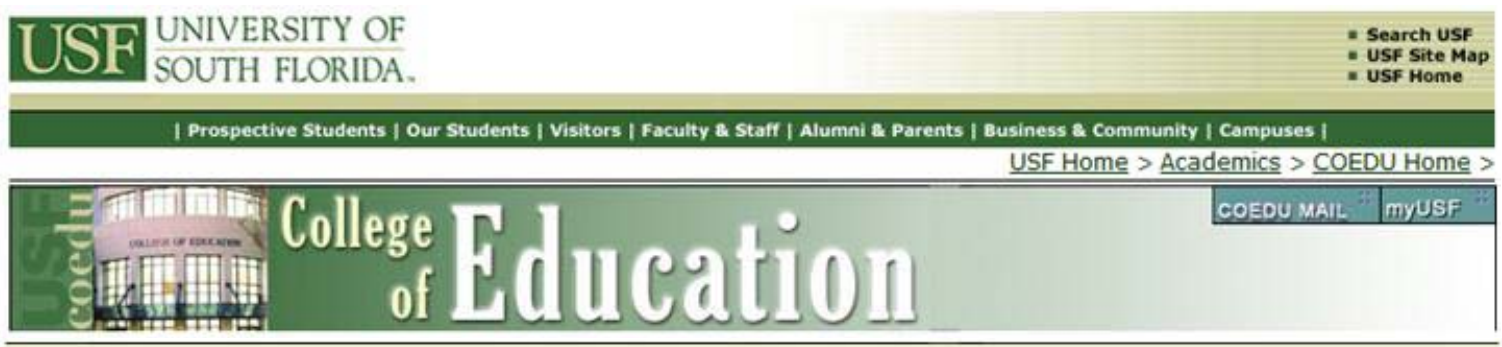

STAGES Hartline Partnership

return to STAGES Homepage

HARIITe Going places.

\section{>>click here to watch HARTline Video}

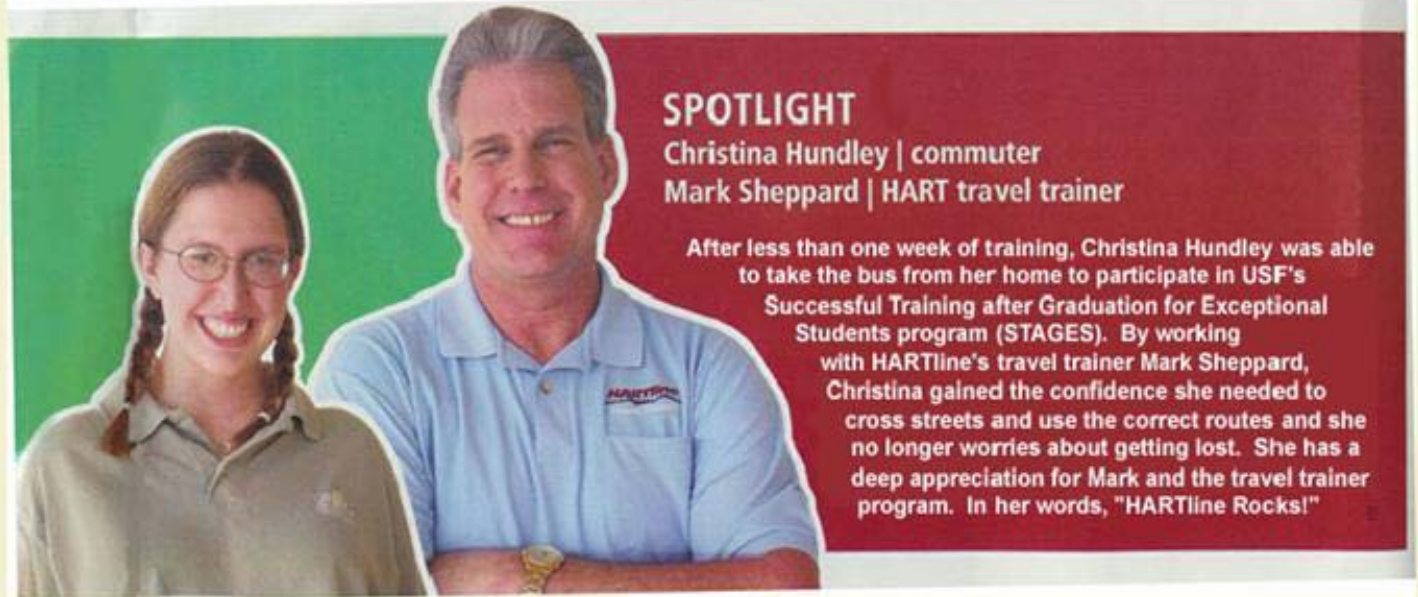

In close association with the STAGES Program at USF, HARTline has offered their expertise to

the task of introducing, instructing, and developing each STAGES student in becoming a

TRAVEL INDEPENDENT individual in using the Hillsborough County public transit system.

\section{Figure 3 - STAGES and HART Partnership}

Source: College of Education, USF at http://www.coedu.usf.edu/main/stages/hartline.html

\subsection{Process of Authorizing Field Tests with STAGES Participants}

The STAGES testing consisted of two primary stages: the processing of individual paperwork for both the USF Institutional Review Board (IRB) and the Hillsborough County School System, including an interview that was conducted with each student and parent, and the actual field test where the student carried a mobile phone with the TAD application installed. The testing of TAD with STAGES students was an extended process that required permission from both USF's IRB and the Hillsborough County School Board.

In late February 2007, a TAD advisory board member with the School District of Hillsborough County (SDHC) requested an agreement between the SDHC Board and USF to allow STAGES students to participate in the project. After many revisions, the School Board and USF reached a consensus and received the fully executed agreement from 
Hillsborough County in September 2007. After receiving approval to work with STAGES students, the research team began working directly with Ms. Gonzalez of STAGES and Mr. Sheppard of HART to recruit volunteers for the initial field tests and, by early October, was ready to hold the initial information session on TAD. All interview scripts with students were approved by the Hillsborough County School Board on October 26 and submitted to USF's IRB for approval.

All students had been previously travel trained by Mr. Sheppard as part of the life skills training in the STAGES program. Three research team members, including the travel trainer, were present during each of the six orientations/signing sessions that were held on the USF campus (at STAGES or CUTR buildings), with the exception of one held at a student's home. Each orientation session lasted, on average, 60 minutes. Mr. Sheppard explained how TAD works by providing examples from experiences with travel training and bus stops familiar to participants. CUTR team members explained the IRB process and the field test procedures, answering all questions asked by the participants before obtaining signatures. The required signatures are indicated in Table 6.

Table 2 - Number of Required Signatures for IRB and HCSB Forms

\begin{tabular}{||l|c|c|c|c||}
\hline & Student & $\begin{array}{l}\text { Parent / } \\
\text { Guardian }\end{array}$ & $\begin{array}{l}\text { PI or } \\
\text { Co-PI }\end{array}$ & Witness \\
\hline $\begin{array}{l}\text { Assent to Participate in Research } \\
\text { Information for individuals who cannot } \\
\text { provide informed consent (3 pages) }\end{array}$ & 1 & 0 & 1 & 0 \\
\hline Consent of Proxy (9 pages) & 0 & 2 & 2 & 2 \\
\hline Parental Informed Consent (8 pages) & 1 & 3 & 3 & 4 \\
\hline Adult Consent for Participant (5 pages) & 1 & 0 & 1 & 0 \\
\hline $\begin{array}{l}\text { Adult Consent for Parent/guardian of } \\
\text { participant (3 pages) }\end{array}$ & 0 & 1 & 1 & 0 \\
\hline \multicolumn{2}{|l|}{ Total 28 pages and 25 signatures } \\
\hline
\end{tabular}

All IRB documents that had to be signed by participants, parents/guardians, and research team are available in Appendix B of this final report.

\subsection{Discussion}

Existing literature on navigation skills for those with cognitive impairments was consulted as part of the TAD design process. Since TAD focuses primarily on prompting the individual when he or she should request a stop on the bus, the notification method was the primary focus of this research.

Some past studies document that checklists and step-by-step written instructions are the most effective means to guide an individual with a cognitive disability through a series of tasks (27), (28). Other studies have documented success using a recorded voice as a means of prompting an individual (29), (30), (31).

Recent research suggests that the task of real-time navigation is most successful when guided by auditory prompts. One study found that auditory alerts are not only the most 
effective type of prompts for real-time navigation for cognitively impaired individuals, but they were also the most preferred by participants (32). The authors attribute these findings to the cognitive process of navigation that occupies the visual processing components of the brain. Prompts that require visual attention such as maps, images, or written directions can conflict with the visual component of navigation itself. Therefore, the auditory processing of directives does not directly conflict with the visual information that the individual is receiving and allows the subject to handle both tasks simultaneously. These findings are similar to other studies examining individuals without cognitive disabilities that determined that audio prompts were preferred for multi-tasking situations where the visual attention of the participant was required for real-time navigation (33), (34), (35).

Based on the above research in the field, TAD was designed to primarily use an auditory prompt to alert the individual to exit the bus. Additional visual and tactile (i.e., vibration) prompting also were implemented as secondary prompting methods.

To create a design for TAD that was appropriate for the target population, Mark Sheppard, Travel Trainer for Hillsborough Area Regional Transit (HART), and Gigi Gonzalez, Transition Facilitator for Exceptional Student Education for the Successful Transition After Graduation for Exceptional Students (STAGES) program at USF, were included as members of the research team. In addition, an advisory group was created and briefed on the TAD concept to obtain further feedback from those involved in travel training or special education. This group includes individuals from the Louis de la Parte Florida Mental Health Institute (FMHI) at USF, the Florida Department of Transportation, MacDonald Training Center, and the Hillsborough County School District. Additional travel instructors also were consulted through a presentation and dialogue at the 2005 National Conference for ATI. 


\section{CHAPTER 3 - SUMMARY OF STATE OF THE ART}

The research team conducted an extensive analysis of mobile phone technology to evaluate the feasibility of using mobile phones as a travel assistant device. This investigation included an analysis of positioning methods available for cellular networks and devices, methods of software development to gain access to position data, software standardization and compatibilities for mobile phones, and the status of positioning techniques.

\subsection{Location-Based Services Technology for Cellular Networks}

Location-based services (LBS) are emerging technologies in the telecommunications industry. Common applications of LBS include real-time vehicle navigation systems, while newer location-aware applications include location-based messaging, social networking, and photography. With the recent advancements in mobile phone and network technology, LBS are growing exponentially. According to recent market research, the world population of GPS-enabled, location-aware services subscribers will grow from 12 million in 2006 to a projected 315 million by 2011, and North American growth is projected to increase from 500,000 users in 2006 to 20 million users in 2011 (36), (37). ABI Research predicts that satellite-based positioning devices and systems will generate yearly revenues of $\$ 240$ billion by 2013 (38). By 2010, Gartner Research estimates that 500 million cell phones capable of navigation will be sold annually, compared with standalone GPS device sales of 95 million (39). Since LBS are well suited for transportation applications, new types of location-aware transportation applications can be developed and deployed on a large scale (40), (41), (42).

GPS-enabled mobile phones can serve as computing platforms that utilize continuous position data, including speed and heading data calculated by the phone or network using Global Positioning Systems (GPS), network-based triangulation, or a similar positioning technology. The TAD research project utilizes assisted GPS to provide frequent and accurate position updates that are required for real-time application decisions. GPS is highly accurate, with most position requests being accurate within 3 to 30 meters and speeds shown to be accurate within 0.2 meters/sec in past studies (43). GPS fixes can be collected with a frequency of up to once per second for a mobile phone, thereby generating real-time position information that can be used to make instantaneous application decisions.

Location-aware applications require access to geographic data that describes the real-time position of the device. There are three common classes of positioning techniques that can be utilized to obtain geographic information:

1. Device-based methods, those in which the end-user device performs the necessary calculations to determine the position of the device.

2. Cellular network-based methods, which determine the device position by analyzing the wireless communication with the device.

3. Hybrid methods, which are used primarily to improve the Time-To-First-Fix (TTFF) and the accuracy of the position estimation by providing assistance information to the position calculating entity. Two primary categories of hybrid 
methods are device-assisted network-based technology or network-assisted devicebased technology.

The Federal Communication Commission's E911 mandate requiring cellular providers to identify the position of 911 wireless callers has been the driving force behind the implementation of LBS in the United States. Since many different technologies can be used to implement any of the above positioning methods, Phase 2 of the E911 mandate has left the implementation of the positioning system technology up to each carrier and has specified only accuracy requirements. Device-based solutions must be within 50 meters for 67 percent of calls, and 150 meters for 95 percent of calls. In the case of networkbased solutions, 67 percent of calls must be within 100 meters, and 95 percent within 300 meters (44). Table 2 includes a summary of all positioning methods discussed in the following sections and the U.S. carriers utilizing them. The current trend for U.S. cellular carriers is to provide Assisted Global Positioning Systems (A-GPS) solutions for handsets, regardless of the solutions implemented to meet the E911 mandate requirements. This trend is because most location-aware commercial products such as real-time navigation require the high precision positioning data that only A-GPS is capable of providing. Therefore, if the cellular carrier is interested in recovering the cost of implementing LBS on its network and maintaining a steady income based on commercial LBS, A-GPS must be available in devices on the network.

Table 3 - Summary of Available Positioning Methods

\begin{tabular}{|c|c|c|c|}
\hline \multicolumn{4}{|c|}{ Location Technologies for Cellular Phones } \\
\hline Technology & Type & Accuracy & U.S. Carrier \\
\hline Cell-ID & Network & $\begin{array}{l}\text { 100m-3km (depends on the } \\
\text { size of the cell) }\end{array}$ & All \\
\hline Cell-ID + Timing Advance (TA) & Network & $\begin{array}{l}\text { Band size configurable; } \\
\text { default is } 500 \mathrm{~m}\end{array}$ & AT\&T \\
\hline $\begin{array}{l}\text { Enhanced Forward Link } \\
\text { Triangulation (EFLT) }\end{array}$ & Network & $250-350 \mathrm{~m}$ & None \\
\hline Angle of Arrival (AOA) & Network & $100-200 m$ & None \\
\hline $\begin{array}{l}\text { Advanced Forward Link } \\
\text { Trilateration (AFLT) }\end{array}$ & Network & $50-200 m$ & Sprint and Verizon \\
\hline $\begin{array}{l}\text { Enhanced Observed Time } \\
\text { Difference (EOTD) }\end{array}$ & Device & $50-200 m$ & None \\
\hline $\begin{array}{l}\text { Uplink Time Difference of } \\
\text { Arrival (U-TDOA) }\end{array}$ & Network & $40-60 \mathrm{~m}$ & T-Mobile, AT\&T \\
\hline $\begin{array}{c}\text { Assisted Global Positioning } \\
\text { System (A-GPS) }\end{array}$ & Hybrid & $5-30 m$ & $\begin{array}{l}\text { Sprint, Nextel, Alltel, } \\
\text { Verizon, and AT\&T }\end{array}$ \\
\hline
\end{tabular}

Source: Federal Communication Commission Official Website link to 911 services http://www.fcc.gov/911/enhanced/

All information shared in this report is publicly-available information collected from a variety of sources, including the wireless service providers' and cell phone manufacturers' websites and documentation hosted on these websites. Information such as software 
compatibilities and mobile phone performance data was gathered through empirical testing of GPS-enabled cell phones using software created by the research team. A detailed description of positioning technologies available to mobile phones, as well as their tradeoffs, is available in the 2008 NCTR/FDOT publication, "Smart Phone Applications to Influence Travel Behavior (TRAC-IT Phase 3)” (42).

\subsection{Software Developer Methods to Obtain Position Data}

Although different technologies are used to calculate the user's position, software development should not be further complicated by the need to differentiate the details of one type of technology from another when using position data in a software application. As a third party software, the goal of location Application Programming Interfaces (APIs) is to provide developers access to position data while hiding some of the implementation details from the software developer. There are many APIs available for this purpose, including those defined for software that executes on handsets as well as those defined for use by network applications. Handset-based APIs are accessed by software running on the mobile device through handset-initiated location requests, while network-based APIs are accessed by web applications that send network-initiated location requests to a server in a cellular network (Figure 4). There are advantages and disadvantages to each approach detailed in the 2008 NCTR/FDOT report, "Smart Phone Applications to Influence Travel Behavior (TRAC-IT Phase 3)” (42).

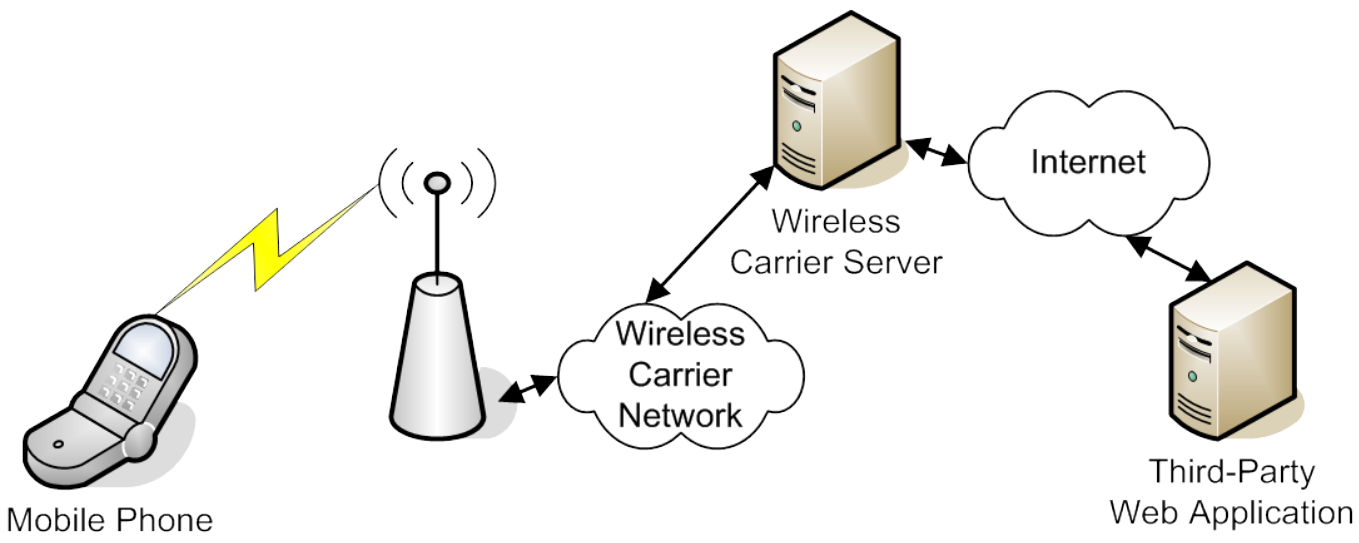

Handset-Initiated Location Request

Initiated by software running on mobile phone

\section{Network-Initiated Location Request}

Initiated by web application running on third-party application server

\section{Figure 4 - Handset-Initiated vs. Network-Initiated Location Requests}

Handset-initiated assisted GPS was chosen as the primary positioning technology for the TAD application since it provides low-latency and highly accurate position information at intervals as frequent as every second. 
To implement a software system that can take advantage of handset-initiated assisted GPS requests, software must be developed for the mobile phone. The large number of different mobile device manufacturers and cellular carriers make software development for mobile devices rather complex. There are many different programming languages available, many of which have functions proprietary to a particular chipset or operating system. Therefore, while an application developed for a proprietary system may operate on one mobile phone, it would have to be completely re-written to execute on a device from a different manufacturer.

One programming language that has emerged as a platform-independent means of software development for mobile phones is Java Micro Edition (J2ME) (45). J2ME, like Java 2 Standard Edition (J2SE) and Java 2 Enterprise Edition (J2EE) for desktop and server computers, is able to execute on devices and chipsets from different manufacturers. Additionally, J2ME has been designed to work across different cell phone networks independent of the underlying cellular network implementation, such as Code Division Multiple Access (CDMA) or Global System for Mobile Communications (GSM). As a result, a J2ME application designed to meet the basic J2ME standard that utilizes no proprietary libraries should be transferable from one J2ME-enabled device to another with few or no changes in the software. The J2ME Architecture is shown in Figure 5 and is discussed in detail in Section 4.3, which describes the Client-side Modules of TAD.

As J2ME became more prevalent in the mobile device market and location capabilities of mobile phones became more common, it became evident that a standardized API that would allow location-aware software to be deployed to many different devices without the use of various proprietary APIs was required on the J2ME platform. Fortunately, the Java Community Process (JCP) allows new standards to be proposed for Java platforms, including J2ME.

In 2002 “Java Specification Request (JSR) 179: Location API for J2ME” was proposed and accepted as a necessary standard for J2ME (46). An expert group including members such as IBM, Nokia, Symbian, Intel, Motorola, Sony-Ericsson, ESRI, and Sun Microsystems, Inc. was created to develop the specification for this standard and in September 2003, the final standard was released. This standard allows a location-aware J2ME application to be developed that will execute on any J2ME platform that supports the optional JSR179 package. In an effort to improve JSR179 and add additional locationaware functionality, "JSR293: Location API 2.0" was proposed in early 2006 (47). An expert group consisting of Nokia, Motorola, Sprint-Nextel, GPS hardware manufacturer SiRF, Navteq, Samsung, Cingular, Sun Microsystems, Inc., Sony Ericsson, European cellular providers Orange and Telecom Italia, China Mobile Communications Co. Ltd, and USF has been deliberating on this standard since this time, with the public review stagetaking place in mid-2007. JSR293 is expected to be finalized in mid to late 2008 and should appear in commercially available cell phones shortly thereafter. 


\section{J2ME Architecture, including relationship to proprietary APIs}

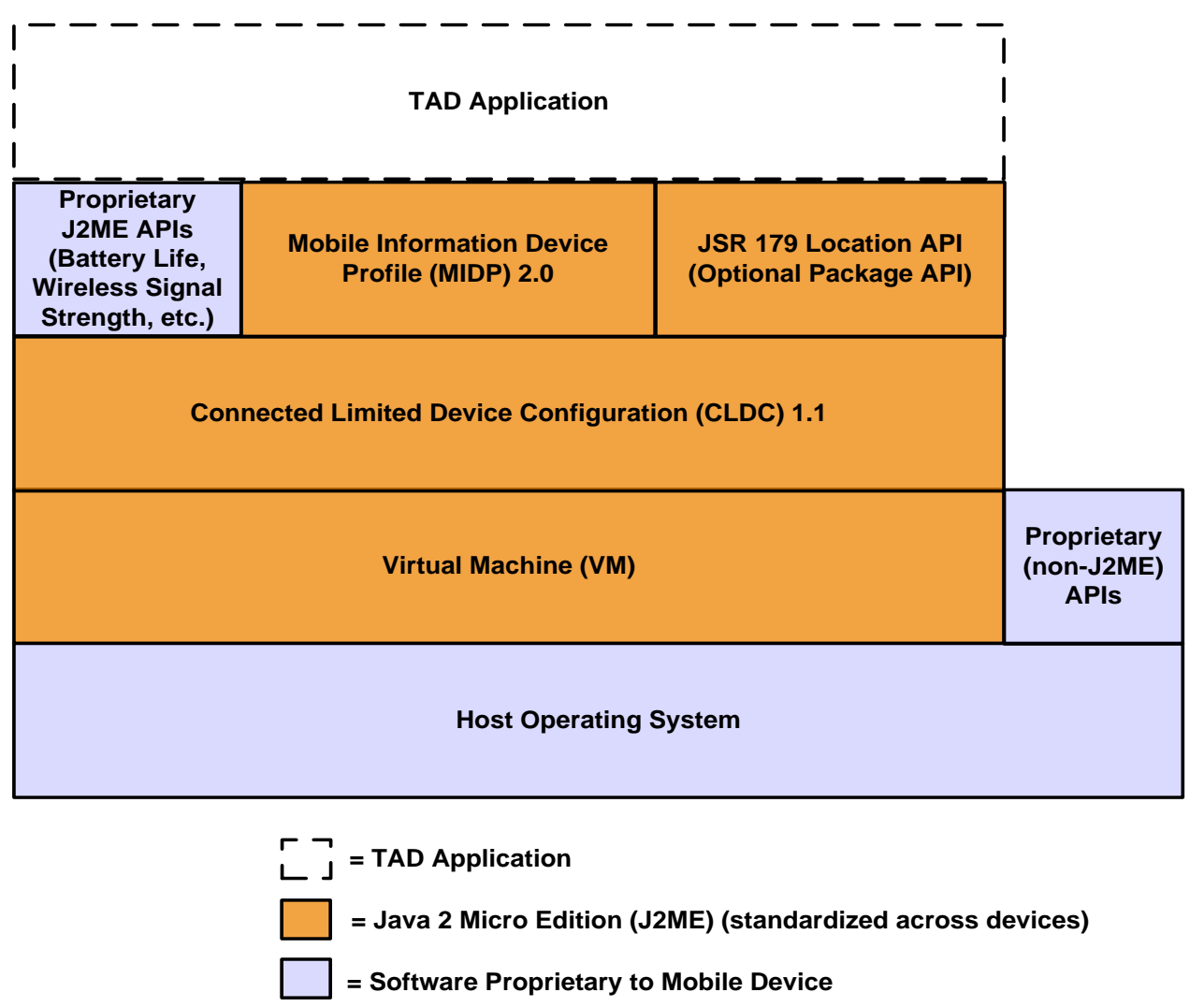

Figure 5 - J2ME Architecture

Note: J2ME Architecture includes relationship to proprietary APIs

Performance of various Location APIs, including proprietary APIs, can differ in terms of response time and accuracy of position data. Software developers should be aware of the particular characteristics of the API they are planning on using, as well as the other options for location APIs on the same device before developing LBS using a particular API (48). TAD uses the JSR179 Location API for programmatic access to position information of the mobile phone, and will support JSR293 when it is released. Further information on JSR179 and a comparison between JSR179 and JSR293 can be found in the March 2008 special issue of Computer Communications on "Advanced Location Based Services" as well as the TRAC-IT Phase 3 Final Report (49), (42).

GPS and Cell-ID are the two primary types of location data that are provided in real-time to the TAD software running on the mobile phone. An example of Cell-ID fixes, or the location of the cellular tower or cellular coverage (Figure 6, point "U") with which a mobile phone was communicating along with its actual geographic location during this time, indicated from the GPS data surrounding the tower, is shown in Figure 6. Cell-ID location fixes are returned by the phone when GPS data is not available. From Figure 5, it is obvious that a Cell-ID location can be a significant distance from the actual geographic position of the mobile phone. Therefore, only GPS should be relied on to provide the service of announcing an upcoming bus stop. 


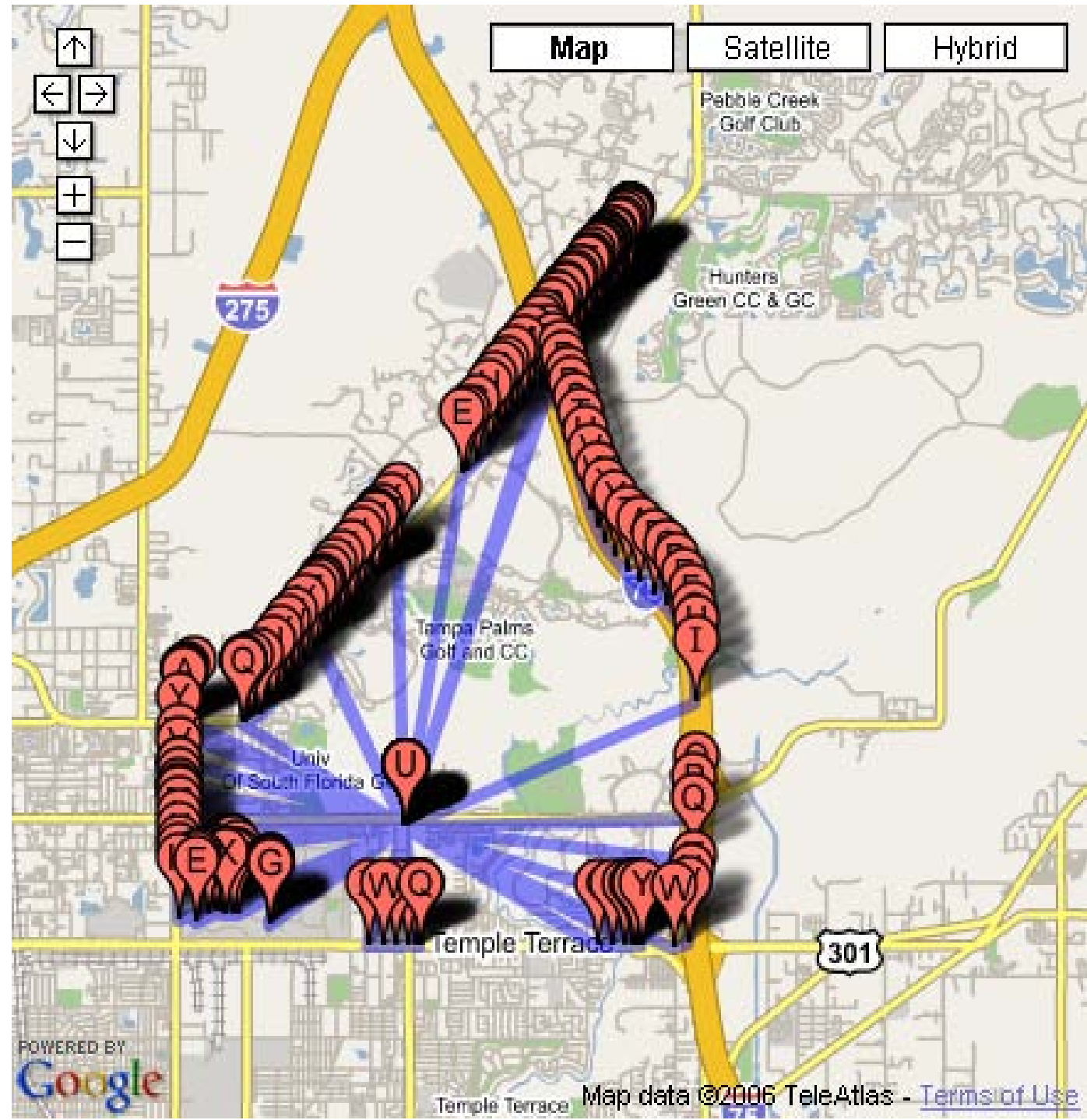

Figure 6 - Satellite Fixes and Cell Tower Coordinates (Point “U”)

\subsection{Current Capabilities of Cellular Providers and Cellular Devices}

The following sections discuss device and network characteristics for developing and deploying LBS applications for mobile phones, and the capabilities of major U.S. cellular carriers to support these applications. Table 4 provides a summary of the extensive technology assessment conducted by the research team on these carriers and their LBS capabilities. Detailed assessments of each carrier can be found in the TRAC-IT Phase 3 Final Report (42). 
Table 4 - Summary of LBS Capabilities by Cellular Carrier

\begin{tabular}{|c|c|c|c|c|c|c|}
\hline $\begin{array}{l}\text { Cellular } \\
\text { Carrier }\end{array}$ & \multicolumn{4}{|c|}{ Handset-Initiated (HI) Location Request } & \multicolumn{2}{|c|}{$\begin{array}{c}\text { Network-Initiated (NI) } \\
\text { Location Request }\end{array}$} \\
\hline \multirow{3}{*}{$\begin{array}{l}\text { Sprint } \\
\text { (CDMA) }\end{array}$} & $\begin{array}{l}\text { Suppo } \\
\text { rt HI? }\end{array}$ & $\begin{array}{l}\text { Restricts } \\
\text { Access HI? }\end{array}$ & $\begin{array}{l}\text { Supports } \\
\text { J2ME? }\end{array}$ & $\begin{array}{l}\text { Embedded GPS } \\
\text { exposed? }\end{array}$ & Supports NI? & $\begin{array}{l}\text { Restricts } \\
\text { Access NI? }\end{array}$ \\
\hline & Yes & Yes & Yes & Yes & Yes & Yes \\
\hline & \multicolumn{6}{|c|}{$\begin{array}{l}\text { Note: Quickly maturing LBS platform for HI and NI. } \\
\text { All devices released after early } 2007 \text { support JSR179 for embedded GPS. } \\
\text { Developer website: } \underline{\text { http://developer.sprint.com }}\end{array}$} \\
\hline \multirow{3}{*}{ Nextel (iDEN) } & $\begin{array}{l}\text { Suppo } \\
\text { rt HI? }\end{array}$ & $\begin{array}{l}\text { Restricts } \\
\text { Access HI? }\end{array}$ & $\begin{array}{l}\text { Supports } \\
\text { J2ME? }\end{array}$ & $\begin{array}{l}\text { Embedded GPS } \\
\text { exposed? }\end{array}$ & Supports NI? & $\begin{array}{l}\text { Restricts } \\
\text { Access NI? }\end{array}$ \\
\hline & Yes & No & Yes & Yes & Yes & Yes \\
\hline & \multicolumn{6}{|c|}{$\begin{array}{l}\text { Note: Mature LBS platform for HI and NI. } \\
\text { All devices released after } 2004 \text { capable of JSR179 support for embedded GPS. } \\
\text { Developer website: } \text { http://developer.sprint.com }\end{array}$} \\
\hline \multirow{3}{*}{$\begin{array}{l}\text { AT\&T } \\
\text { (formerly } \\
\text { Cingular) } \\
\end{array}$} & $\begin{array}{l}\text { Suppo } \\
\text { rt HI? }\end{array}$ & $\begin{array}{l}\text { Restricts } \\
\text { Access HI? }\end{array}$ & $\begin{array}{l}\text { Supports } \\
\text { J2ME? }\end{array}$ & $\begin{array}{l}\text { Embedded GPS } \\
\text { exposed? }\end{array}$ & Supports NI? & $\begin{array}{l}\text { Restricts } \\
\text { Access NI? }\end{array}$ \\
\hline & Yes & Yes & Yes & No* & Yes & Yes \\
\hline & \multicolumn{6}{|c|}{$\begin{array}{l}\text { Note: LBS still emerging and still closed to 3rd party developers. } \\
\text { Only devices supporting JSR179 with embedded GPS are PDAs } \\
\text { Developer website: } \underline{\text { http://developer.att.com/ }}\end{array}$} \\
\hline \multirow{2}{*}{ Verizon } & $\begin{array}{l}\text { Suppo } \\
\text { rt HI? }\end{array}$ & $\begin{array}{l}\text { Restricts } \\
\text { Access HI? }\end{array}$ & $\begin{array}{l}\text { Supports } \\
\text { J2ME? }\end{array}$ & $\begin{array}{l}\text { Embedded GPS } \\
\text { exposed? }\end{array}$ & Supports NI? & $\begin{array}{l}\text { Restricts } \\
\text { Access NI? }\end{array}$ \\
\hline & Yes & Yes & No & Yes & No & N/A \\
\hline & \multicolumn{6}{|c|}{$\begin{array}{l}\text { Note: LBS still closed to 3rd party developers. BREW Only for applications. } \\
\text { Only RIM Blackberry, Palm Treo, and Windows Mobile devices w/ external Bluetooth support 3r } \\
\text { party LBS applications. } \\
\text { Developer website: } \text { http://www.vzwdevelopers.com }\end{array}$} \\
\hline \multirow{3}{*}{ Alltel } & $\begin{array}{l}\text { Suppo } \\
\text { rt HI? }\end{array}$ & $\begin{array}{l}\text { Restricts } \\
\text { Access HI? }\end{array}$ & $\begin{array}{l}\text { Supports } \\
\text { J2ME? }\end{array}$ & $\begin{array}{l}\text { Embedded GPS } \\
\text { exposed? }\end{array}$ & Supports NI? & $\begin{array}{l}\text { Restricts } \\
\text { Access NI? }\end{array}$ \\
\hline & Yes & Yes & No & Yes & No & N/A \\
\hline & \multicolumn{6}{|c|}{$\begin{array}{l}\text { Note: Only BREW LBS applications or RIM Blackberry devices are supported for 3rd party } \\
\text { software development. } \\
\text { Developer website: http://developer.alltel.com }\end{array}$} \\
\hline \multirow[t]{3}{*}{ T-Mobile } & $\begin{array}{l}\text { Suppo } \\
\text { rt HI? }\end{array}$ & $\begin{array}{l}\text { Restricts } \\
\text { Access HI? }\end{array}$ & $\begin{array}{l}\text { Supports } \\
\text { J2ME? }\end{array}$ & $\begin{array}{l}\text { Embedded GPS } \\
\text { exposed? }\end{array}$ & Supports NI? & $\begin{array}{l}\text { Restricts } \\
\text { Access NI? }\end{array}$ \\
\hline & No & N/A & Yes & No* & No & N/A \\
\hline & \multicolumn{6}{|c|}{$\begin{array}{l}\text { Note: LBS still closed to 3rd party developers. No direct developer support. } \\
\text { Only RIM Blackberry } 8800 \text { has embedded GPS. } \\
\text { Developer website: N/A }\end{array}$} \\
\hline \multicolumn{7}{|c|}{$\begin{array}{l}\text { HI = Handset-initiated location requests by 3rd party applications } \\
\text { NI = Network-initiated location requests by 3rd party applications } \\
(*) \text { Unlocked GSM devices w/ embedded autonomous GPS may be available through other vendors outside of the } \\
\text { U.S. market } \\
\text { All information current as of 11/16/2007 }\end{array}$} \\
\hline
\end{tabular}


Capabilities of cellular providers have progressed rapidly over the last few years. A general evaluation of cellular networks' features is shown in Table 5. Each U.S. cellular carrier is at a different stage of network deployment. A comparison of the various cellular network technologies deployed by the major U.S. cellular carriers is shown in Table 6.

Table 5 - Cellular Data Networks

\begin{tabular}{|c|c|c|c|c|c|c|}
\hline & $1 G$ & $2 G$ & $2.5 G$ & $3 G$ & $3.5 G$ & $\begin{array}{l}4 G \text { and } \\
\text { Beyond }\end{array}$ \\
\hline Technology & AMPS & $\begin{array}{l}\text { GSM, } \\
\text { CDMA, } \\
\text { iDEN }\end{array}$ & $\begin{array}{l}\text { GPRS, } \\
\text { 1xRTT, } \\
\text { EDGE }\end{array}$ & $\begin{array}{l}\text { UMTS, } \\
\text { 1xEV-DO }\end{array}$ & $\begin{array}{l}\text { HSDPA } \\
\text { (upgrade for } \\
\text { UMTS), } \\
\text { 1xEV-DV } \\
\end{array}$ & WiMax, LTE \\
\hline Speeds & $\mathrm{n} / \mathrm{a}$ & $\begin{array}{l}\text { Less than } \\
20 \mathrm{Kbps}\end{array}$ & $\begin{array}{l}30 \mathrm{Kbps} \text { to } \\
90 \mathrm{Kbps}\end{array}$ & $\begin{array}{l}\text { 144Kbps to } \\
2 \mathrm{Mbps}\end{array}$ & $\begin{array}{l}\text { 384Kbps to } \\
14.4 \mathrm{Mbps}\end{array}$ & $\begin{array}{l}\text { 100Mbps to } \\
1 \mathrm{Gbps}\end{array}$ \\
\hline $\begin{array}{l}\text { Features } \\
\text { for single } \\
\text { user }\end{array}$ & $\begin{array}{l}\text { Analog } \\
\text { (voice } \\
\text { only) }\end{array}$ & $\begin{array}{l}\text { Voice; } \\
\text { SMS; } \\
\text { conference } \\
\text { calls; caller } \\
\text { ID; push to } \\
\text { talk }\end{array}$ & $\begin{array}{l}\text { MMS; } \\
\text { image; Web } \\
\text { browsing; } \\
\text { short } \\
\text { audio/video } \\
\text { clips; } \\
\text { games, } \\
\text { applications, } \\
\text { and ring } \\
\text { tone } \\
\text { downloads }\end{array}$ & $\begin{array}{l}\text { Full-motion } \\
\text { video; } \\
\text { streaming } \\
\text { music, 3D } \\
\text { gaming; } \\
\text { faster Web } \\
\text { browsing }\end{array}$ & $\begin{array}{l}\text { On-demand } \\
\text { video; video } \\
\text { conferencing }\end{array}$ & $\begin{array}{l}\text { High-quality } \\
\text { streaming } \\
\text { video; high- } \\
\text { quality video } \\
\text { conferencing; } \\
\text { Voice-over- } \\
\text { IP telephony }\end{array}$ \\
\hline
\end{tabular}

When discussing handset-initiated location requests and software running on handheld devices, the focus is on traditional mobile phones owned by the majority of consumer wireless subscribers. Larger PDA devices such as Palm Treos, RIM Blackberries, and devices running Windows Mobile platforms are excluded from this group of devices because they represent a smaller segment of the wireless device market and are much more expensive than the widely used cell phones. Proprietary development environments are also necessary for Palm, RIM, and Windows Mobile platforms (50), (51). RIM Blackberry and Palm devices support J2ME applications through some modifications in their respective proprietary IDEs. Currently, Windows Mobile does not support the J2ME platform. This research project focused primarily on devices that support the J2ME platform and can easily run J2ME applications developed using open IDEs for Java such as Netbeans or Eclipse (52), (53).

To facilitate development of J2ME applications, Sun Microsystems provides a generic software J2ME emulator known as the Sun Java Wireless Toolkit for CLDC that runs MIDP and CLDC-compliant applications in a desktop environment (54). Support for additional APIs defined by JSRs is included in the emulators allowing software developers to develop and test J2ME applications without necessarily installing them on an actual device. There is no substitution for field-testing any application, particularly those with LBS. Emulators do provide a simple method of testing the basic functionality of a MIDlet, which is a J2ME application. 
Table 6 - Cellular Network Technologies by Carrier

\begin{tabular}{|c|c|c|c|c|c|c|}
\hline \multicolumn{7}{|c|}{ Cellular Data Networks for Mobile Phones } \\
\hline $\begin{array}{l}\text { Cellular } \\
\text { Carrier }\end{array}$ & Network Type & $\begin{array}{c}\text { Network } \\
\text { Classification }\end{array}$ & $\begin{array}{c}\text { Avg. } \\
\text { Download } \\
\text { Speed }\end{array}$ & $\begin{array}{c}\text { Burst } \\
\text { Download } \\
\text { Speed }\end{array}$ & $\begin{array}{l}\text { Avg. } \\
\text { Upload } \\
\text { Speed }\end{array}$ & $\begin{array}{l}\text { Burst } \\
\text { Upload } \\
\text { Speed }\end{array}$ \\
\hline \multirow{4}{*}{ Alltel } & $\begin{array}{l}\text { CDMA } \\
(1 \mathrm{xRTT})\end{array}$ & $2 \mathrm{G}$ & $\begin{array}{l}40- \\
70 \mathrm{Kbps}\end{array}$ & 144Kbps & $\begin{array}{l}\sim 40- \\
70 \mathrm{Kbps}\end{array}$ & $\sim 144 \mathrm{Kbps}$ \\
\hline & \multicolumn{6}{|c|}{ http://www.alltel.com/business/enhanced/mobilelink.html } \\
\hline & EV-DO & $3 \mathrm{G}$ & $\begin{array}{l}400- \\
700 \mathrm{Kbps}\end{array}$ & $2.4 \mathrm{MB}$ & $\begin{array}{l}\sim 40- \\
60 \mathrm{Kbps}\end{array}$ & 100Kbps \\
\hline & \multicolumn{6}{|c|}{ http://www.alltel.com/business/enhanced/mobilelink.html } \\
\hline \multirow{6}{*}{$\begin{array}{l}\text { AT\&T } \\
\text { Wireless } \\
\text { (formerly } \\
\text { Cingular) }\end{array}$} & GPRS & $2.5 \mathrm{G}$ & $\begin{array}{l}\sim 25- \\
35 \mathrm{Kbps}\end{array}$ & $\sim 90 \mathrm{Kbps}$ & $\begin{array}{l}\sim 25- \\
35 \mathrm{Kbps}\end{array}$ & $\sim 90 \mathrm{Kbps}$ \\
\hline & \multicolumn{6}{|c|}{ http://www.cingular.com/sbusiness/data_connect } \\
\hline & EDGE & $2.5 \mathrm{G}$ & $\begin{array}{l}70- \\
135 \text { Kbps } \\
\end{array}$ & $200 \mathrm{Kbps}$ & $\begin{array}{l}\sim 70- \\
135 \mathrm{Kbps}\end{array}$ & $\sim 200 \mathrm{Kbps}$ \\
\hline & \multicolumn{6}{|c|}{ http://www.cingular.com/sbusiness/data_connect } \\
\hline & $\begin{array}{l}\text { UMTS/HSDPA } \\
\text { (in } \\
\text { deployment) }\end{array}$ & 3G & $\begin{array}{l}400- \\
700 \mathrm{Kbps}\end{array}$ & $\sim 1.8 \mathrm{Mbps}$ & $\begin{array}{l}\sim 220- \\
320 \mathrm{Kbps}\end{array}$ & $\sim 384 \mathrm{Kbps}$ \\
\hline & \multicolumn{6}{|c|}{ http://www.wireless.att.com/businesscenter/built-for-business/network.jsp?WT.svl=calltoaction } \\
\hline \multirow{2}{*}{ Nextel } & iDEN & $2 \mathrm{G}$ & $56 \mathrm{Kbps}$ & $56 \mathrm{Kbps}$ & $56 \mathrm{Kbps}$ & 56Kbps \\
\hline & \multicolumn{6}{|c|}{ http://coverage.sprintpcs.com/IMPACT.jsp?PCode=vanity:coverage } \\
\hline \multirow{5}{*}{$\begin{array}{l}\text { Sprint } \\
\text { (now } \\
\text { Sprint- } \\
\text { Nextel) }\end{array}$} & $\begin{array}{l}\text { CDMA } \\
(1 \mathrm{xRTT})\end{array}$ & $2 \mathrm{G}$ & $\begin{array}{l}60- \\
80 \mathrm{Kbps}\end{array}$ & $144 \mathrm{Kbps}$ & $\begin{array}{l}\sim 60- \\
80 \mathrm{Kbps}\end{array}$ & $\sim 144 \mathrm{Kbps}$ \\
\hline & \multicolumn{6}{|c|}{ http://coverage.sprintpcs.com/IMPACT.jsp?PCode=vanity:coverage } \\
\hline & EV-DO & $3 G$ & $\begin{array}{l}400- \\
700 \mathrm{Kbps} \\
\end{array}$ & $2 \mathrm{MB}$ & $\begin{array}{l}40- \\
70 \mathrm{Kbps}\end{array}$ & $\sim 100 \mathrm{Kbps}$ \\
\hline & EV-DO Rev. A & $3 G$ & $\begin{array}{l}\text { 600Kbps- } \\
1.4 \mathrm{mbps}\end{array}$ & $\sim 3.1 \mathrm{Mbps}$ & $\begin{array}{l}\text { 350Kbps- } \\
500 \mathrm{Kbps}\end{array}$ & $\sim 1.8 \mathrm{Mbps}$ \\
\hline & \multicolumn{6}{|c|}{ http://coverage.sprintpcs.com/IMPACT.jsp?PCode=vanity:coverage } \\
\hline \multirow{4}{*}{ T-Mobile } & GPRS & $2.5 \mathrm{G}$ & $\begin{array}{l}20- \\
35 \mathrm{Kbps}\end{array}$ & $\sim 56 \mathrm{Kbps}$ & $\begin{array}{l}\sim 20- \\
35 \mathrm{Kbps}\end{array}$ & $\sim 56 \mathrm{Kbps}$ \\
\hline & \multicolumn{6}{|c|}{ http://www.t-mobile.com/plans/default.asp?tab=internet } \\
\hline & $\begin{array}{l}\text { UMTS/HSDPA } \\
\text { (status } \\
\text { unknown) }\end{array}$ & $3 G$ & $\begin{array}{l}\sim 400- \\
700 \mathrm{Kbps}\end{array}$ & $\sim 1.8 \mathrm{Mbps}$ & $\begin{array}{l}\sim 220- \\
320 \mathrm{Kbps}\end{array}$ & 384Kbps \\
\hline & \multicolumn{6}{|c|}{ http://www.t-mobile.com/plans/default.asp?tab=internet } \\
\hline \multirow{5}{*}{$\begin{array}{l}\text { Verizon } \\
\text { Wireless }\end{array}$} & $\begin{array}{l}\text { CDMA } \\
(1 \times R T T) \\
\end{array}$ & $2 \mathrm{G}$ & $\begin{array}{l}60- \\
80 \mathrm{Kbps}\end{array}$ & $144 \mathrm{Kbps}$ & $\begin{array}{l}\sim 60- \\
80 \mathrm{Kbps}\end{array}$ & $\sim 144 \mathrm{Kbps}$ \\
\hline & \multicolumn{6}{|c|}{ http://b2b.vzw.com/broadband/coveragearea.html } \\
\hline & EV-DO & $3 G$ & $\begin{array}{l}400- \\
700 \mathrm{Kbps}\end{array}$ & $2 \mathrm{MB}$ & $\begin{array}{l}40- \\
6 \sim \text { Kbps }\end{array}$ & 100Kbps \\
\hline & EV-DO Rev. A & $3 G$ & $\begin{array}{l}600- \\
1.4 \mathrm{Mbps}\end{array}$ & $\sim 3.1 \mathrm{Mbps}$ & $\begin{array}{l}500- \\
800 \mathrm{kbps}\end{array}$ & $\sim 1.8 \mathrm{Mbps}$ \\
\hline & \multicolumn{6}{|c|}{ http://b2b.vzw.com/broadband/coveragearea.html } \\
\hline & & ximate speed & ased on net & $\begin{array}{l}\text { ork technolc } \\
\text { I by carrier }\end{array}$ & & \\
\hline
\end{tabular}




\section{Sprint-Nextel iDEN Network}

The Sprint-Nextel iDEN network (formerly Nextel iDEN network) was the first commercial cellular network in the U.S. to expose location-based services capabilities to third party application developers. Additionally, as of November 2007, Sprint-Nextel's iDEN network was the only cellular network to allow free and open access for handsetinitiated location requests on devices with embedded GPS. (Note: This does not include international GSM devices with autonomous GPS that do not require network resources, since these devices can be used on U.S. GSM networks without carrier knowledge.) Any software developer can create and test J2ME applications compliant with MIDP 2.0 and CLDC 1.1 specifications on Motorola iDEN handsets without restriction or required permission. All Motorola iDEN models released from the i860 up to and including the most recent i880 iDEN model also support the standardized JSR179 Location API.

Nextel phones utilize an A-GPS method as well as a Cell-ID method for position determination (55). Either method can be requested specifically by the application through input to the JSR179 API. Under normal operation, if a highly accurate A-GPS fix is requested but a position cannot be determined using GPS, the Cell-ID location information will be returned instead. For the Nextel iDEN network, the actual physical geographic location of the cell phone tower is returned instead of the position of the center of the serving cell, which can potentially differ depending on the area of coverage in relation to the tower position. Positioning is possible when the iDEN network is not available by using autonomous GPS.

Networking support through Java is also important for location-aware applications so they can transfer location and other data back to a server to enable features such as real-time tracking. While the J2ME MIDP 2.0 specification requires only HTTP to be supported so that a device is certified as MIDP 2.0-compliant, iDEN phones support Transmission Control Protocol (TCP), Secure Sockets Layer (SSL) (secure version of TCP), User Datagram Protocol (UDP), Hypertext Transfer Protocol (HTTP), and Hypertext Transfer Protocol over Secure Socket Layer (HTTPS) through J2ME, thus giving software developers many options to choose the protocol that best fits their application (56). Many iDEN phones released since the i870 support the JSR172 J2ME Web Services Specification API, which allows the device to directly access and utilize web services using Simple Object Access Protocol and XML to enable distributed applications (58), (60).

For position data to be transferred from the cell phone to a server, a data plan is required. An unlimited data plan is preferred so that there is an upper limit on the cost incurred by the subscriber. An unlimited data plan can be added to any Nextel iDEN plan for $\$ 10$ per month.

\section{Sprint-Nextel CDMA Network}

Sprint-Nextel's CDMA network (formerly Sprint PCS CDMA network) is second in the U.S. only to the iDEN network in terms of longevity of LBS for consumers. In the past, 
Sprint CDMA devices have not had certain advanced software capabilities such as support for JSR179 and multitasking Java virtual machines that were common on iDEN devices. However, handsets exhibiting these features released in early 2007 for the Sprint CDMA network promise to push LBS to the next level on this particular platform and even surpass iDEN LBS capabilities.

Sprint CDMA devices support CLDC 1.1 and MIDP 2.0 compliant J2ME applications. All cell phone models released since the Sanyo 7050 in early 2007 have shown increasing levels of LBS support that rival iDEN handsets, including capabilities for simultaneous execution of J2ME applications referred to as Multi-Tasking Virtual Machines (MVM), and support of JSR179 Location API 1.0. MVM devices allow J2ME application to continue executing in the background while minimized, which is an important trait for many LBS applications such as TAD. It appears that all Sprint CDMA devices released after early 2007 will support both JSR179 and MVM.

Sprint exposes multiple types of location fixes to software running on the mobile phone through JSR179 including CellID, Advanced Forward Link Trilateration (AFLT), Assisted GPS, and Autonomous GPS (61). Cell-ID, also referred to as Cell Sector on the SprintNextel CDMA network, is defined as the center of the area of cellular coverage that is currently serving the device. The geographic location of the cell tower with which the phone is currently communicating is also exposed to applications through proprietary Sprint extensions. All positioning technologies are enabled by the gpsOne chipset in Qualcomm CDMA devices (62). TAD utilizes the assisted GPS and autonomous GPS capabilities of Sprint phones to provide real-time location-based services to the transit rider.

Data service, including TCP, SSL (secure version of TCP), UDP, HTTP, and HTTPS, is also exposed to J2ME applications on the handset. A compatible SSL digital certificate must be purchased from VeriSign for an annual fee of $\$ 499$ to enable secure communications between the cell phone and server via SSL or HTTPS. A digital certificate can be used for many applications in a single company. For data communication initiated by a server (i.e., push communication to the phone), server sockets are available on the phone for applications to listen to incoming communications on a particular port. However, while data can be operable when roaming on different CDMA networks, data services are not guaranteed while roaming.

As with most cellular providers today that require the full use of the communication channel for voice when a call is active (i.e., Voice-Over-IP is not yet utilized), a data and voice session cannot exist simultaneously. Therefore, if the user is on a phone call, data will not be sent to the server. Also, if data are being sent very frequently to the server (i.e., a location fix every four seconds), incoming calls to the cell phone may be blocked and may go directly to voicemail. Therefore, the application executing on the cell phone must intelligently manage GPS data transmissions to servers in order to avoid interference with normal cell phone voice communications. As cell phone carriers move towards IP Multimedia Subsystems (IMS) and IP-based voice communication over the next few years, this limitation will disappear and voice and data sessions will be able to coexist. 
For position data to be transferred from the cell phone to a server, a data plan is required. As noted in the section on the IDEN network, an unlimited data plan is preferred so there is an upper limit on the cost incurred by the subscriber. An unlimited data plan can be added to any Sprint CDMA plan for \$15 per month.

\section{AT\&T}

AT\&T, formerly Cingular, is a GSM U.S. cellular provider. AT\&T announced its plans to support location-based services to third-party application developers in early 2007 (63). As of early 2008, AT\&T's network is still closed to application developers that want to develop location-based services for commercially available, consumer-level mobile phones. Multiple requests were made to AT\&T to supply additional information about their LBS platform and to allow access for prototype TAD application testing, but no response was received by the research team.

\section{Alltel}

Alltel is a U.S. CDMA cellular carrier. It uses devices with Qualcomm chipsets that run the BREW platform for the majority of their commercially available mobile phones. Alltel provides few developer resources outside of Qualcomm's BREW resources and, therefore, the application developer is restricted to the BREW operating system (OS) for application development. BREW is not capable of running multithreaded applications, but does support cooperative multitasking (64). However, the absence of multithreading and J2ME severely limits the possibilities of producing an effective, portable LBS tracking application for consumers on the Alltel network.

The research team contacted Alltel through their developer website at http://developer.alltel.com several times for additional information related to LBS on the Alltel network, but did not receive a reply. The fact that Sprint, also a CDMA carrier utilizing Qualcomm technology, has significant support for location-based J2ME applications on its platform indicates that it is possible for Alltel to support similar applications, if desired. However, as of June 2008, Alltel is closed to any such applications.

It should be noted that RIM Blackberry, Windows Mobile, and Palm OS devices are not included in this grouping since they are not BREW OS devices, and the specifications of these devices will dictate their capabilities.

\section{Verizon Wireless}

Like Alltel, Verizon Wireless is a U.S. CDMA cellular carrier that primarily uses devices with Qualcomm chipsets that run the BREW platform. Verizon Wireless provides few resources on their website (http://www.vzwdevelopers.com/) outside of Qualcomm's BREW resources. As previously stated, the absence of multithreading and J2ME severely limits the possibilities of producing an effective, portable LBS tracking application for consumers on the Verizon Wireless network. It is possible for Verizon Wireless, if 
desired, to support similar J2ME applications. However, as of June 2008, Verizon Wireless is closed to any such applications.

As was the case for Alltel, RIM Blackberry, Windows Mobile, and Palm OS devices are not included in this grouping since they are not BREW OS devices, and the specifications of these devices dictate their capabilities. As of June 2008, all devices on these platforms on the Verizon Wireless network require an external GPS unit with a Bluetooth ${ }^{\mathrm{TM}}$ interface.

In late 2007, Verizon announced that, by late 2008, it will allow open access to any device and application on its network (65). However, the meaning of open access is debatable and has not yet been clarified by Verizon. Therefore, at this time it is unknown how this announcement will affect application developers and their ability to produce applications for Verizon Wireless customers (66).

\section{T-Mobile}

T-Mobile, a GSM U.S. cellular provider, provides no developer support on its current website. Therefore, developers must consult individual device manufacturers regarding development on their particular platform.

As with AT\&T, it is possible to use unlocked GSM devices (i.e., international cell phones not dedicated to a U.S. cellular carrier) on T-Mobile's network. Access to autonomous GPS information from J2ME applications is possible on these devices and is dictated by the device manufacturer's specifications. However, these unlocked GSM devices are rare, expensive, and not officially supported by T-Mobile. Network dependant location features, including assisted GPS, Cell-ID, or cell signal trilateration, will not function on these devices while operating on U.S. cellular carrier network.

\subsubsection{FCC Wireless Spectrum Auction Results}

The Federal Communication Commission (FCC) held an auction in early 2008 to license the wireless spectrum that will be abandoned as television is changed from an analog to a digital broadcast. The primary bidders in this auction were wireless telecommunications companies, although Google joined in an effort to further its penetration into the mobile technology world. The auction concluded on March 20, 2008 with Verizon and AT\&T gaining the most wireless spectrum.

However, the most significant result was a benefit for mobile application developers. The auction's bidding surpassed the threshold set by the FCC that will require the licensees to allow "all devices and all applications" on any network in the specified spectrum (67). This requirement will help future cellular networks to become more open and allow applications such as TAD to function on any mobile phone, and on any wireless service provider. Such mobile applications could easily be downloaded to the mobile phone by using the phone's internet browser to click on a website link in similar way that applications are downloaded to traditional desktop computers. 


\subsection{Discussion}

Based on the review conducted by the research team, the following function requirements or capabilities were defined as necessary for the TAD system.

\subsubsection{Positioning Technology}

Since highly accurate position information is a requirement for providing alerts to the transit rider at the appropriate time, assisted GPS should be utilized as the primary positioning technology. Autonomous GPS can be utilized as a fallback positioning technology when assisted GPS is not available, but autonomous GPS will not be as reliable as assisted GPS.

\subsubsection{Form-Factor}

Commercially available GPS-enabled mobile phones should be used as the all-in-one device that executes the TAD software. Mobile phones are the least expensive, and potentially the easiest to deploy programmable platform that includes a highly accurate positioning technology as well as real-time wireless communication.

\subsubsection{Method to Retrieve Location Data}

Handset-initiated location requests should be utilized for the TAD system, which requires software that will execute on-board the mobile phone. Handset-initiated location requests have an extremely low latency between the position request and response. Therefore, the TAD software can make instantaneous decisions based on real-time position information and alert the transit rider at the appropriate time.

\subsubsection{Portability}

J2ME was selected as the mobile software development platform since it is the most established and least proprietary platform available for mobile phones. The standard defined for J2ME to access location data, JSR179 Location API, should be utilized for access to position information.

\subsubsection{Coexistence of TAD with Mobile Phone Functionality}

Since TAD will be installed on a device owned by the end user and utilized for other functions such as phone calls, care must be taken to ensure TAD does not interfere with normal mobile phone operations. J2ME platforms must support an MVM to allow TAD to function in the background when minimized. Intelligent utilization of network resources must be implemented in mobile TAD software. The TAD user should have an unlimited data plan to avoid extensive costs to the end user. Smart power management techniques must be implemented in TAD software to avoid severe impact on battery resources. UDP was selected as the data transfer protocol for location updates due to its lightweight design. 


\subsubsection{Interoperability and Forwards-Compatibility}

Java Enterprise Edition 5 (Java EE5) was chosen as the primary development platform for server-side components, with server-side functions being exposed via web services for universal access. Within J2ME, CLDC 1.1 (lightweight version of Connected Device Configuration (CDC), MIDP 2.0 (predecessor to MIDP 3.0), JSR179 Location API (predecessor to JSR293 Location API 2.0) were targeted for development to ensure forwards compatibility with the future evolution of the J2ME platform.

The next chapter presents how these criteria were incorporated into the design concept of the TAD system to meet functionality requirements. 


\section{CHAPTER 4 - TAD SYSTEM DESIGN}

The TAD system is a software communication architecture that enables GPS-enabled mobile phones to provide end-user travel services to the person carrying the phone. For the initial phase of TAD development, three main services were targeted for implementation: the delivery of real-time auditory prompts to the transit rider via the cell phone informing them when they should request a stop (Figure 7); the delivery of an alert to the rider, caretaker, and travel trainer if the rider deviates from their expected route; and a web page that allows travel trainers and caretakers to create new itineraries for transit riders as well as allow monitoring of real-time rider location.

\section{Travel Assistant Device}

\section{Using Cell Phone Technology to Aid Transit Riders}

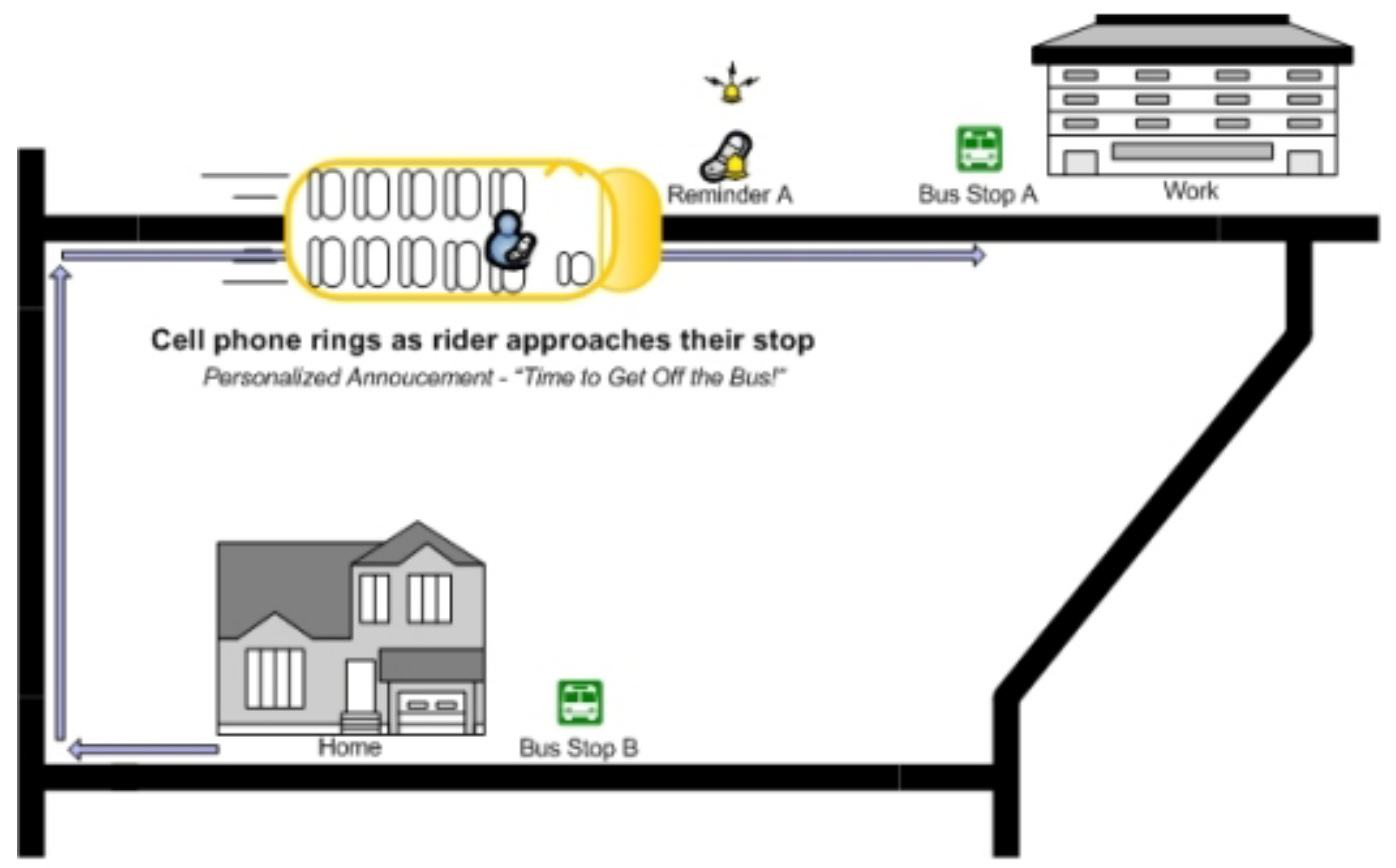

Figure 7 - Travel Assistant Device Concept

In the TAD system design, there were three primary goals:

1) Make the system low-cost and widely accessible.

This involves using off-the-shelf, consumer-grade, GPS-enabled cell phones for a compact, inexpensive, all-in-one solution. Also, standards-based solutions will be used to allow interoperability on multiple platforms (i.e., different cell phones and cellular carriers). In addition, open-source solutions will be used when possible to reduce implementation and management costs to transit agencies. Finally, the software will be forward compatible with future mobile devices to minimize future development costs. 
2) Make the architecture modular so system components can be reused when possible and new features can be easily added in future versions.

Web services will be used to allow the TAD systems to operate in heterogeneous computing environments on multiple platforms and operating systems. System entities are encapsulated so that elements (i.e., database server) may be exchanged without disrupting the entire system.

3) Provide a reliable service tailored to transit riders with special needs.

A simple, uncluttered user interface is provided for the user. To avoid confusion, only two auditory announcements ("Get ready" and "Pull the cord now!") are used. The phone also will vibrate to alert the user when to request a stop.

\subsection{TAD Server-Client Model}

To accomplish these goals, flexible, modular and easily portable software architecture would have to be established, including software that executes on the cell phone, a server, and a web client to implement a web page. The TAD system architecture is shown in Figure 8. The Java programming language was chosen to implement this system, since it provides platforms for the desktop (Java 2 Standard Edition, or J2SE), mobile phone (Java 2 Micro Edition, or J2ME), and server (Java 2 Enterprise Edition, or J2EE). The Java architecture allows Java platforms to support execution of software applications written in Java on multiple operating systems without requiring any changes to code or recompilation of software, therefore providing a high degree of platform independence. Therefore, the TAD server software, which provides the mobile phone with transit route information, could be hosted on servers with different types of operating systems (e.g. Linux, Windows) and the mobile phone software, which provides the notification for exiting the transit vehicle to the rider, can be executed on mobile phones from many different manufacturers without any significant changes to the software system. The Java-based Google Web Toolkit (68) also creates web pages, used to monitor real-time rider location and create new trip itineraries for the rider, that can be accessed from different types of internet browsers (e.g. Internet Explorer, Firefox) running on different operating systems (e.g. Linux, Windows). Utilizing the Java programming on all platforms reduces development time since the code can be reused. J2ME is deployed on billions of devices, and, therefore, is currently the best platform for reaching as many mobile devices as possible (45).

To support a modular design, web services were utilized as the interface between client and server-side software. Web services provide a well-defined interface by which a client application can request a service that is executed server-side and have a result returned to the client application.

Extensible Markup Language (XML) is used to format the data passed to and from the server, and SOAP is the protocol used to exchange XML between the client and server. SOAP can be implemented using any networking protocol, but it is most often used on top of the Hypertext Transfer Protocol (HTTP) due to the near universal use of HTTP. Since HTTP, SOAP, and XML are independent of any programming language, web services 


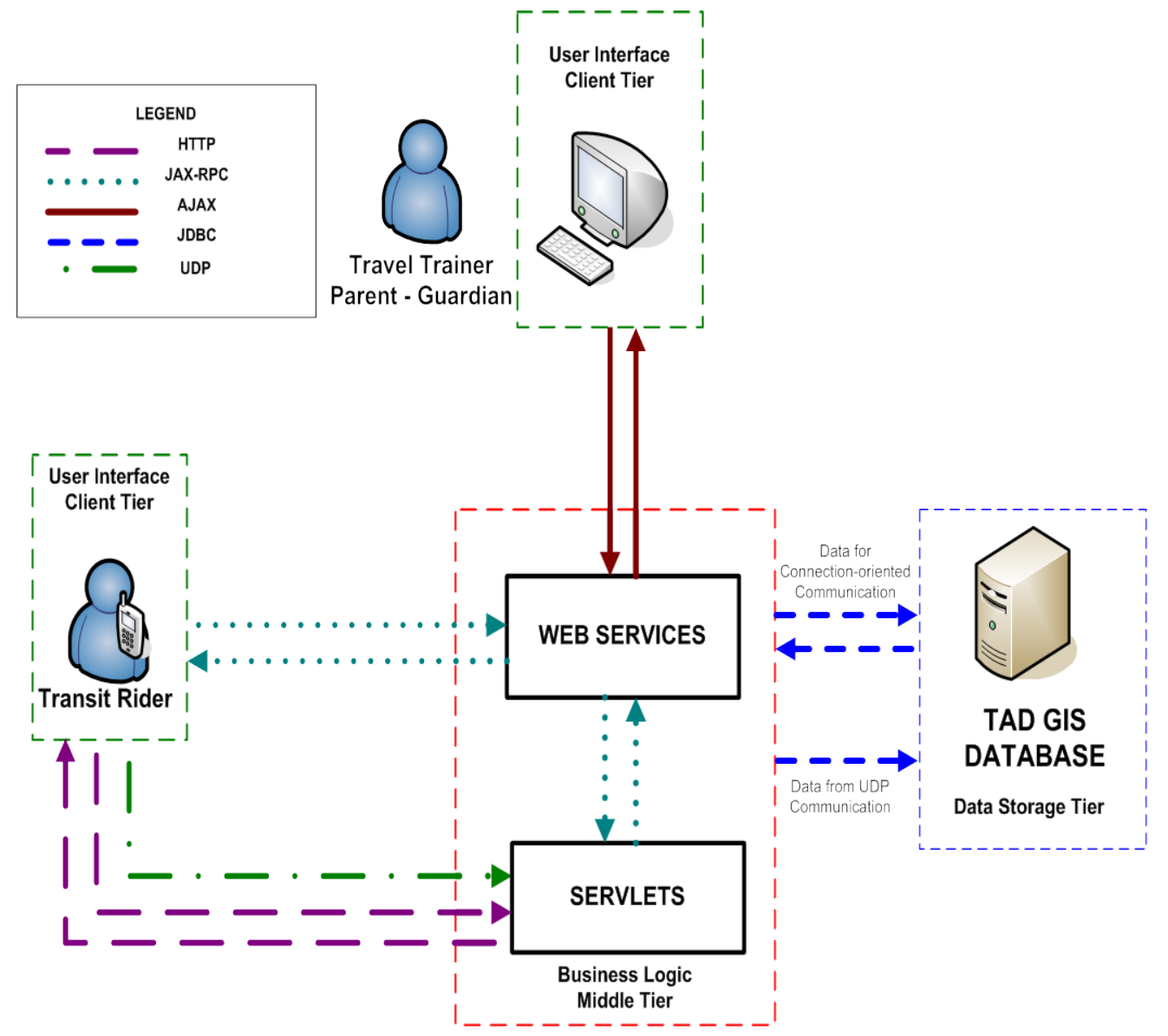

Figure 8 - Travel Assistant Device System Architecture

allow the exchange of data in heterogeneous environments where the communicating entities may be implemented in completely different languages or running on different computing platforms or operating systems. This architecture also allows the addition of new server-side components that may be implemented in programming languages other than Java, thus extending the potential for future capabilities. Additionally, the implementation of a web service is completely independent of the client making the request.

Cell phone access to web services is implemented via Java API for XML-Based Remote Procedure Calls (JAX-RPC), defined for J2ME in "Java Specification Request (JSR) 172: J2ME Web Services Specification” (58). If a cell phone's J2ME environment supports JSR172, it can directly access the same web services as a web or desktop client via SOAP and XML. If a cell phone does not support JSR172, it can access the web services via a servlet proxy (as shown in Figure 8). In this scenario, the cell phone communicates with the servlet proxy using the HTTP protocol, which must be supported in all Connected Limited Device Configuration (CLDC) 1.1 Java devices. The servlet can, in turn, translate these requests to JAX-RPC or a similar web services access method to invoke the web service, or the servlet can implement the same functionality as the web service if located in the same application server instance. In both instances, the proxy then returns a HTTP 
response to the phone. Since JAX-RPC is not yet widely supported by J2ME devices, this method guarantees that any CLDC 1.1 J2ME device will be able to access the web service.

\subsection{TAD Web Page}

The TAD web page provides the means through which the travel trainer or caretaker/parent can create new trips for the individual to take via transit, and allows them to monitor the location of the rider in real-time if appropriate. A flowchart of TAD web page navigation is shown in Figure 9, and a detailed diagram of the TAD Web Page architecture is shown in Figure 10.

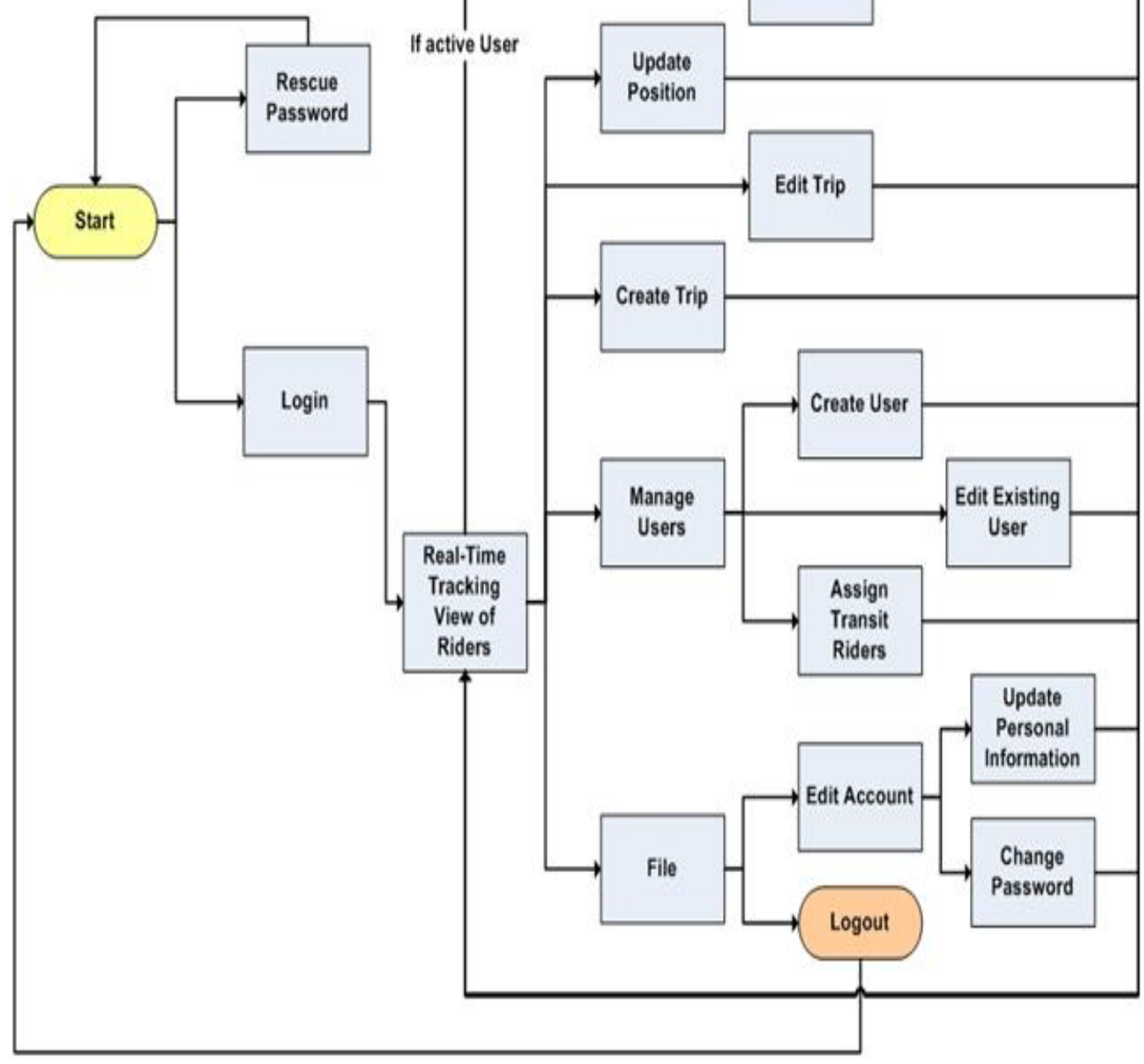

Figure 9 - TAD Web Page Navigation Flowchart 


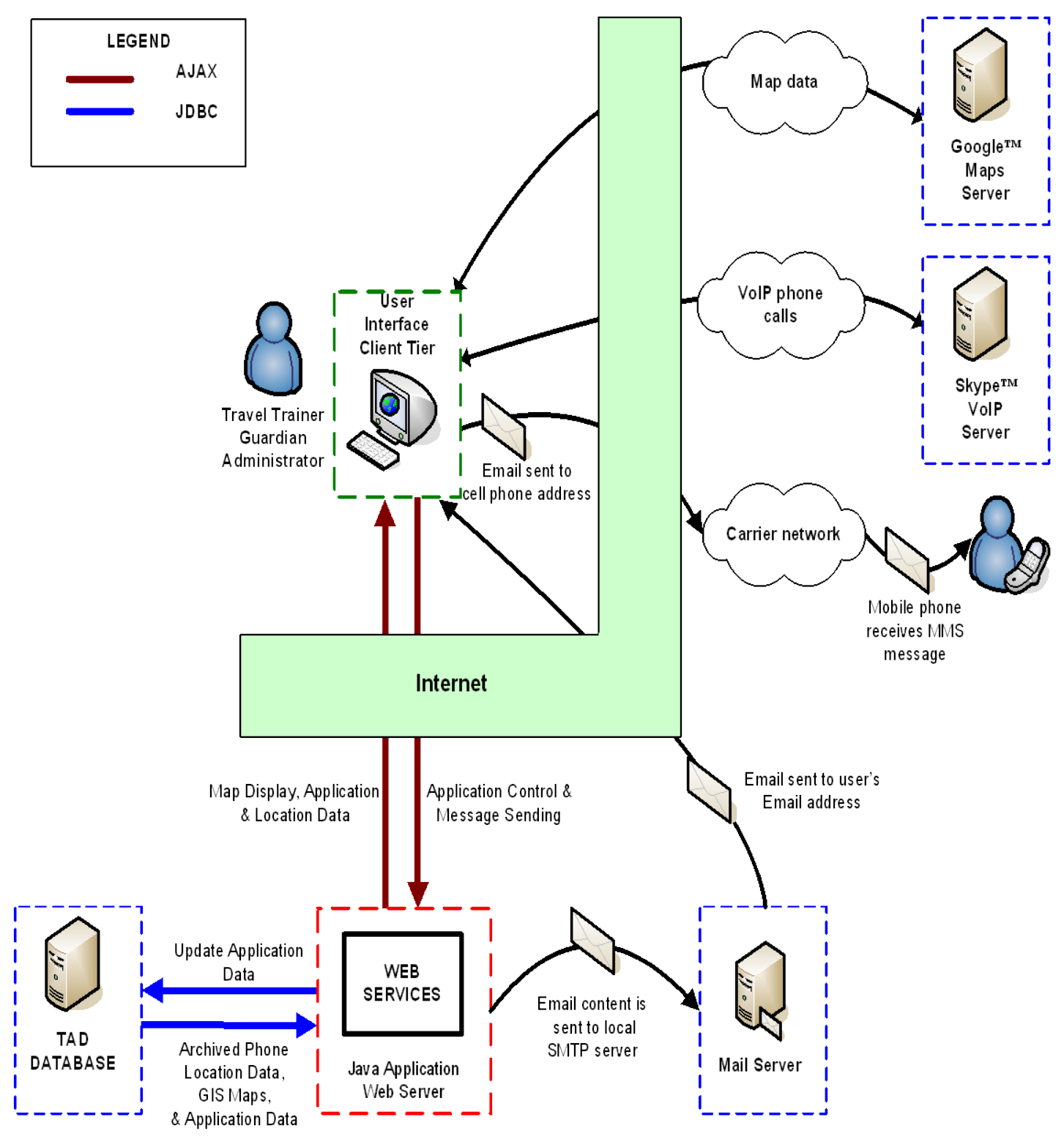

Figure 10 - TAD Web Page Architecture 
Figure 11 illustrates the communication protocol between the web client and the server.
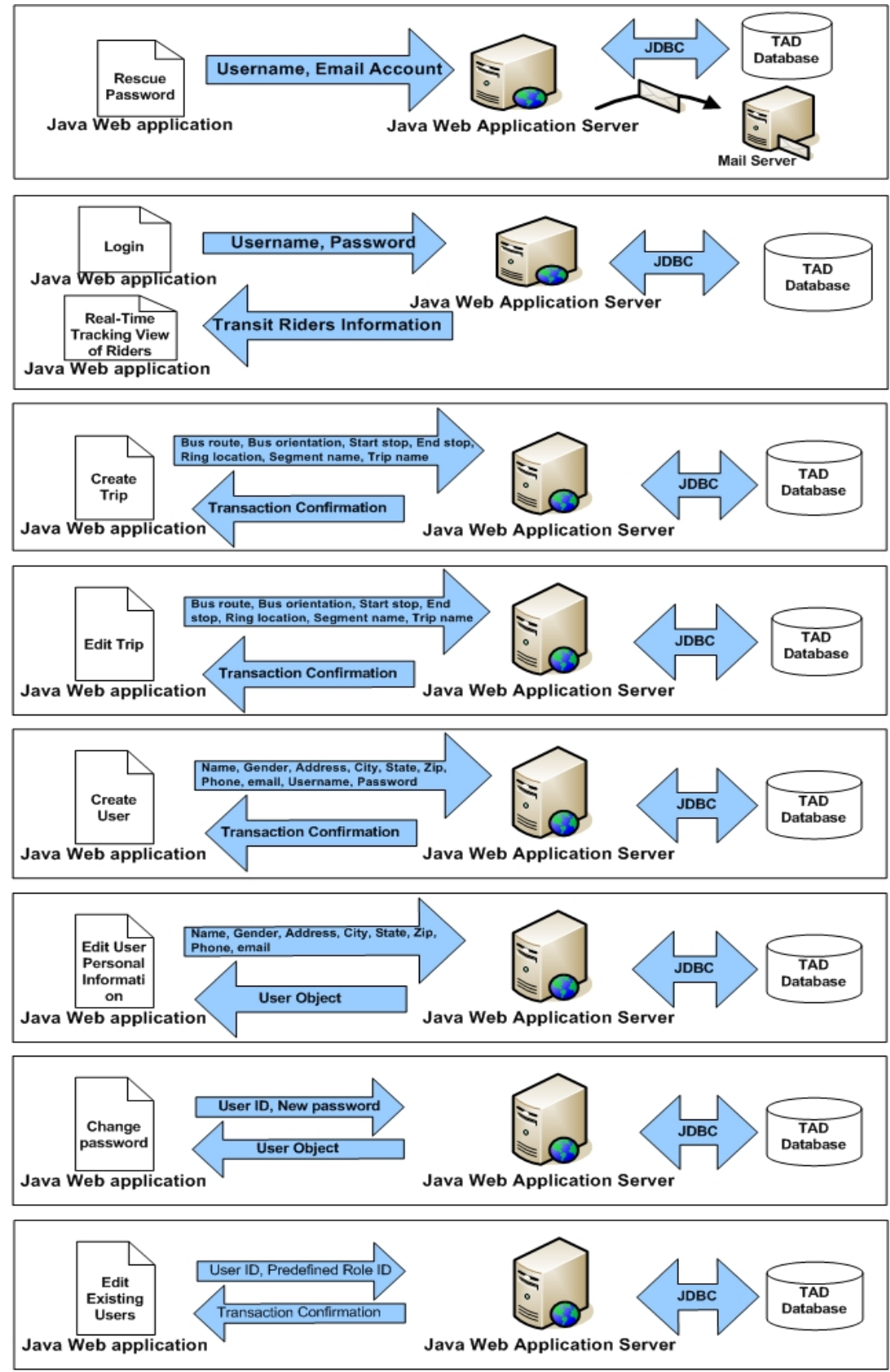

Figure 11 - TAD Communication Protocol between the Webpage Client and the Server 
The TAD web page was developed using the Google Web Toolkit (68), which allows the development of Web 2.0 applications using Java as the development language. Many new web applications, termed Web 2.0, use Asynchronous JavaScript and XML (AJAX) to provide similar functionality to traditional desktop applications. AJAX uses JavaScript to exchange small pieces of information, usually in XML, between a client and server instead of reloading the entire web page every time new information is presented. By exchanging only small bits of information and manipulating only that part of the web page that requires updating, AJAX provides an enhanced web application experience that is more responsive and interactive but still based on real-time server updates. AJAX provides the functionality to connect to TAD's web services. The TAD web services then access GIS and relational databases to retrieve and store information. While AJAX provides unique web page functionality, it combines multiple technologies (e.g., JavaScript, XML, HTML, CSS, ASP.NET, PHP, Java Server Pages, etc.), and the learning curve for developing advanced AJAX applications is steep.

Few AJAX development environments facilitate the creation of AJAX applications. The Google Web Toolkit, however, allows the use of Java IDEs to develop web applications in Java using the traditional client-server model and remote procedure calls. It then translates the client-side into JavaScript so AJAX may be used when the webpage is viewed. This procedure greatly simplifies the AJAX development process since all code writing takes place in the Java programming language while still giving the end-user the AJAX experience.

Access to the TAD web page is restricted to those with an authorized user name and password, as shown in Figure 12. The user must have an administrator, travel trainer, or guardian role. New users must be created by an administrator.

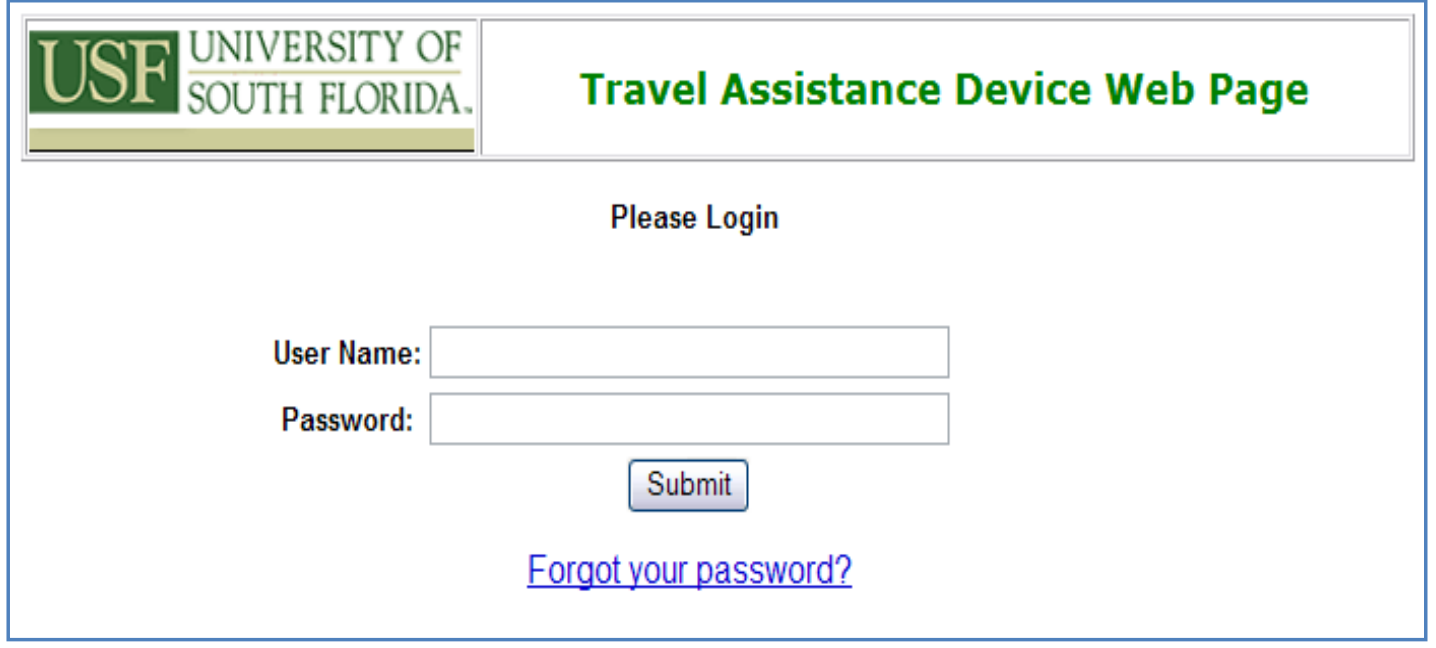

Figure 12 - TAD Web Interface - Login Screen

Note: The website is secured with user name and password access protection. 
The TAD web page provides the functionality for users to retrieve their password by providing the system with their user name and email account, as shown in Figure 13. A temporary password is sent to the user's email account. The user then has the ability to change the password upon logging.

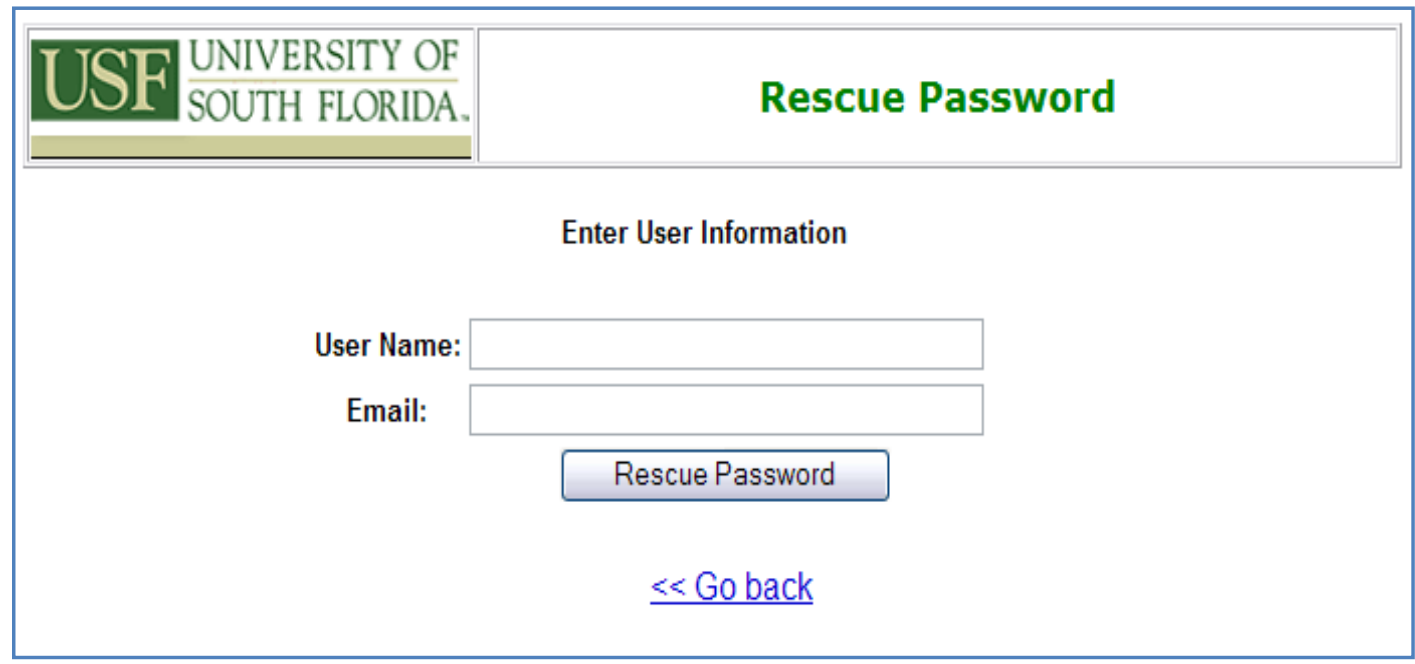

Figure 13 - TAD Web Interface - Password Rescue

The TAD map shown on the web page utilizes the easy-to-use Google ${ }^{\circledR}$ Map interface (Figure 14). The user can easily change the current view of the map by clicking and dragging the map in any direction or by clicking on the four directional arrows in the upper left-hand corner of the map. Double-clicking on a point on the map will automatically center the map on that location. Zooming in or out is performed by clicking on the plus $(+)$ or minus (-) buttons just below the four directional arrows. This feature allows the supervisor to easily zoom in to see a very fine resolution of distance (down to a matter of feet) or to instantly zoom out to view conditions on a statewide, national, or even international scale. The map interface scales appropriately and shows information only relevant to the current zoom level. This feature allows the user to focus on the location information that is relevant, while the markers remain placed in the correct location and accessible at all levels.

The TAD web page allows supervisors to track their transit riders or passengers as shown in Figure 14. On the upper right side of the website is a list of transit riders that indicates whether they are active or inactive. If a transit rider is active, a red marker will appear on the map showing the actual location of the user. 


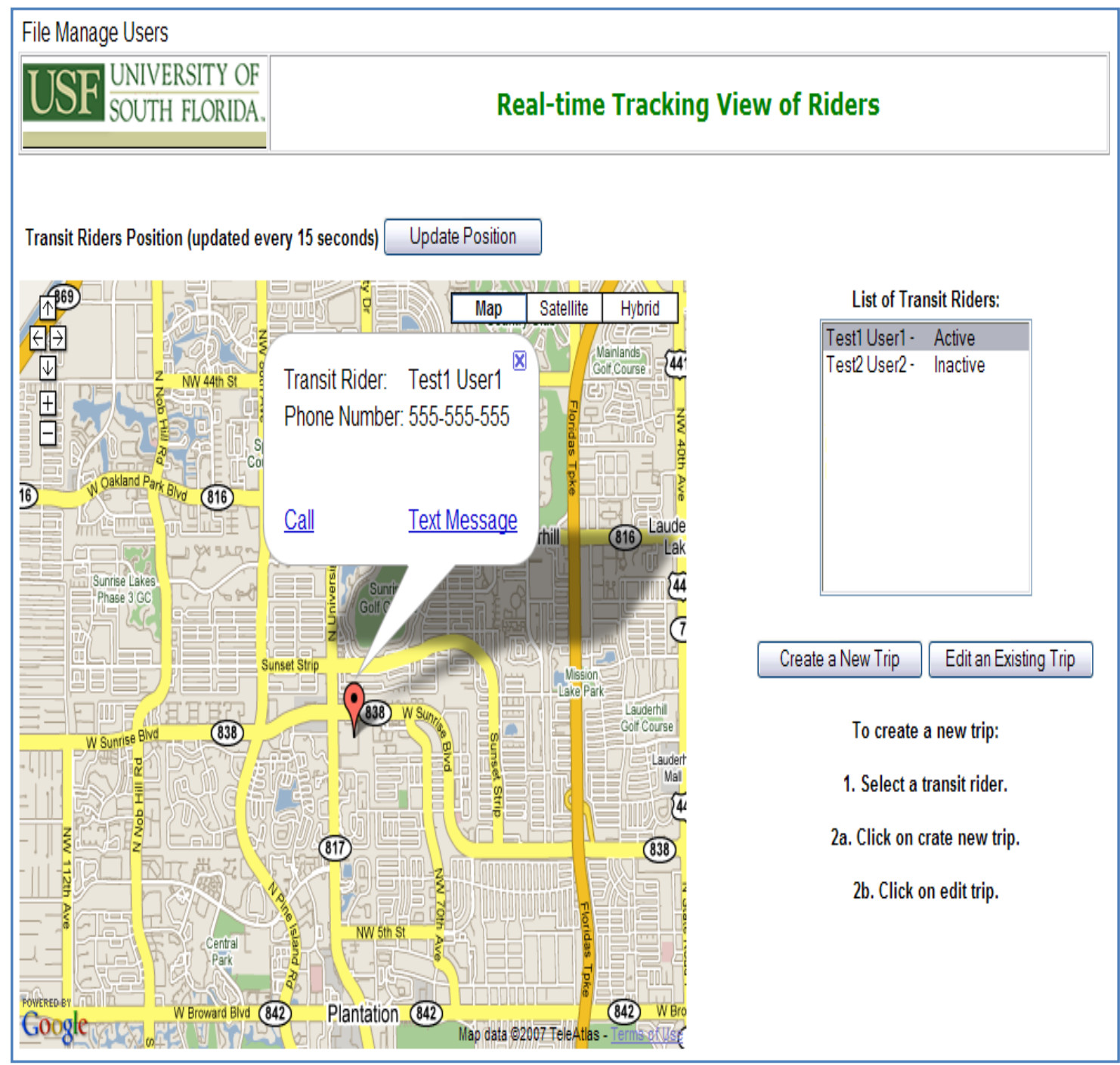

Figure 14 - TAD Web Interface - Real-Time Viewing

Note: Clicking on the red marker allows transit trainers to identify the user as well as make a call or send a text message to the user's phone.

The user can select one of three modes to control what kind of mapping data is shown: Map, Satellite, and Hybrid, as shown in Figure 15. The normal Map mode displays a traditional street map. This mode is useful for quickly identifying nearby streets by name. Satellite mode replaces the street map with photographic images taken from satellites, while the Hybrid mode overlays information from street maps over the satellite imagery. Satellite imagery allows the supervisor to quickly recognize a location in reference to commonly known buildings and visual landmarks. 


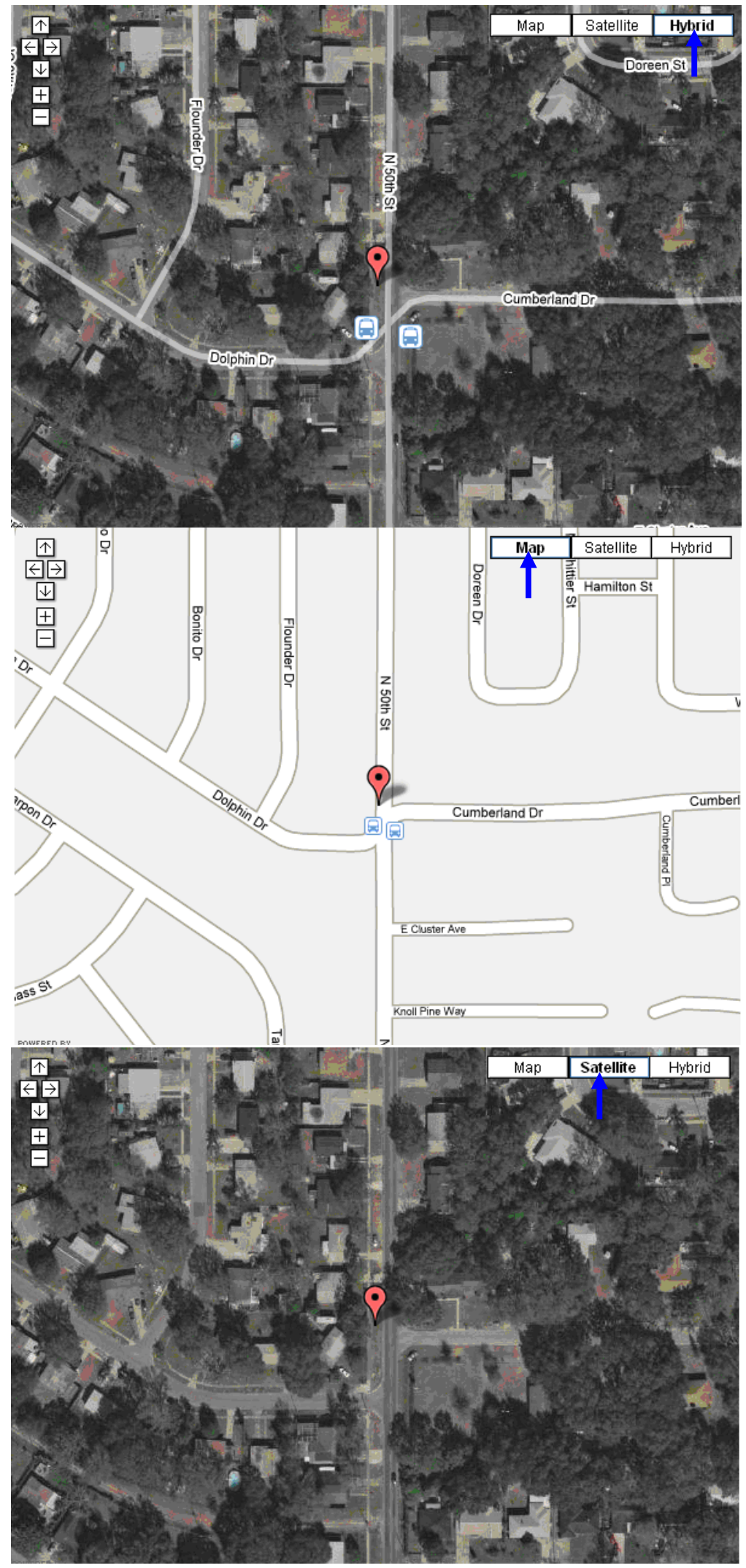

Figure 15 - Hybrid, Street Map, or Satellite View Options 
When the user clicks on the marker, a bubble appears with the user's name and phone number as well as two links for enabling communication between the supervisor and the transit rider. Clicking on the Call link allows the supervisor to call the user through Skype $^{\mathrm{TM}}$, as shown in Figure 16. In the same manner, clicking on the Text Message link allows the web page user to send a text message to the transit rider's phone. Microsoft Outlook can be used as an editor for this text message.

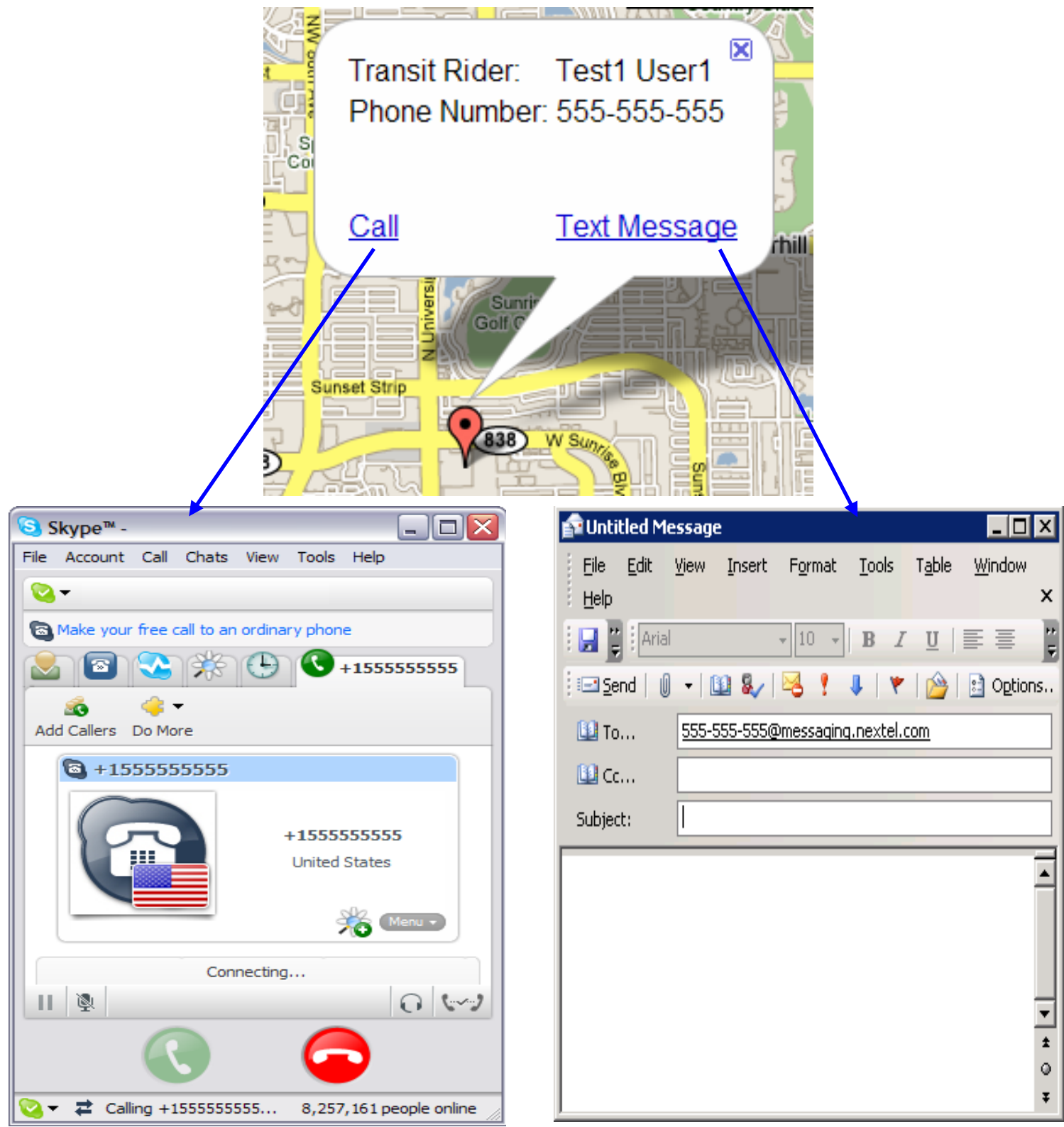

Figure 16 - Communication via Phone or Text Message from Web Interface User to Rider 
By clicking the Call link, Skype ${ }^{\mathrm{TM}}$ Voice-Over-IP (VoIP) technology instantly connects the web page user to the passenger, and the cell phone will begin ringing as if it were receiving a normal call. The web page user can use a headset or the computer microphone and speakers to conduct the conversation with the cell phone user. This convenient feature allows the web page user to instantly call any local, long distance, or international number with a click of a mouse and an Internet connection required at the web page user's PC or laptop. Rates for calling cell phones or landlines through the service called "SkypeOut" are extremely low; the current rates average around \$0.021 per minute. Skype ${ }^{\mathrm{TM}}$ can be downloaded free at www.skype.com and must be installed on the supervisor's computer to use this feature.

While the rider is on the bus, the parent/guardian has the ability to track the rider's current position through the web page. The rider's position is shown in real-time on the TAD web page and is indicated by a red marker (Figure 17). While the rider is being monitored, the server keeps track of whether he or she is on the correct route and sends notification to the travel trainer and/or parent/guardian if the rider deviates from his or her planned route. 


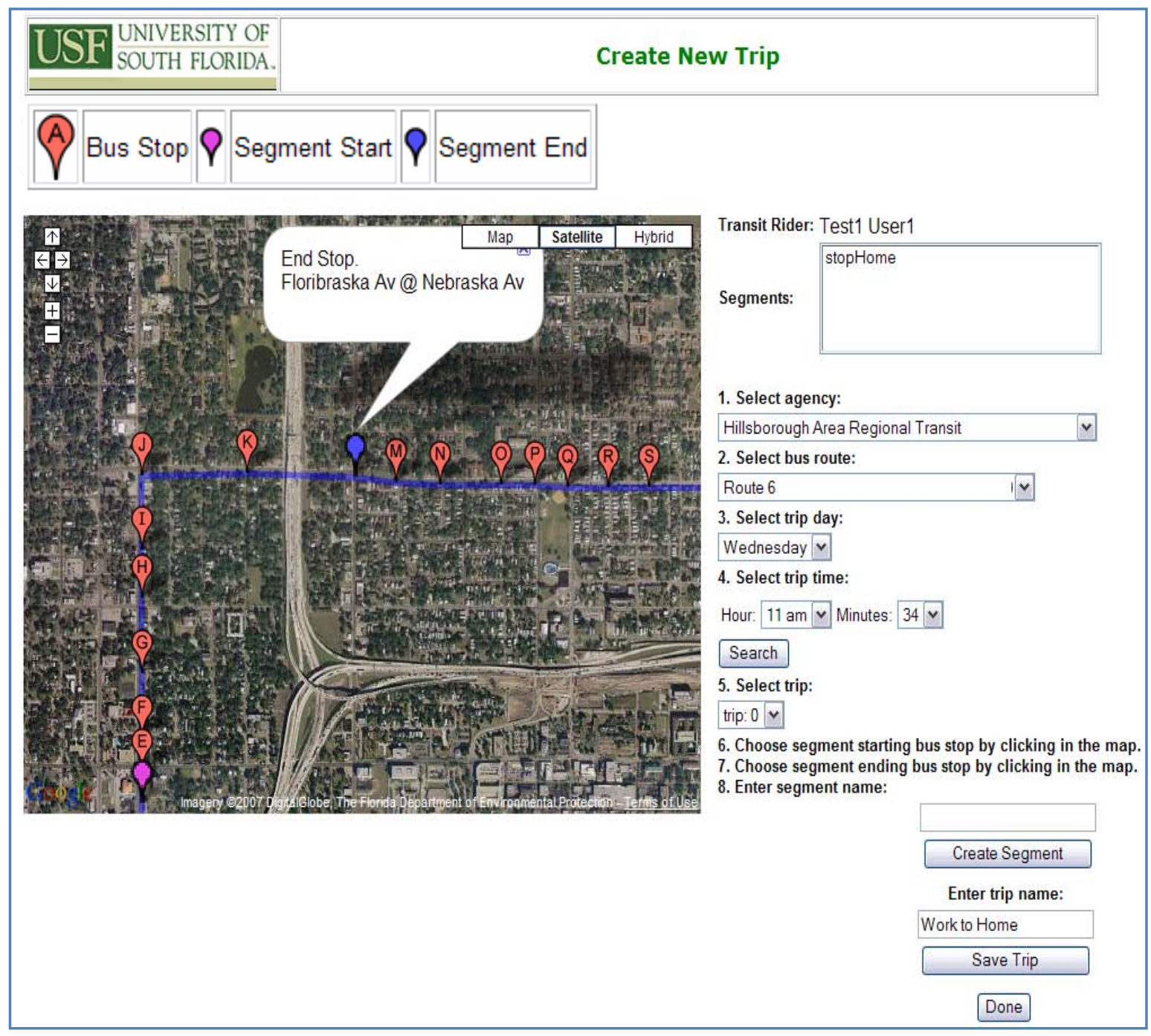

Figure 17 - TAD Web Interface New trip itineraries can be created for a particular user

The TAD web page allows travel trainers or administrators to create new trips for a selected user. From the current design of TAD, a trip is defined as travel from a starting location (e.g. home) to and ending location (e.g. work). To create a new trip, it is necessary to first select the transit agency. Immediately, the bus routes available will be displayed on the list located on the upper right side of the website, as shown in Figure 18. The travel trainer or administrator chooses the desired bus route as well as the date and time when the trip will be taken. After selecting the trip, the route stops will be loaded into a map depicting the entire bus route. By clicking on the markers, an information window appears with comments related to the stop. The next step is to choose the bus starting and ending point by clicking on the appropriate bus stop plotted in the map. Finally, the trip creation continues with the assignment of a name for the segment and trip. A single trip may span more than one bus route and involve transfers between buses. In this case, multiple segments within a trip would exit. 
Existing trips can be modified by the supervisor when needed, as shown in Figure 18. This functionality allows supervisors to customize their passengers' travel information according to their needs. Segments related to the trip can either be added or deleted. Trips already created by the supervisor can also be deleted; the existing segments related to the trip must first be deleted, and then the selected trip can be deleted. Furthermore, new segments can be added to an existing trip by the supervisor. By clicking on the Add Segment button, a view similar to the new trip creation will appear, as shown in Figure 19. The new segment is added in the same manner a segment is created in the trip creation functionality.

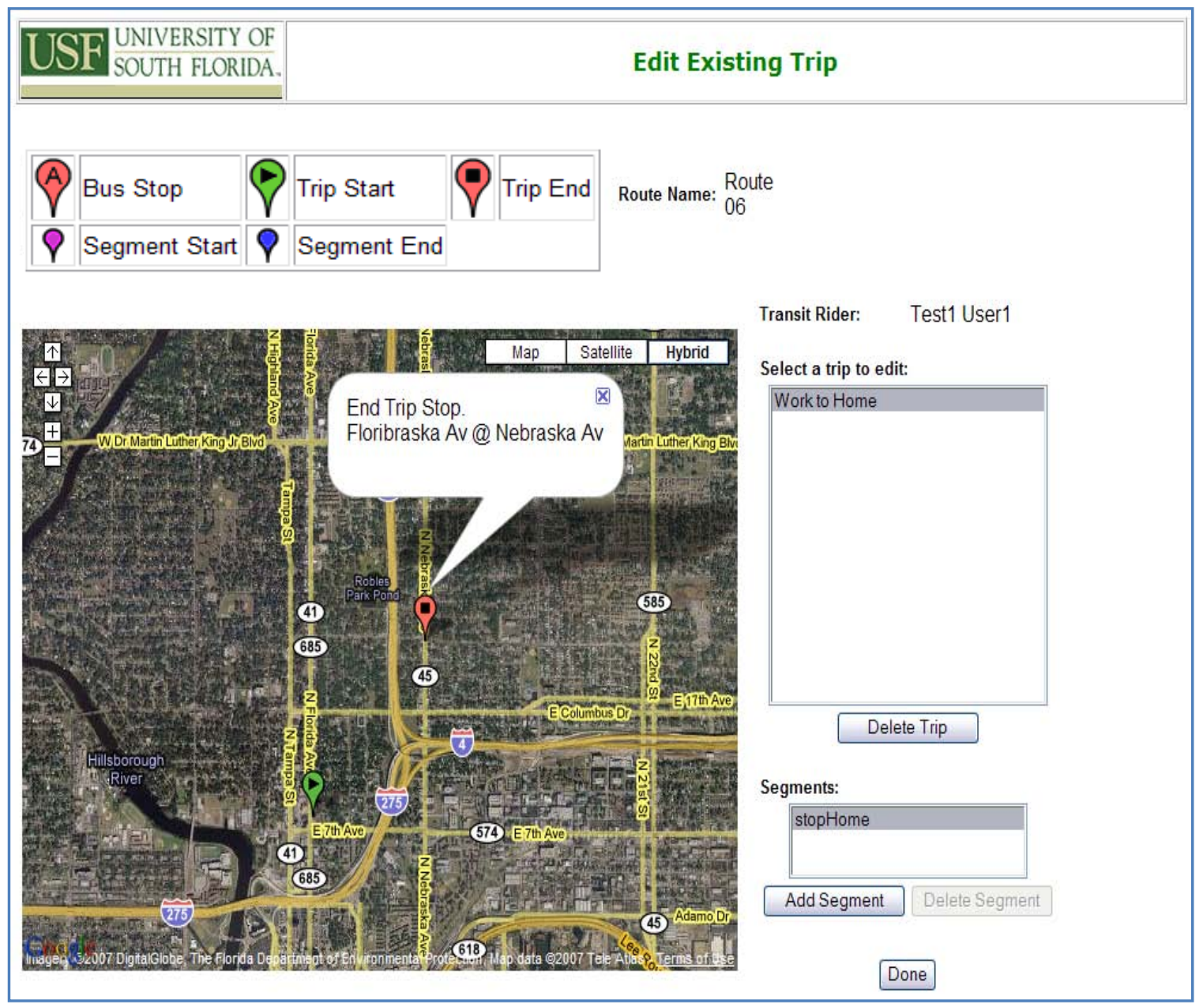

Figure 18 - TAD Web Interface Existing trip itineraries can be edited using the website

Selecting a trip will cause the stops related to the starting and ending trip locations to appear in the map. In the same way, when selecting a segment, the stops related to the starting and ending points will appear. By clicking on the markers, an information window will appear with some comments related to the stop location. 


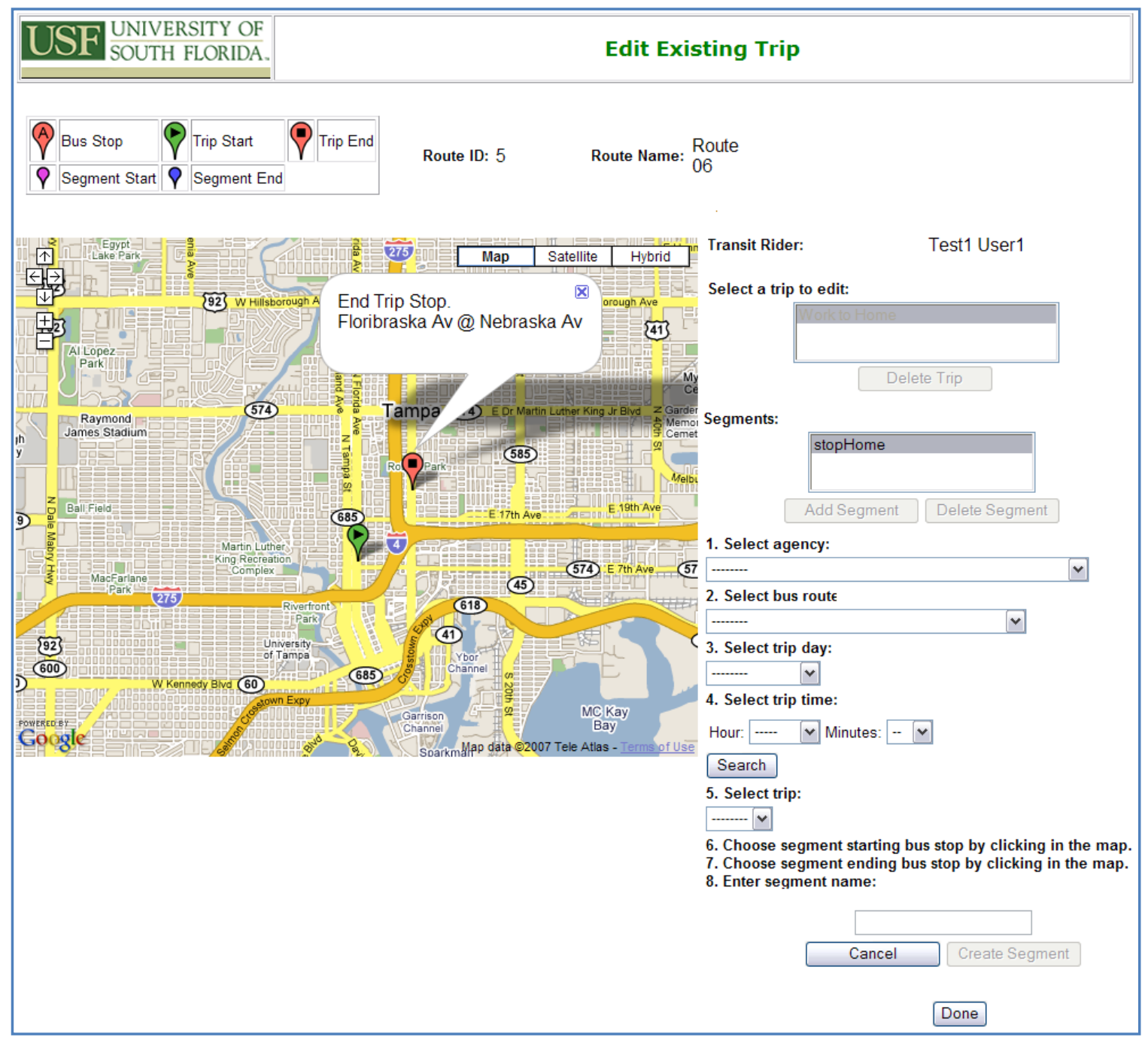

Figure 19 - TAD Web Interface -

Segments can be added to an existing trip.

Other functionalities are available in the TAD web page through the File and Manage User menus, which are visible at the top of the main TAD real-time tracking screen. The File menu allows the user to change personal information and account password, as well as log out of the TAD web page. The Manage Users menu allows the administrator to create or edit a user and assign passengers to a supervisor.

Users can be created by an administrator, who enters the information necessary to create the user profile, as shown in Figure 20. As soon as the user is able to log in to the TAD web page, he/she will be able to update his/her personal information, as well as change his/her password, as shown in Figure 21 and 22. These functionalities allow personal information to be edited and updated securely by providing the option to change the password. 


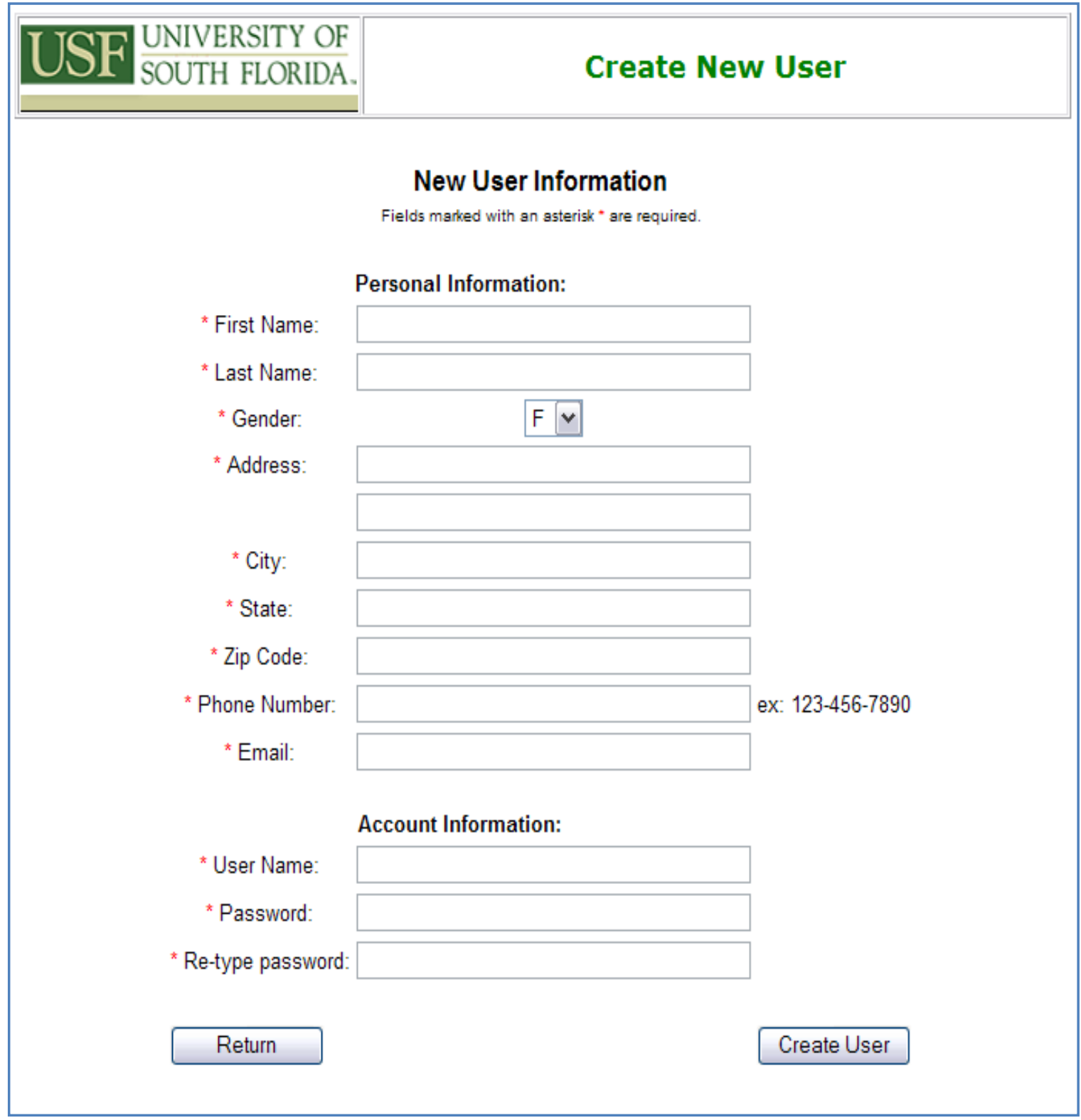

Figure 20 - TAD Web Interface TAD web page allows the creation of new users. 


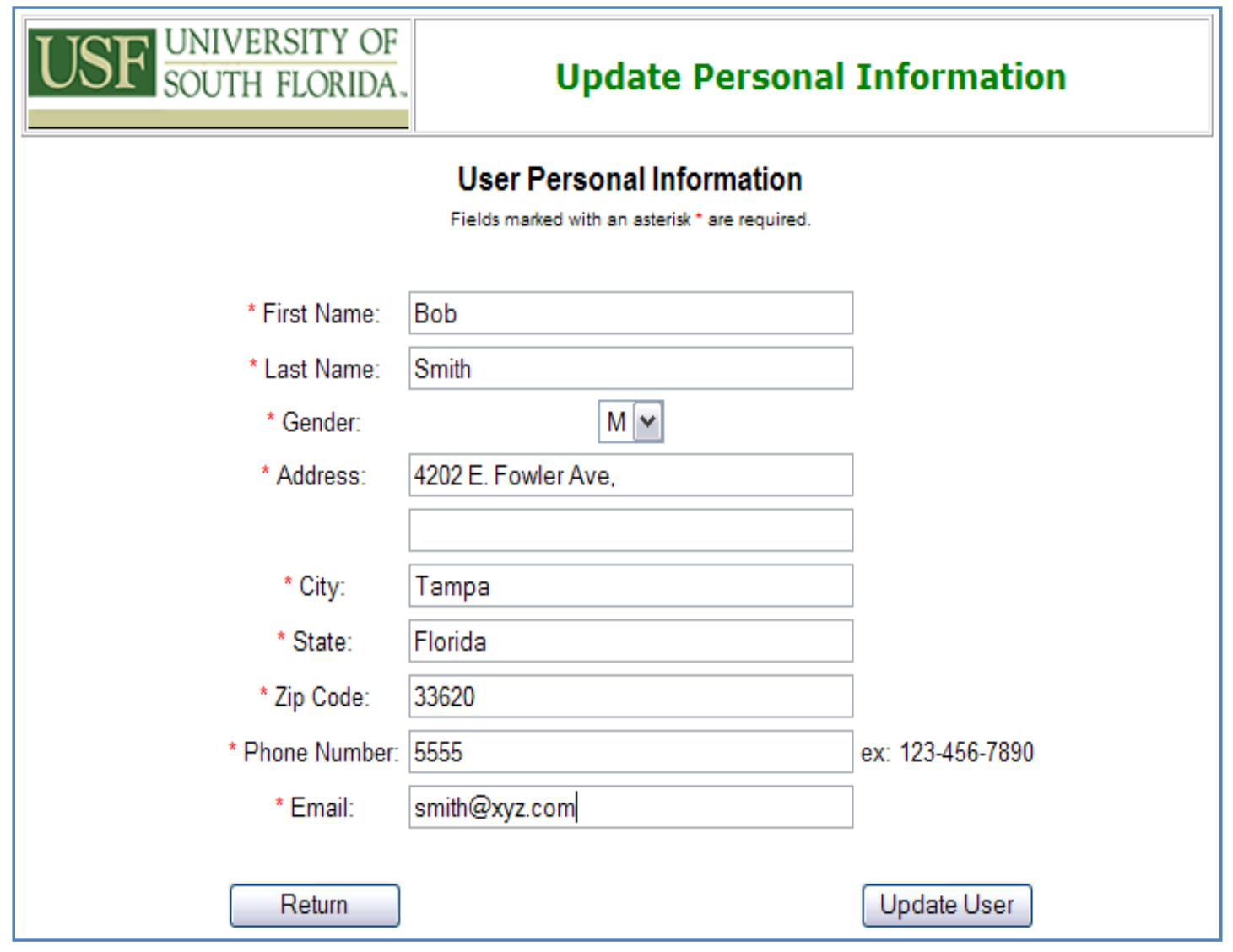

Figure 21 - TAD Web Interface -

Account information can be updated.

\section{Change Password}

\section{Account Information}

Fields marked with an asterisk ${ }^{*}$ are required.

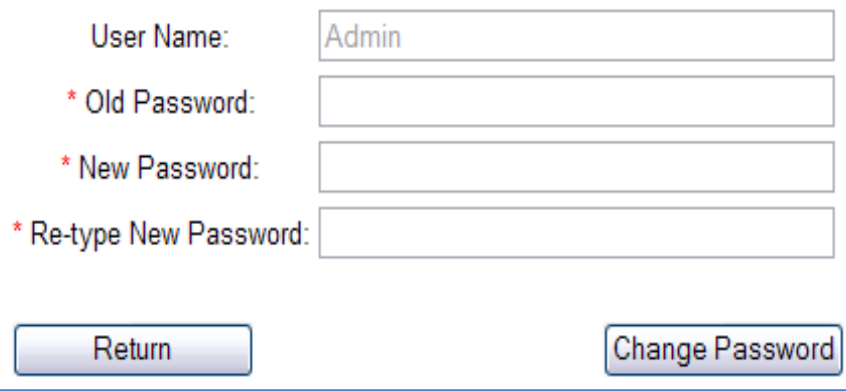

Figure 22 - TAD Web Interface -

Account password can be updated. 
The TAD web page provides four roles that can be assigned to users according to their needs: administrator, travel trainer, guardian, and transit rider. The roles define a set of privileges associated with the user's account. For example, only users who have the role of administrator can edit user information and manage accounts. Only users with travel trainer, administrator, or guardian roles can log into the website to view the real-time position of the transit riders that are assigned to them. Only users with the role of travel trainer or administrator can create trips for a transit rider. Only users with a transit rider role can use the TAD application on the mobile phone. The Edit Existing User screen shown in Figure 23 shows a list of the existing users on the left side of the website. When a user is selected from this list, the roles that have already been assigned will appear on the Current Roles of Selected User list, located on the right side of the website. The roles that are in this list can be removed. Note that a single user may be given multiple roles. For example, if a user is given a travel trainer and a transit rider role, they are able to create their own trips on the website and use the TAD mobile phone application to travel via transit.

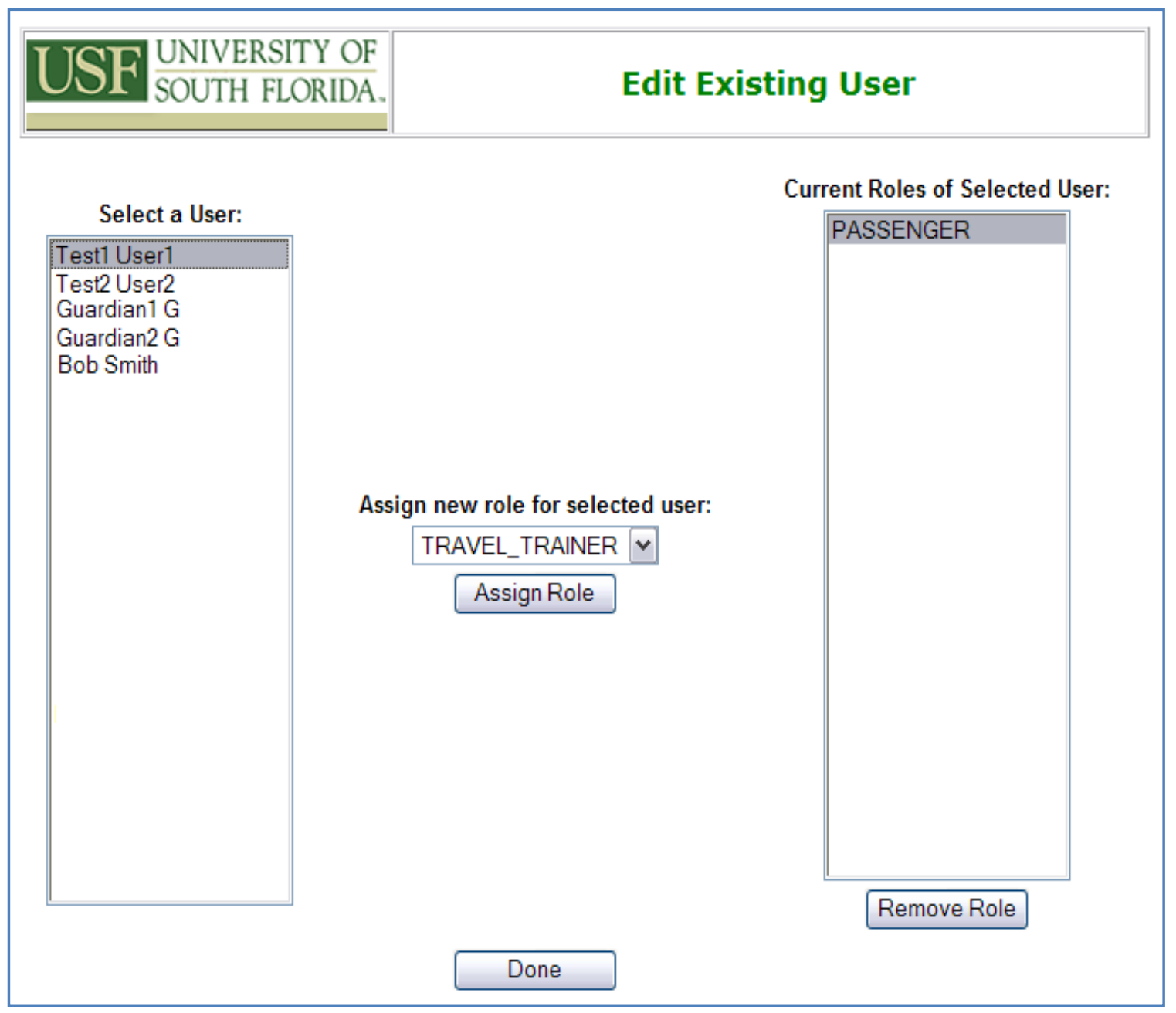

Figure 23 - TAD Web Interface Possible roles assigned to users. 
The TAD web page also manages the assignment of passengers to travel trainers and/or parents/guardians. Travel trainers and parents/guardians can view the real-time location of and create trips for only the transit riders who are assigned to them. As shown in Figure 24 , users with a role of supervisor, administrator, guardian, or travel trainer appear on the list located on the left. To assign a transit rider to a supervisor, it is necessary to first select the supervisor, then the user to be assigned, and finally click the Assign Transit Rider button. As a result, the transit rider assigned will then appear on the list located on the right.

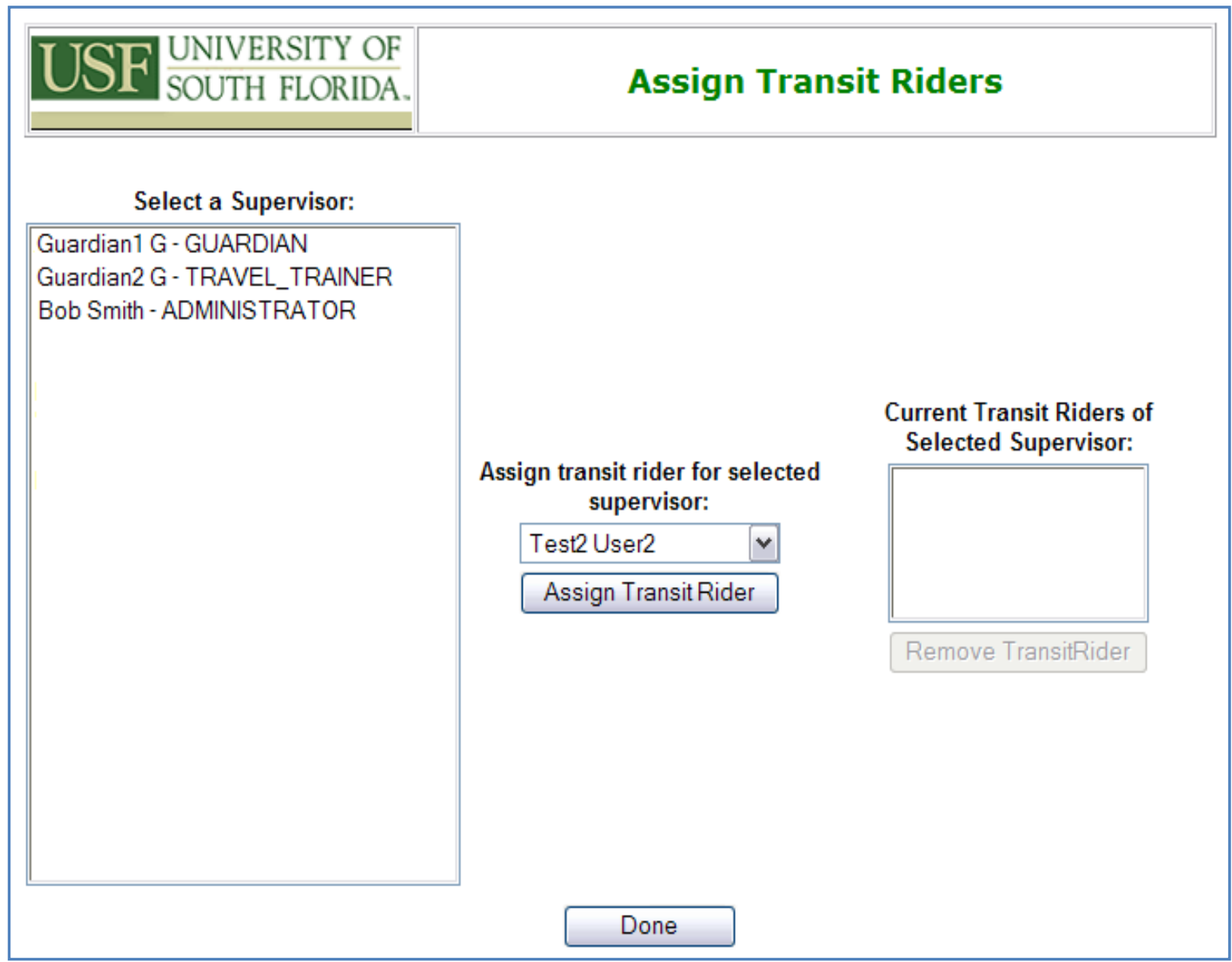

Figure 24 - TAD Web Interface Users can be assigned to a supervisor.

\subsection{TAD Cell Phone Application}

The TAD cell phone application is the primary interface to the transit rider and is responsible for providing the transit rider with alerts at the proper place and time. The TAD phone software is able to communicate with the database server to retrieve data such as users, transit route and stop information, and custom defined trips. Using wireless communication, the cell phone application logs the user into the TAD system and requests information on the transit route he or she will be traveling. For ease of use, the user is required only to log into the system the first time the application is used. Thereafter, the information is saved on the cell phone, and the user will automatically be logged in and 
screen B is displayed allowing the user to choose a previously created trip, as shown in Figure 25. The list of trips (Screen B in Figure 25) shows the descriptions for each trip entered on the website at the initial trip creation by the travel trainer or caretaker/parent. Once the transit rider chooses the trip he or she will be traveling, the phone automatically retrieves all relevant information for the segments included in the trip (i.e., bus stops, routes, etc.). The cell phone next reveals a screen with a green or red square along with the distance to the next stopping point (Screen C in Figure 25).

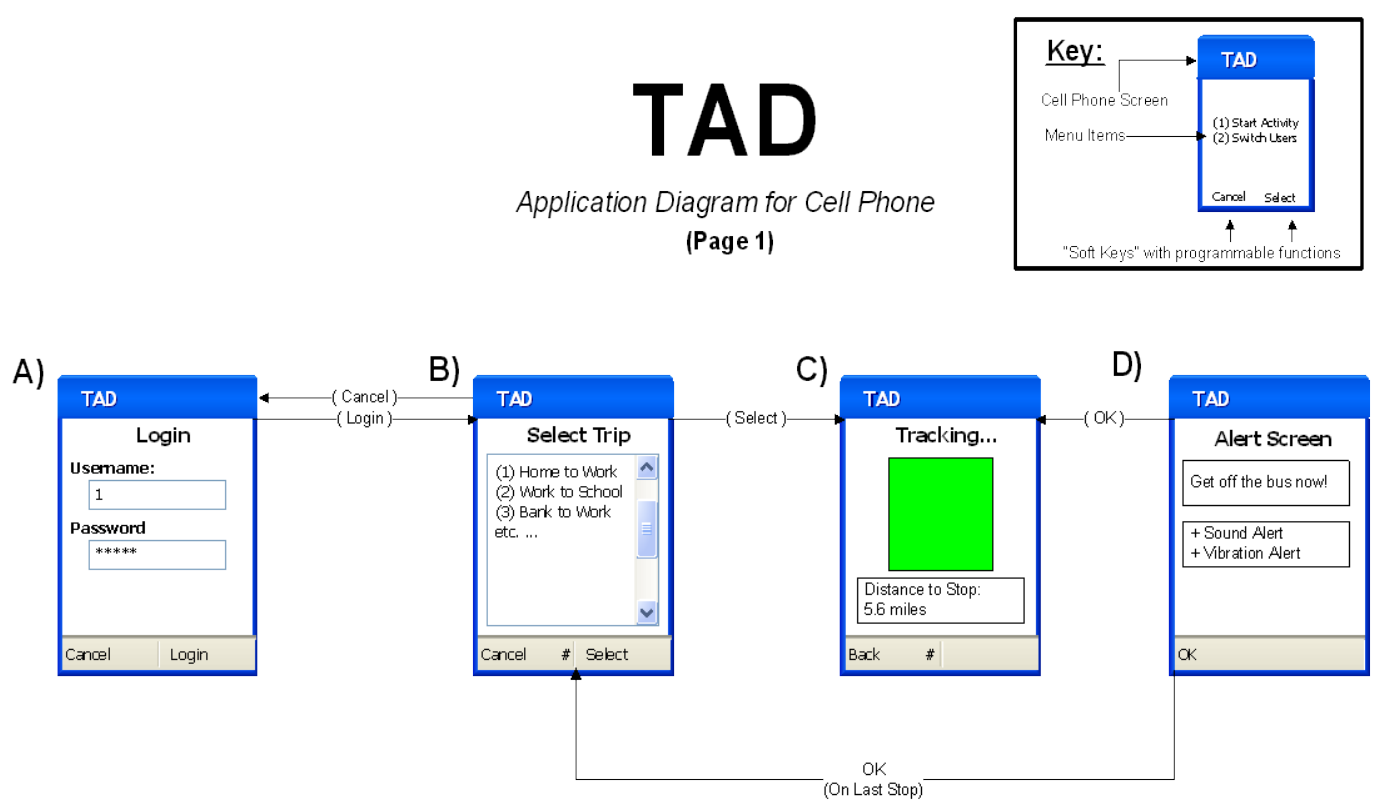

Figure 25 - TAD Cell Phone User Interface

If the square remains green, the cell phone should reliably provide the stop alert to the transit rider, and they will receive the notification when appropriate. If, however, the GPS signal fades due to obstructions such as overpasses or nearby tall buildings, the square will turn red and a warning beep announces to the user that he or she will not receive a notification when he/she nears the stop. If the cell phone maintains connectivity and continues to calculate an accurate GPS position, the user interface will display a distance countdown to the next stop along with the green square illustrating that TAD is working properly. After discussions with Mark Sheppard, professional travel trainer for HART (Hillsborough Area Rapid Transit), the researchers learned that approximately 80 percent of HART's travel trainees have some kind of cognitive disability. Therefore, it was decided to utilize two stop reminders for individuals having cognitive disabilities; when the rider is approximately 300 meters away from his/her goal stop, the TAD announces "Get ready" twice. When it reaches 160 meters, it announces "Pull the cord now!" and the cell phone vibrates and shows the same message on the screen (Screen D in Figure 25). In the future, TAD could also be modified to incorporate different types of alerts tailored for individuals who are sight or hearing-impaired. 
This announcement will continue until the rider confirms they have exited the vehicle by pressing a cell phone key. If another travel segment exists, the cell phone user interface will display screen $\mathrm{C}$ again and repeat the process for subsequent segments. Once the traveler has completed the last segment, the phone will display Screen B again, where the traveler can simply close the phone or choose to exit the program.

The software architecture of the TAD mobile application as it relates to the J2ME architecture is shown in Figure 26. Since the real-time user position is of vital importance to the system, the check for proximity of the device to the upcoming bus stop position must be performed in real-time on the cell phone. The cell phone J2ME application utilizes the JSR179 Location API (46) to gather location information from the device. TAD uses assisted GPS provided by the embedded GPS chip in the cell phone. One of the unknown variables was the GPS signal quality that could be expected inside a moving transit vehicle. (For a full analysis, see (41).) In phase 1 of TAD implementation, proximity detection was performed as a geo-fencing operation using the device. This allowed the cell phone to work autonomously from the server in the event communication was lost while the rider was on the bus. Future work will focus on implementing more robust and reliable stop detection mechanisms using Automatic Vehicle Location (AVL).

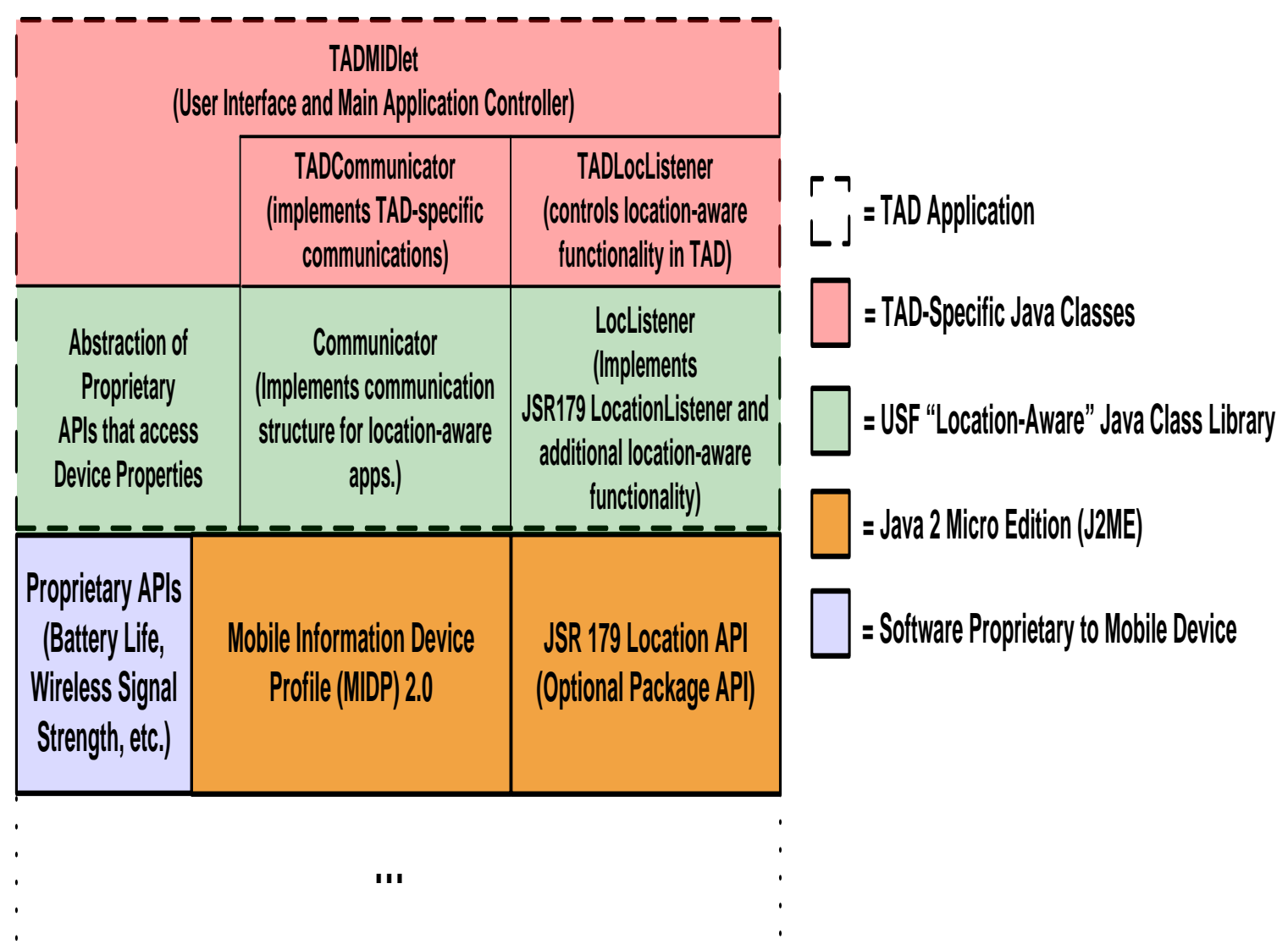

Figure 26 - Software Architecture for TAD Mobile Application as Related to J2ME Architecture 
While web services use connection-oriented communications that expect an immediate response such as retrieving transit route information, the User Datagram Protocol (UDP) is used for transmitting real-time cell phone location data to the server. UDP is a connectionless protocol that is useful for communications where timeliness of data is more important than its reliability (58). If a single UDP packet is lost, it is not critical since more UDP packets with updated locations will follow. UDP allows the mobile phone to rapidly transmit location data at a rate of up to one GPS location per second without requiring a lengthy acknowledgement and possible retransmission process for each packet as required by the TCP protocol. Therefore, UDP saves battery power through reduced transmissions while allowing the mobile device to transmit location information in a timely manner, (41).

Figure 27 - Components of the TAD Mobile Phone Application shows the main components of the TAD mobile application and their interactions. MIDlet is the main class of the project. It is responsible for providing phone specific functions, controls the GUI and the phone specific functions inherited from J2ME library, such as Vibration and Lighting control of the phone. All of the GUI interaction is handled through the MIDlet.

The Location Listener is responsible for listening to GPS coordinates at a predefined interval and updating the navigation service provider with these new coordinates. If the Navigation State Machine is enabled, the interval for the GPS updates is dependent on the distance to the target location.

The Communicator is responsible for sending data to the server using UDP transmission as well as communicating using Servlets for tasks such as logging in, getting services, and segments. It features an ability to buffer the UDP data to save battery life. 


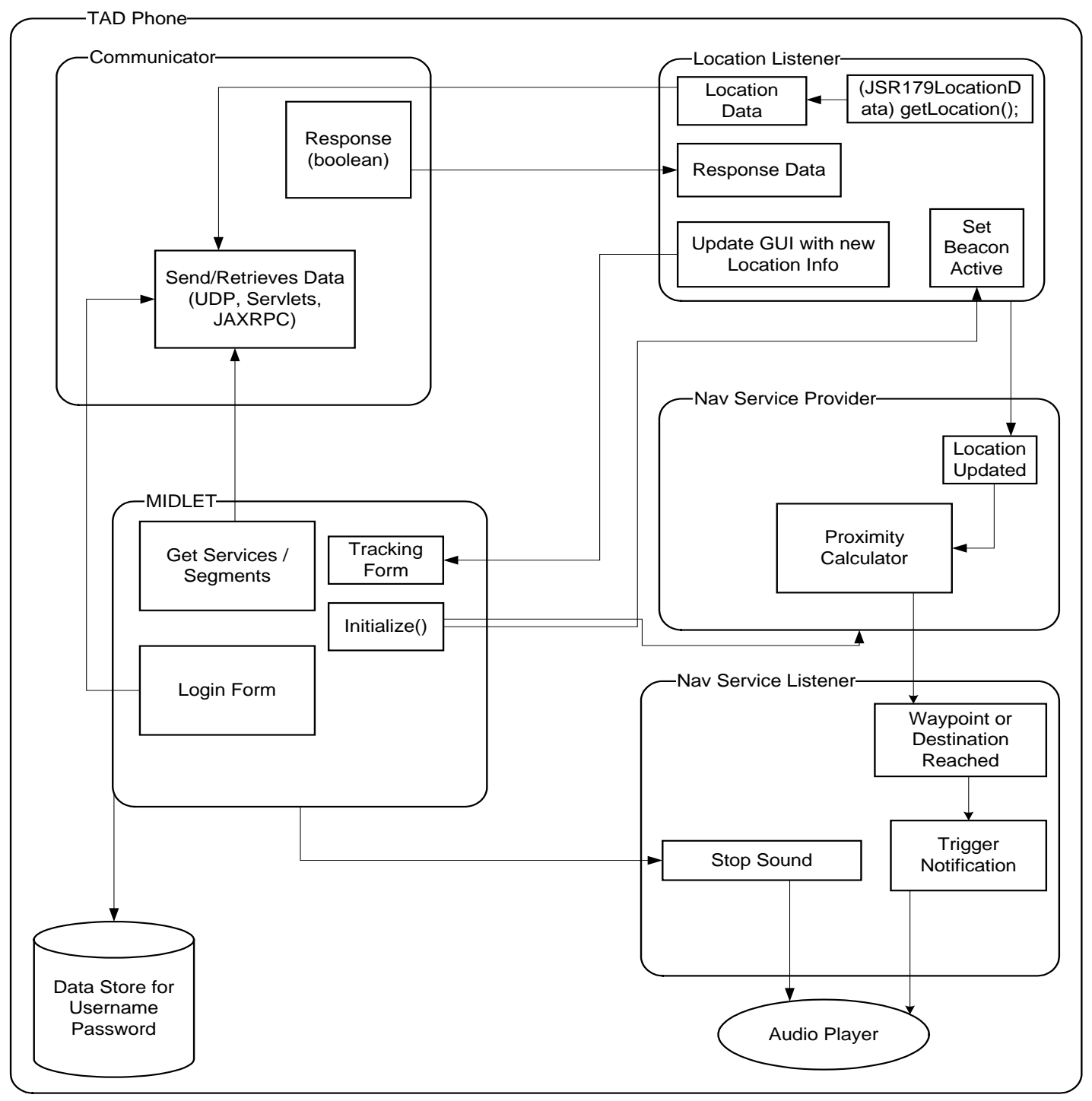

Figure 27 - Components of the TAD Mobile Phone Application

Navigation Service Provider (NSP) is responsible for accurately navigating the service and alerting the rider about the stop based on the data passed to it through Location Listener. Every time new data are passed to the NSP, it verifies that it is inside the defined trigger area for that specific segment and, if so, sends a proximity alert. Only one proximity alert can be sent per segment. After the alert has been fired and the rider has been notified of the stop, the segment is switched to the next one in the series, and the tracking continues based on the new segment data. NSP is also responsible for loading services and segments when selected by the user through GUI, switching segments for multi-segment trips and counting the distance traveled by the user on each specific segment.

The Navigation Service Listener (NSL) is alerted by NSP to play different kinds of alerts. It uses a generic Audio Player class to play recorded audio alerts as well as phone-specific 
lighting and vibration functions. When the proximity alert is sent from the NSP, the NSL plays the appropriate user notification and stops when the user confirms receipt by pressing a button on the phone.

\subsection{TAD Mobile Application Optimizations}

Several application features were implemented to improve application performance, provide a longer battery life, or give the users and administrators useful information about the traveling habits of riders. These are UDP Buffering, Navigation State Machine, the critical point algorithm, and distance calculation systems.

\subsubsection{UDP Buffering}

UDP buffering saves the battery life and bandwidth used by the phone by using a buffer on UDP transmissions. The system waits until a certain number of location updates have been stored in the buffer and then proceeds to send them in one transmission sequence to the server. The size of the buffer is set by the application developer. By sending location updates in groups, the application avoids over-occupying the communication channel and preventing incoming phone calls from ringing at the handset. There is a trade-off between buffering and real-time rider monitoring at the website. Buffering more fixes results in more phone calls reaching the handset and less battery power consumption. However, the server will receive updates on the device position only every ( $\mathrm{X}$ multiplied by interval) seconds, where $\mathrm{X}$ is the number of fixes buffered and interval is the position update interval being used by the mobile phone.

\subsubsection{Navigation State Machine}

Navigation State Machine was created to improve the accuracy and battery performance of the TAD application. This state machine switches the phone's GPS position calculation interval depending on the phone's current distance from the final bus stop. For example, if the phone is more than 10 kilometers away from the bus stop, the state machine sets its GPS refresh rate to 60 seconds. The closer the phone gets to the bus stop, the faster it refreshes its location. At 400 meters, the phone goes into its minimum interval mode, which is a refresh of a GPS fix every one second.

The state machine concept also can be used outside of the real-time navigation scenario for tracking the rider when they are not onboard the bus. In this situation, the GPS interval is increased when position attempts fail and decreased when position attempts are successful. This behavior prevents the battery power of the device from being drained when repeated unsuccessful positioning attempts are made (e.g., when the phone is indoors). Detailed information about the state machine concept is documented in the TRAC-IT Phase 3 Final Report (42).

\subsubsection{Critical Point Detection}

When GPS data are recorded frequently by the mobile phone, a large amount of data that are not necessary to reconstruct a transit rider's trip is generated. Examples of unnecessary 
data include GPS points collected when the phone is not moving and multiple GPS points that create a straight line. The data that are needed to reconstruct a user's travel path are referred to as critical points. A critical point for the TAD system is defined as a GPS fix that occurs when a traveler changes direction by more than a certain threshold. To ensure that directional changes are not calculated due to readings that are inaccurate within the accuracy uncertainty limit, fixes are assessed only if the corresponding speed reported is greater than a speed threshold. The first and last points of every segment also are considered critical. These techniques comprise a critical point detection algorithm (Patent Pending USF, 2008) that has been integrated into the TAD system software.

One of the primary benefits of critical point detection is a reduction in the number of wireless transmissions from the phone to the server, complementing the implementation of the buffer. This reduction of transmissions results in reduced bandwidth usage as well as significant battery power savings. Figure 28 shows a simulation of a brief walking trip on Google Maps with all the UDP data points plotted in the left picture of the figure. As can be easily seen by examination of the route, several of the points hold information that, for the purposes of overall trip analysis, can be extracted to form a much smaller data set.

The picture on the right side of Figure 28 shows the same trip with only the critical points displayed. The general route of the trip, the time of travel, and the key events (such as stopping and changing direction) all remain intact, although only one-third of the transmitted data were necessary to obtain them. When real-time tracking is taking place, a trade-off exists between reporting fewer locations to the server and saving energy versus transmitting all fixes and always seeing the real-time position of the transit rider. Detailed information about the critical point algorithm can be found in TRAC-IT Phase 3 Final Report (42).

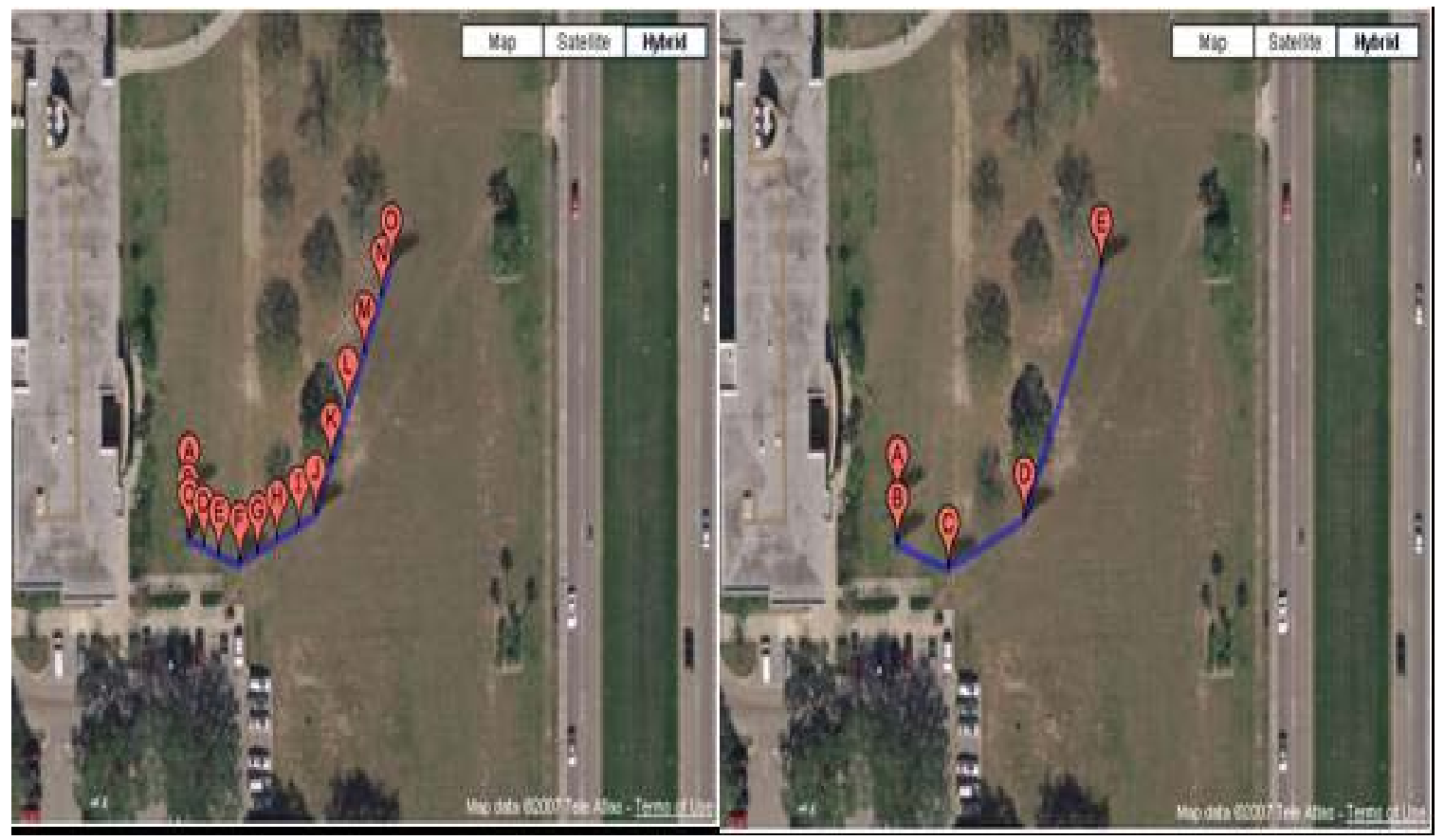

Figure 28 - Trip with all GPS Points (left) vs. Critical Points (right) 


\subsection{TAD Server Applications}

The server-side software consists of several applications that work together to provide the storage of transit, trip, and user information, as well as provide the services of detecting when the user unexpectedly deviates from the planned route. A PostGIS database server that performs spatial queries is used to store the geographic information associated with the transit routes, and a Microsoft SQL Server is used to store all other information (69). Glassfish was chosen as the primary Java application server that implements the web services and servlets and hosts the web page (70). A detailed diagram of the communication that occurs between the phone and the server during an active TAD session is shown in Figure 29. Figure 30 shows the components of the Java application server software.

Once the transit rider is traveling on a route, his/her position is reported to the server in real-time. When the travel trainer initially creates the rider's trip on the web page, a custom geo-fence is automatically defined around the planned route. The rider's position is checked in real-time against the sequence of routes the rider has chosen to travel. Therefore, the system is fully programmable based on the input from the website and the trip chosen by the rider's cell phone.

The UDP Receiver is responsible for listening for the location data sent from the phone using UDP protocol. When data are received, it is parsed, and the phone session to which the data belongs is updated on the server.

The Phone Session Manager (PSM) handles all of the sessions; the specific list of functionality is shown in Figure 30. PSM is responsible for creating new sessions, removing sessions, retrieving the sessions based on object and session ID, and loading crashed and expired phone sessions.

One of PSM's important features is to handle crashes of the server/phone. When the server crashes and restarts, the PSM automatically loads all sessions that were active before the crash. If the phone crashes or loses signal, its session will expire after a predefined period. However, when the phone regains signal or restarts, the PSM will load the expired session for that specific phone/user and the data will continue being recorded in the same session.

Inside the CUTR Utilities section, many classes implement various functionalities of the TAD project. Rider Location Detection is one of TAD's safety features; it includes Point in Buffer, Trip Detector, SMTP Notification, and Route Detector classes that use a combination of geographical libraries (Post GIS) and Java Mail to detect the user's current location and notify the guardian if the user deviates from the designated route. The GIS data for all routes is pre-loaded into the PostgreSQL database from the shape files provided by the transit agency. Every time the UDP receiver gets a new location update for a specific session, it is referenced through the database to determine if the rider is on his/her correct route. If not, an alert is sent to the designated email addresses for the travel trainer and/or parent/guardian. 
An important server-side module is a transit schedule update application. Since changes to bus schedules, routes, and bus stops can be frequent, it is very important for an automatic update procedure to be in place if TAD is to be deployed to multiple transit agencies. The TAD server update application utilizes data formatted via the Google Transit Feed specification posted by transit agencies on their respective websites (71). Google Transit is a free trip planner for transit agencies to provide to their customers as long as the transit agency formats its data in a specific format and keeps an updated copy of that format on its website. The TAD system utilizes these same postings to update its own database, which enables TAD to add new transit agencies to its database or update existing transit agency data with the click of a button. Since Google Transit is a free resource for transit agencies, this provides an incentive for the agency to keep its data current. 


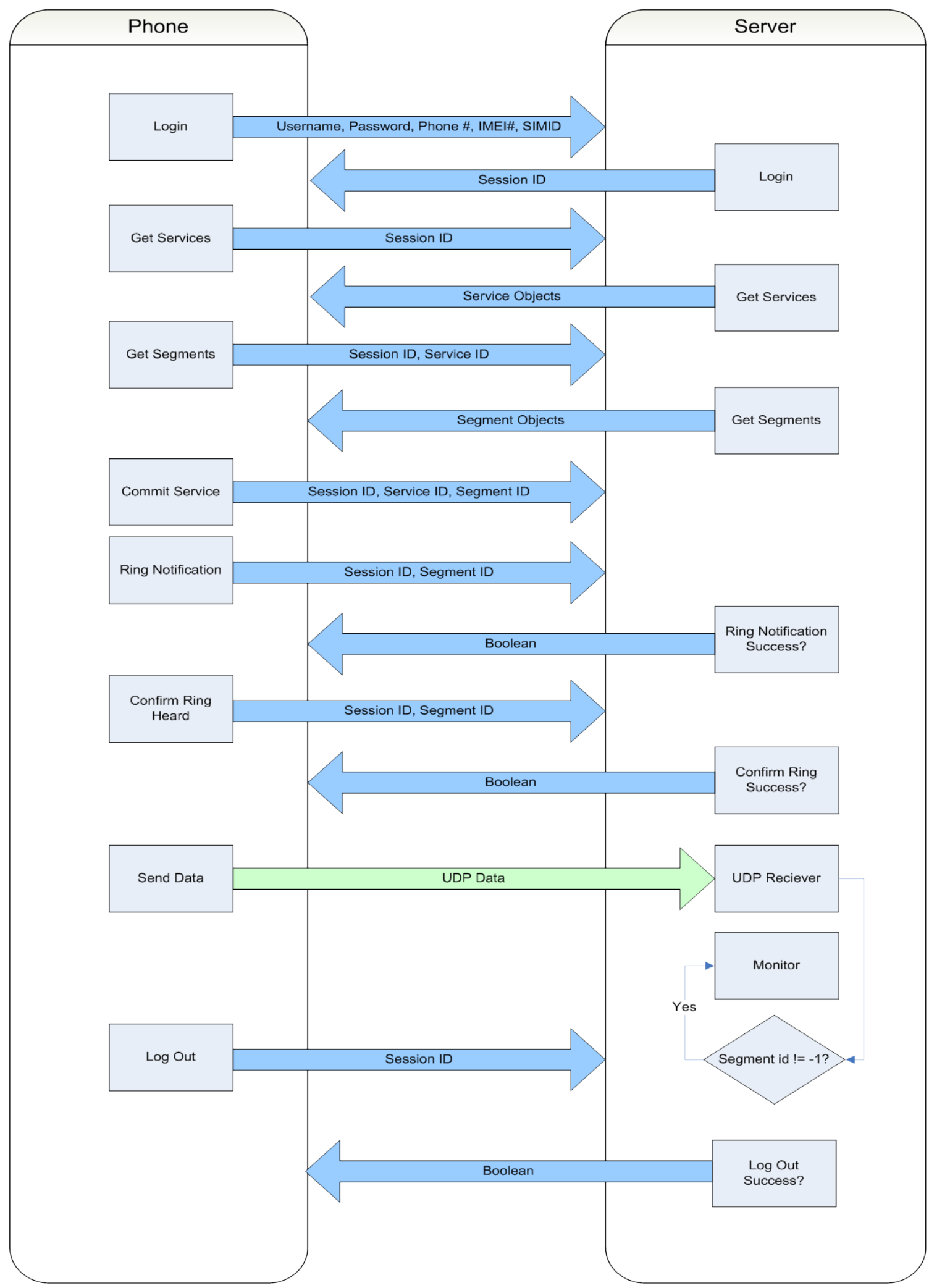

Figure 29 - TAD Protocol Overview 


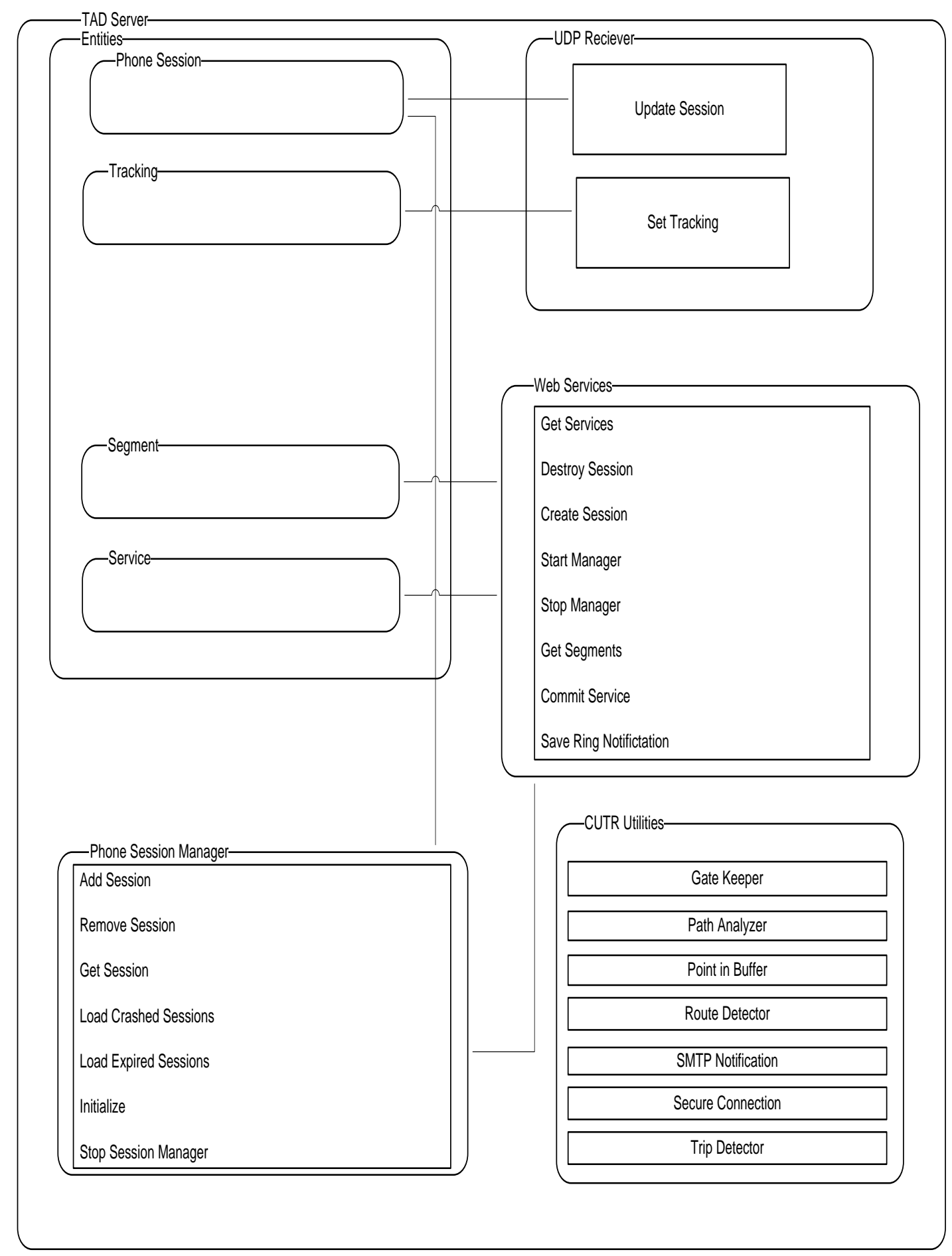

Figure 30 - Components of the TAD Application Server Software 


\section{CHAPTER 5 - FIELD TESTS}

\subsection{Overview}

For more than a year, TAD was continually tested by project staff using Motorola iDEN i870 and Motorola iDEN i580 cell phones on the Sprint-Nextel iDEN network and the Sanyo 7050 on the Sprint-Nextel CDMA network. TAD was run through iterative testing, development, re-testing, and debugging processes while resolving technical and software issues that were encountered during the testing period. To date, qualitative results indicate that TAD works precisely and is able to deliver notifications to the user in the exact location chosen on the web page by the travel trainer (73).

In early testing with the iDEN phones, it was observed that, occasionally, the GPS signal was obstructed by overpasses, nearby tall buildings, or even the transit vehicle. However, results from tests with the Sanyo 7050, which has a more sensitive GPS receiver chip, have been extremely consistent with GPS signal strength adequate to obtain a reliable position fix where older model cell phones were unable to do so.

The most frequently recurring errors encountered during TAD testing were related to inaccurate bus stop locations in HART's bus stop inventory. Recently, HART updated the bus stop inventory by re-geo-coding all bus stop using GPS surveying units. Future TAD field tests utilizing that new inventory may find the error due to bus stop inaccuracy resolved.

As part of the training and support provided by the STAGES program, enrolled students receive one-on-one travel training from HART. Some STAGES students find traveling via public transportation more challenging than others do, and the hope is that the TAD will enable these individuals to travel independently and, therefore, increase their quality of life.

In anticipation of field tests being conducted by students from STAGES, several HART routes were selected and tested to minimize any problems with actual field-testing. Origins and destinations for six round trips were selected, taking care to eliminate destinations already familiar to students since all have previously been travel-trained on particular routes. An example of one of these tests, conducted using the Sanyo 7050, is documented in this next section. It should be noted that for the convenience of testing a return trip was created as a second segment of the same trip. However, it is expected that during normal use each one-way trip would be created as a separate trip within TAD. For example, "Home to Work" would be one trip activated by the user when leaving home, and "Work to Home" would be a second trip activated by the user when they are ready to leave work. This design helps TAD to minimize the impact on device battery life by only using GPS when necessary for real-time navigation. 


\subsubsection{Example of a Preliminary Field Test Evaluation}

- Originating bus stop: intersection of Holly Dr. and Maple Dr., USF campus, Route 6, stop near Greek Village

- Mode: HART Bus Route \#6

- Destination bus stop: intersection of Sligh Ave. at $56^{\text {th }}$ St.

- Position of phone: closed, on belt holster, antenna not extended

\section{First Segment (Figure 31):}

- Starting the trip: Drove to a parking lot approximately 200 meters from the starting bus stop, started TAD application and put the phone on belt holster. Walked to the starting stop; phone properly detected stop. Returned phone to belt holster, waited for the HART bus Route \# 6

- During the trip: Got on bus and sat down in middle facing inwards with back to windows. Proceeded to ride through the route, checking phone every 10-15 minutes for operation. Everything worked as expected

- Ending the trip: Opened phone to check distance when approaching final bus stop. Phone gave the "Get ready" and "Pull the cord now!" prompts at approximately 400 and 160 meters from the destination stop, respectively as calculated by the phone. (Figure 29). The actual distance from the destination stop when the prompts were given, as measured after the trip using mapping tools, was around 380 and 145 meters, respectively. Pulled cord at alert and got off bus.

- Phone detected final stop and started to search for first stop of second segment.

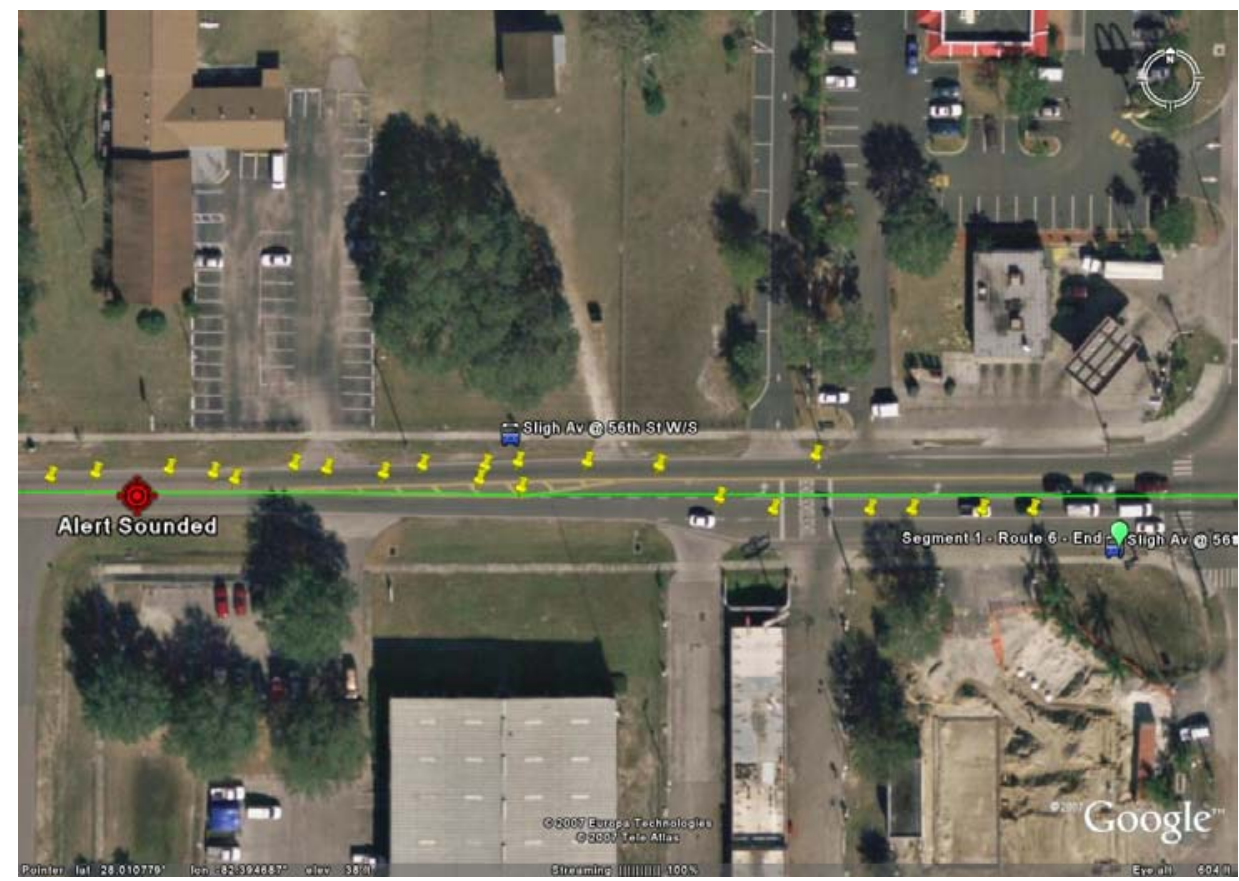

Figure 31 - Sample TAD Test - Route 6 Segment 1 


\section{Second Segment (Figure 32):}

- Starting the trip: Walked across street, checking phone for detection of first stop of return segment. Phone detected stop correctly. Proceeded to wait for bus.

- During the trip: Got on bus and sat down in back facing forward, with phone still on belt holster. Checked phone every 10-15 minutes. Everything worked as expected.

- Ending the trip: Opened phone to check distance and, as expected, phone proceeded to give alerts to get ready and get off at approximately 400 and 160 calculated remaining distance to the destination stop. This time, actual distances were approximately 420 and 150 meters, which gave ample time to pull cord and bus stopped on the stop. Phone detected this stop as well and proceeded to switch back to trip selection screen.

- Overall grade: Good - phone provided alerts in correct locations during both segments of trip. Noted that user must have good reaction time to pull cord in time.

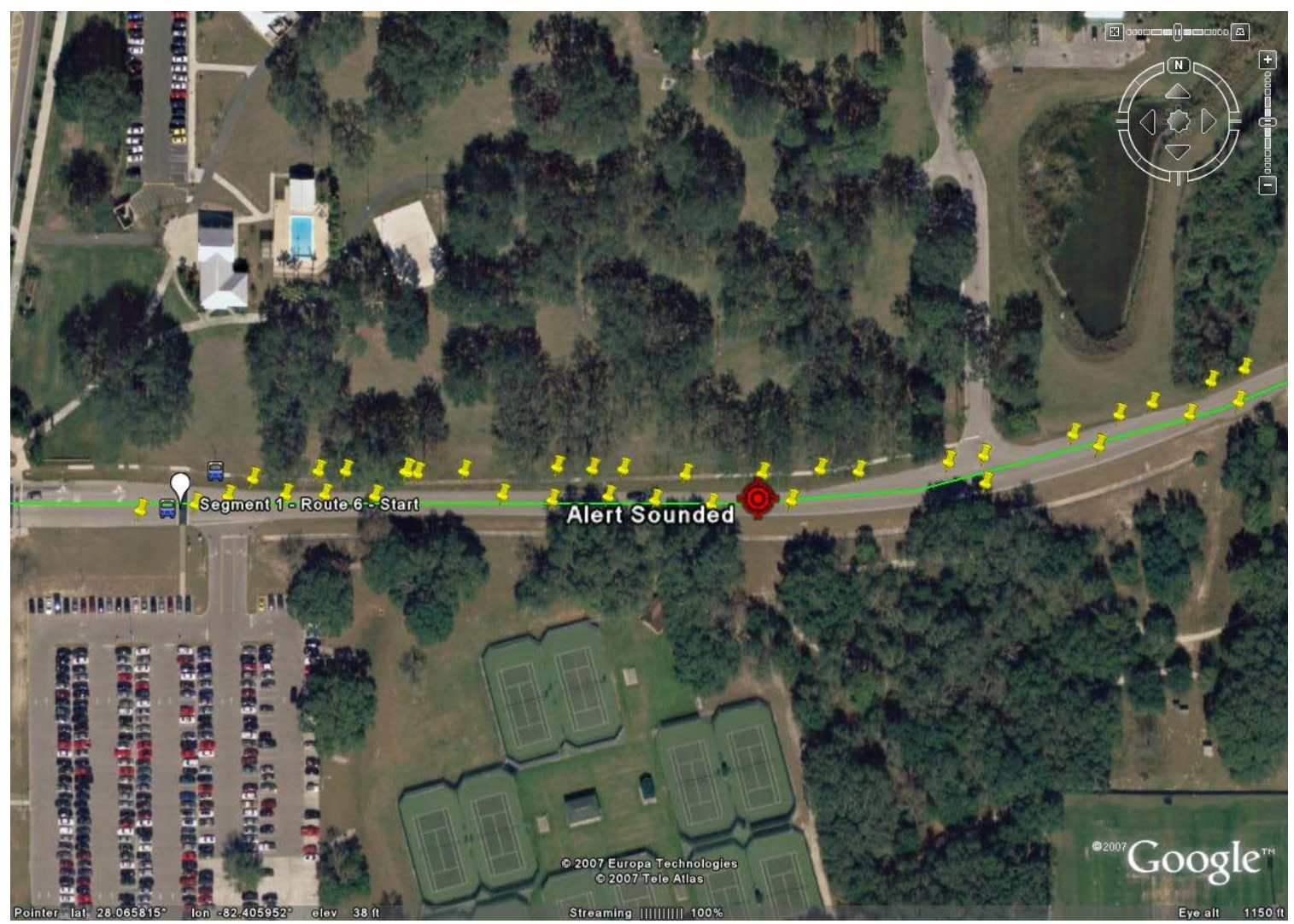

Figure 32 - Sample TAD test - Route 6 Segment 2

Additional tests were also ongoing by Mr. Sheppard while traveling as part of his normal job. The results of 38 trips documented by the research team are shown in Table 7 . Three occasions where the prompt issued either late or not at all were due to inaccurate bus stop information. One bus stop had been moved as part of a HART service change and was not 
yet reflected in the TAD database. The research team had intentionally not updated the TAD system due to troubleshooting technical issues, so this problem should not occur during normal TAD operation. The second bus stop had been geo-coded in an incorrect location and, therefore, TAD never triggered the notifications. It is hoped that HART's newly geo-coded bus stop inventory will help with this issue during future TAD testing. A late prompt resulted from a location where bus stops were positioned very close to one another. The effect of bus stops in very close proximity on the current TAD alert triggering algorithm is discussed in detail in Section 5.3.3.

Detailed documentation of testing completed for 11 of these trips, including map data, is available in Appendix A.

Table 7 - Summary of Results from TAD Testing Conducted on Random Bus Stops

\begin{tabular}{||c|c||}
\hline Number of Ideal Prompts & 34 \\
\hline Number of Late Prompts & \\
\hline Incorrectly Geo-coded Bus Stop & 1 \\
\hline Close Proximity of Bus Stops & 1 \\
\hline Number of Times No Prompt Given & \\
\hline HART Service Change & 1 \\
\hline Incorrectly Geo-coded Bus Stop & 1 \\
\hline Total Number of Trips & $\mathbf{3 8}$ \\
\hline
\end{tabular}

\subsection{Evaluation of TAD by STAGES Students}

\section{The following sections discuss the results of the evaluation of TAD by STAGES students. The results of these trips are shown in Evaluation \#1}

TAD did not successfully detect the GPS starting point bus stop location due to a wireless network connection failure, which is required for a GPS to function properly. The trip was aborted and rescheduled. Since the mobile phone was unable to connect to the wireless carriers development location sever, the phone was unable to obtain a GPS fix. This issue is not under the control of the research team and has been experienced only a few times during TAD development and testing. The research team is now working with the wireless carrier to utilize a more stable location server, which should substantially increase the reliability of GPS for future testing. This type of failure should only occur in development environments, and is not expected to be an issue in general TAD deployment as a normal mobile phone application. 
Table 8. Two trips, which were accidentally aborted by the research team before TAD could provide the alert, are omitted from this table. For trips where TAD alerted the user with "Get Ready..." and "Pull the Cord Now!" notifications are further broken down into three categories for analysis. Ideal prompts are those given in the location between the stop prior to the destination stop and the destination stop while giving the user enough time to react and pull the stop request cord. Late prompts are those given after the stop prior to the destination stop but require very fast reaction time by the user to avoid missing the stop. Early prompts are those given to the user before they reach the stop prior to the destination stop.

\section{Evaluation \#1}

TAD did not successfully detect the GPS starting point bus stop location due to a wireless network connection failure, which is required for a GPS to function properly. The trip was aborted and rescheduled. Since the mobile phone was unable to connect to the wireless carriers development location sever, the phone was unable to obtain a GPS fix. This issue is not under the control of the research team and has been experienced only a few times during TAD development and testing. The research team is now working with the wireless carrier to utilize a more stable location server, which should substantially increase the reliability of GPS for future testing. This type of failure should only occur in development environments, and is not expected to be an issue in general TAD deployment as a normal mobile phone application.

Table 8 - Result of TAD Evaluation with STAGES Students

\begin{tabular}{|c|c|}
\hline Number of Ideal Prompts & 5 \\
\hline \multicolumn{2}{|l|}{ Number of Early Prompts } \\
\hline $\begin{array}{r}\text { Received prompt while bus was stopped at 2nd-to-last bus } \\
\text { stop }\end{array}$ & 1 \\
\hline \multicolumn{2}{|l|}{ Number of Late Prompts } \\
\hline Close Proximity of Bus Stops & 2 \\
\hline GPS drift & 1 \\
\hline User did not hear alert when it was first issued & 1 \\
\hline \multicolumn{2}{|l|}{ Number of Times No Prompt Given } \\
\hline $\begin{array}{r}\text { Due to Lack of Connection to Wireless Carrier Location } \\
\text { Server }\end{array}$ & 1 \\
\hline Due to Incorrectly Geo-coded Bus Stop & 1 \\
\hline Total Number of Trips & 12 \\
\hline
\end{tabular}

\section{Evaluation \#2}

TAD did not successfully detect the starting bus stop of the trip due to erroneous bus stop location information stored in the TAD database. The actual bus stop location is indicated by the red balloon-shaped marker in Figure 33, while the nearby blue bus square indicates the location stored in the bus stop inventory. The preliminary testing did not uncover the error since all tests approached the bus stop from the south, and therefore still passed near 
enough the database stop location to detect it. However, during the actual field test, the bus stop was approached from the north, and TAD did not come near enough the database stop location for it to be detected. This issue has been resolved by correcting the location data in the TAD database.

It is also hoped that a new bus stop inventory from HART will address remaining bus stop inventory inaccuracies in the database. Additionally, future versions of TAD will not require proximity detection of the boarding bus stop location in order to detect the destination stop. Therefore, TAD will only rely on the accuracy of two bus stops (i.e., the destination stop and stop prior to the destination) instead of three stops.

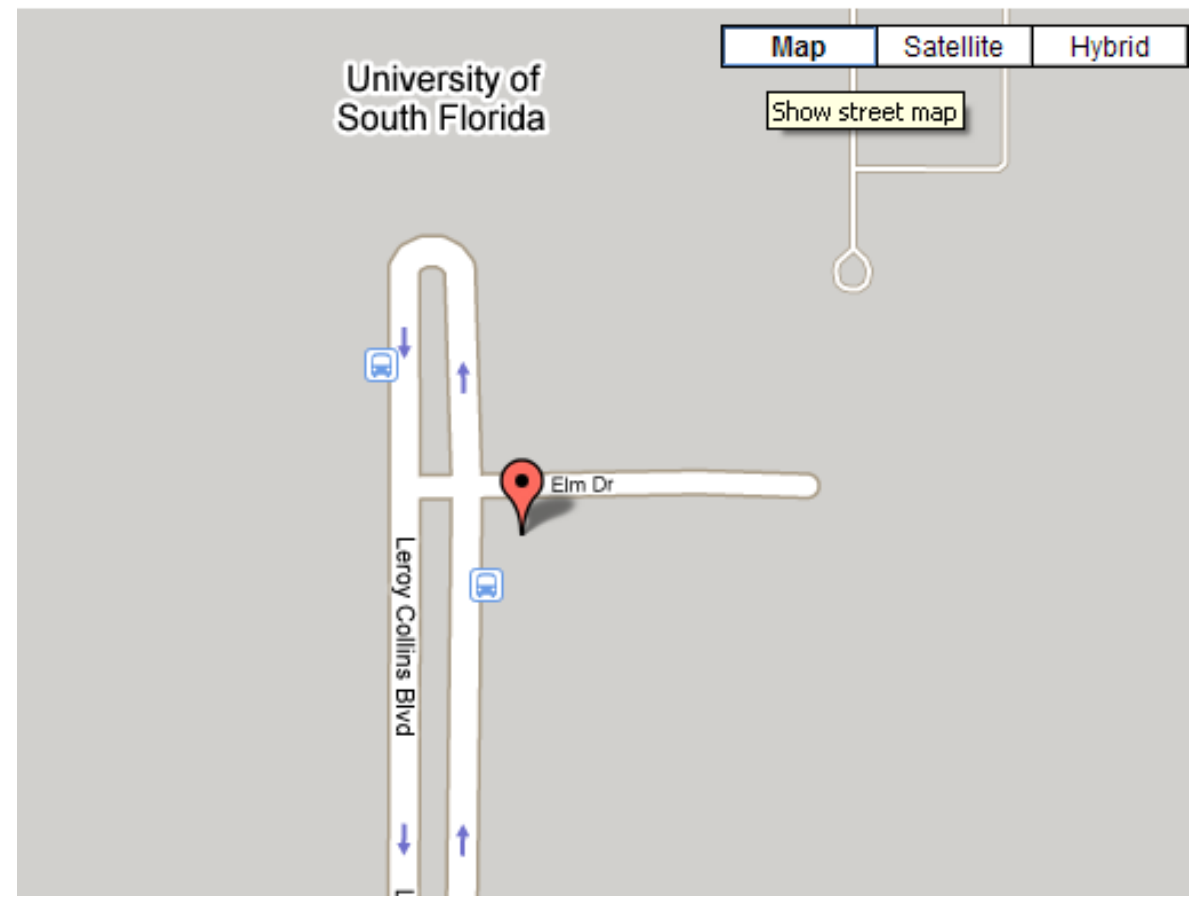

Figure 33 - Inaccuracy in Bus Stop Location Data in Second Field Test

\section{Evaluation \#3}

On the first segment of the trip, TAD delivered the alert to the user near the destination stop. However, the user received the alert slightly early while the bus was stopped at the bus stop prior to the destination stop. Ideally, it is desired that TAD alert the user immediately after the bus departs from the second-to-last stop. This was caused by two factors: the small distance of approximately 135 meters between destination stop and the stop prior to it and the fact that the bus came to a halt to allow riders to board or alight at the second-to-last stop. The TAD application is set to alert the user at approximately 165 meters prior to the final destination; thus, the alert sounded prior to passing the second-tolast bus stop. If the bus did not stop at the stop, the alert likely would have been executed in an ideal position. These problems result from the desire to maximize the radius of the 
geo-fence to provide the user with early warning along with the restriction of the radius size being at most the minimum possible distance between bus stops (to avoid giving the prompt too early). Future TAD versions should examine potential improvements to the current alert mechanism, which takes into account the second-to-last bus stop location and the velocity of the bus on the approach to the final stop to make a more accurate alert.

On the second segment of this trip, the research team accidentally aborted the test before the final destination stop was reached due to a miscommunication within the research team. The TAD application did provide the alert in an ideal location after the research team exited the bus with the user.

\section{Evaluation \#4}

On the first segment, the user reported that TAD provided the alert too close to the final stop, approximately 60 meters before the intended bus stop. Upon the review of the GPS log, it appears that TAD should have been triggered by several GPS fixes at approximately 165, 145, and 130 meters distance from the bus stop, as shown in Figure 34 . Further testing was not able to replicate this observation. Based on the available information, it is believed that the user did not hear or feel the alert until very close to the stop. Future versions of TAD should be enhanced to automatically indicate in the GPS log exactly where the notification was given to the rider to better aid in the troubleshooting process. Additionally, future versions should examine delivering the alert through a Bluetooth ${ }^{\mathrm{TM}}$ wireless headset to increase the chance that the rider will hear the alert as soon as it is issued. 


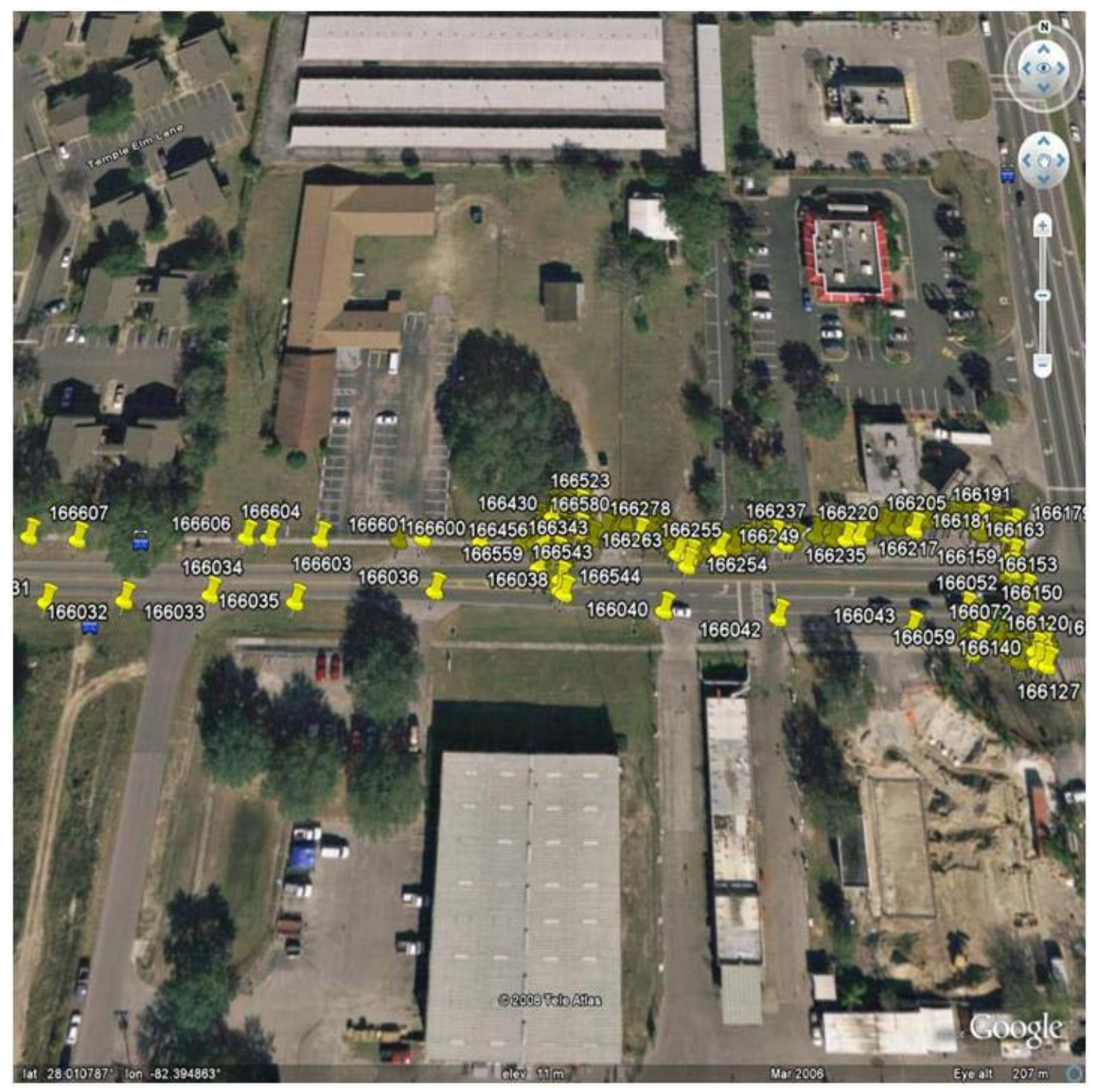

Figure 34 - GPS log from Field Test \#4 Route 6 Segment 1 End

On the second segment of this trip, TAD delivered the prompts to the user in an ideal location.

\section{Evaluation \#5}

On the first segment of this trip, the research team accidentally aborted the trip before the final destination stop was reached due to a miscommunication within the research team. TAD gave the alert in the ideal location for all subsequent tests of the first segment of Route 18.

On the second segment of this trip, TAD delivered the alert to the user as they were approaching the destination stop. The "Pull the cord now!" alert sounded as the trainer and student were preparing to exit the bus, which too late for the rider to safely request a stop if the bus was moving at full speed. As mentioned above, future TAD versions should 
examine potential improvements to the stop detection algorithm that would aid in alerting the user as soon as possible after the bus passes the second to last stop, which could avoid some of these late alert occurrences.

\section{Evaluation \#6}

This trip was taken on the same route as Field Test \#5. For the first segment of the trip, the TAD gave the rider the alert in an ideal location.

For the second segment, as in the second segment of Field Test \#5, the user reported that the phone gave the alert too close to the final stop. As mentioned above, this is likely due to the extremely short distance between the bus stops. Further investigation of enhanced alert triggering algorithms should take place in future versions of TAD that could help deliver the alert sooner than the existing stop detection algorithm.

\section{Evaluation \#7}

This trip was taken on the same day as trips \#5 and \#6 on the same route. For both the first and second trip segments, TAD delivered the alert in an ideal location.

\section{Evaluation \#8}

For the first segment, TAD delivered the alert in an ideal location. For the second segment, the user reported that TAD delivered the alert too close to the destination stop. After the review of the GPS data logs from the phone (Figure 35), one possible cause for this anomaly could be attributed to temporary loss of GPS accuracy. Figure 34 shows a clear sign of GPS drift starting at point of intersection of Fowler Ave. and 30th St. For example, point 179259 had estimated horizontal accuracy of approximately 132 meters, which means the rider could have been anywhere in a circle within radius of 132 meters, with the center at point 179259 , which allows for the possibility of being extremely close to final destination, yet the TAD software would believe that the rider was still far away. 


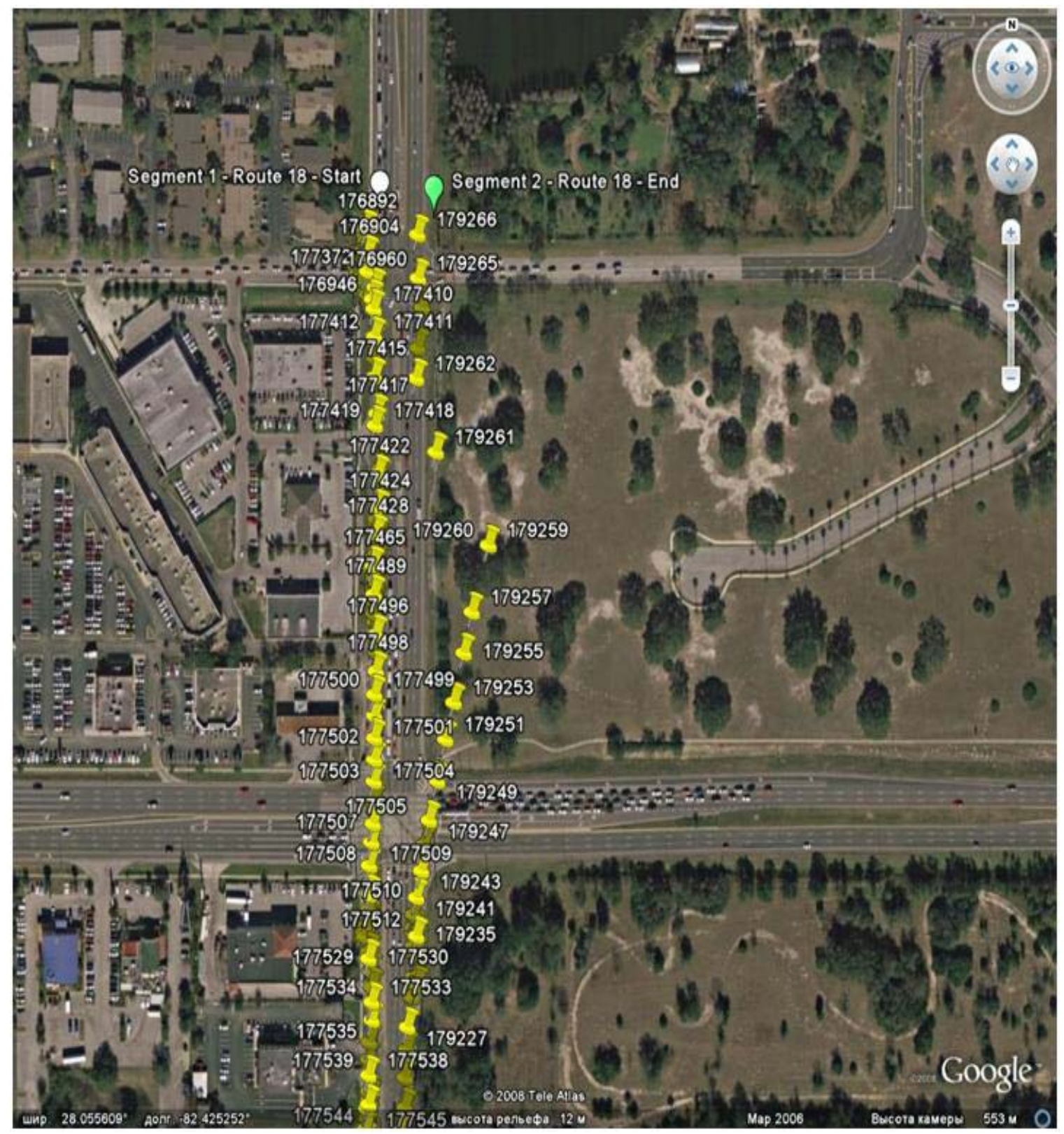

Figure 35 - GPS Log from Route 18 - Segment 2

The research team could not replicate this behavior by traveling this route multiple times before and after the STAGES testing.

A temporary loss of GPS accuracy can be attributed to many causes, including weather, position of the phone in the bus, wireless interference, and incorrect assistance information from a location server. The research team is working with the wireless carrier to utilize a more stable location server to assure that reliable assistance data is available during all testing. Future mobile phone models should show a further increase in GPS sensitivity that should also provide better positioning information, therefore reducing the chance of GPS drift. The research team will also look to enhance the stop detection algorithm to provide the user with alerts earlier in order to give the rider more notice before they must pull the 
stop request cord. As this was the only occurrence of GPS drift observed during system testing, GPS drift does not seem to be a significant problem for the TAD system.

\subsection{Findings from Field Tests}

The TAD field tests successfully demonstrated the proof-of-concept of the TAD system. Many valuable observations were made during these tests, which can be used to improve the system's usability and reliability. The following subsections discuss observations and lessons learned from the initial deployment of TAD.

\subsubsection{Challenge of Working with Special Populations}

Getting TAD into the hands of the target special population was very challenging. There were significant hurdles that had to be overcome regarding the paperwork and process required by the Hillsborough County School System and USF's Institutional Review Board. Some of these hurdles include modifying the informed consent and survey documents so that both Hillsborough County and IRB were satisfied with the final version, as well as having the research team fingerprinted before they could interact with the students.

The many delays introduced because of having a special population use TAD proved to be challenging not only from the project management perspective, but also for the technical management of the TAD system. To minimize the possibility of errors during actual STAGES trips, the research team traveled on each route planned for use by the STAGES students to ensure that TAD worked properly for these areas. In each of these tests, TAD alerted the user at an ideal location. Once these tests were performed and validated, the TAD system was frozen in that state (i.e., no further automatic updates that could cause unexpected changes to the bus stops or routes) in preparation for the trips with the STAGES students. However, as time passed from these initial tests, HART made transit service changes, and construction at several locations resulted in a few bus stops being moved. Ordinarily, these changes would have been automatically integrated into the TAD system via the update from the Google Transit Feed. HART posts updated bus stop and route data to their website in the Google Transit Feed Format, and TAD is able to automatically download and integrate these changes into the TAD database.

However, in an attempt to minimize changes to the system between the preliminary TAD testing and STAGES evaluation, the research team chose to manually update only the stops and routes that were related to the planned STAGES trips and re-test those trips. This service change, manual update, and re-test process happened several times before the actual STAGES trips were performed. Since the system was not initially designed with manual updates in mind, some additional errors in bus stop placement may have resulted from manual adjustments within the database, which requires direct editing of latitude and longitude values through a database record interface. Since TAD was proven very reliable when utilized in a live state (as shown from results in Table 7 and Appendix A) with system updates happening regularly from the Google Transit Feed, it is recommended that the TAD system be kept in a live state for any future field tests. Additionally, the creation 
of a tool for the TAD system, which allows visual editing of stop information through a map interface, would be very useful and would help avoid any potential data entry errors.

Delays in the evaluation by STAGES also led to miscommunications within the research team regarding which exact stops were to be used for test trips due to the amount of time that had elapsed from the initial planning of the trips. This error led to two segments of the field test trips being prematurely aborted since the researcher believed that the destination's stop had already been passed, when, in fact, the bus had not yet reached the destination stop that TAD was programmed to use.

\subsubsection{User Preferences}

When interviewed, several of the STAGES students that used TAD expressed a preference of having the phone's vibration feature function as the primary alert format over a spoken voice alert. Many of the parents expressed preference for an audio alert. This situation seems to be the result of the transit rider not wanting to draw unnecessary attention, while the parents believed that the audio alert would best gain the rider's attention if he or she was distracted. Future TAD development should examine the use of Bluetooth ${ }^{\mathrm{TM}}$ wireless headsets in conjunction with the TAD mobile phone software. The use of the wireless headset to deliver the audio alert would allow the transit rider to retain his/her privacy but still provide a spoken prompt to the user. Since a few of the transit riders also reported that the audio alert was hard to hear in the noisy bus environment, the headset should help address this issue as well.

\subsubsection{Bus Stop Detection and Alert Trigger Algorithm}

The stop detection algorithm on the mobile phone must be extremely efficient due to the limitations of computing resources on the mobile phone that prevents advanced spatial queries and the lack of complex spatial data from the Google Transit Feed that would define the actual path the bus travels. For the TAD project, a simple geo-fencing algorithm was implemented that detected when the device comes within a certain distance of the destination bus stop while the user is traveling on the bus (Figure 36).

It is desired that the geo-fence radius from the destination stop be maximized to give the alert to the user as soon as possible to allow him/her to prepare to exit the bus. However, to prevent the "Pull the cord now!" notification from being triggered too soon, the radius of the geo-fence cannot exceed the distance between the second-to-last stop and the destination stop. Since the actual travel distance between the stops is not necessarily known from the transit agency's Google Transit Feed data, the minimum possible distance between bus stops must be assumed when using this algorithm. Considering that there is an uncertainty value associated with the GPS position calculated by the mobile phone, to use this algorithm in the real world, the radius of the geo-fence must actually be at least several meters less than the GPS uncertainty value subtracted from the distance between the second-to-last stop and the destination stop. 


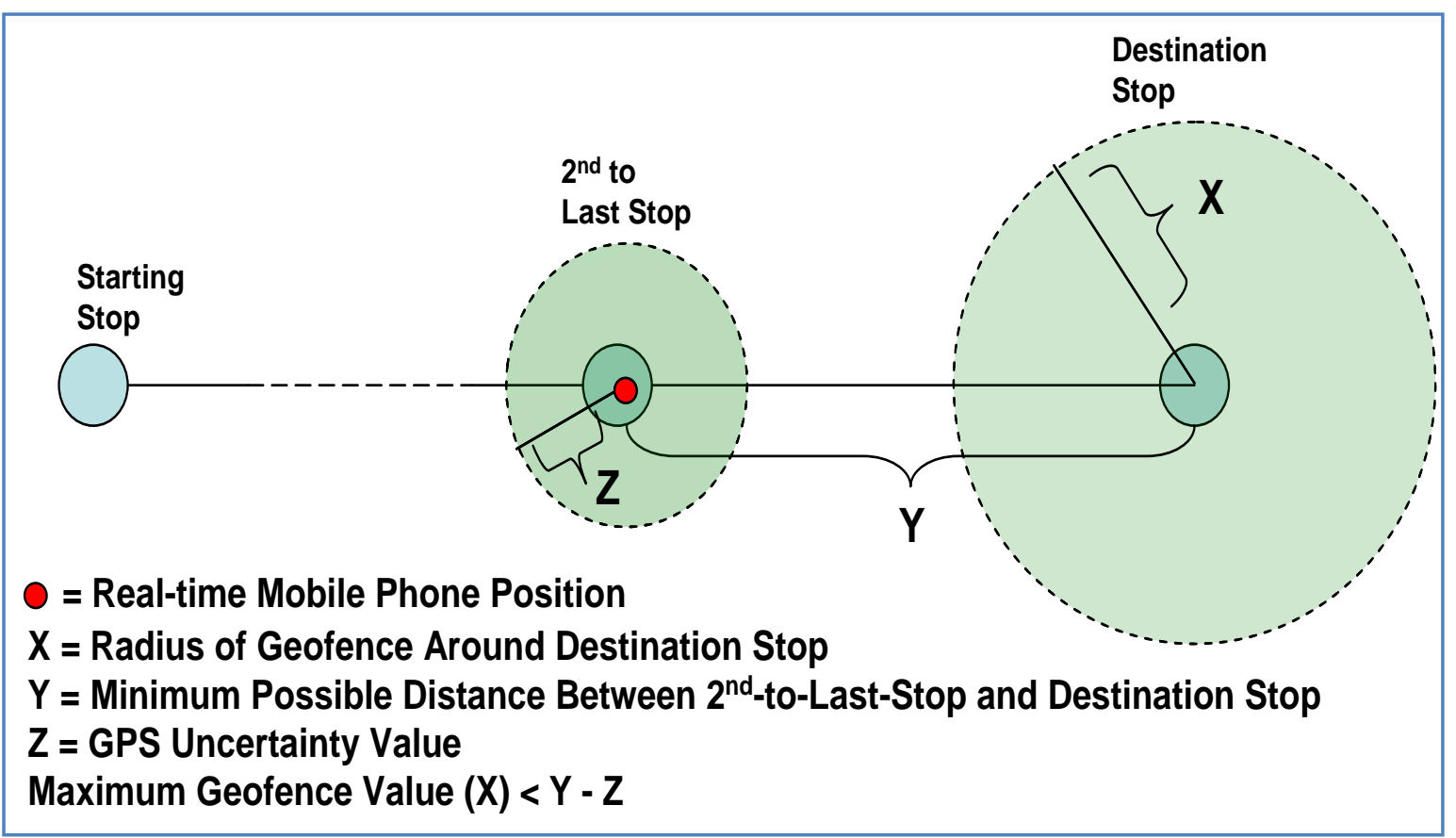

Figure 36 - Bus Stop Detection Algorithm used in TAD

While the majority of the time TAD is able to properly give the "Pull the cord now!" notification somewhere between the second-to-last stop and the destination stop as desired, this situation causes some challenges when attempting to give the rider the alert at the proper time when bus stops are very close together. Additionally, a very early alert is not possible for bus stops that are far apart since the algorithm is limited by the minimum possible distance between the second-to-last stop and destination stop. The resulting early and late prompts were observed several times during the evaluation of TAD by STAGES students, which occurred primarily in several locations where bus stops are positioned very close together. In TAD testing on random stops, where stops were generally spaced further apart, and fewer late alerts were observed.

Several of the occasions where TAD gave the notification to the rider too close to the destination stop could potentially be improved by a more advanced stop detection algorithm based on the knowledge of the location of the second-to-last bus stop in coordination with other measurements and should be investigated in a future version of TAD. This advanced algorithm could potentially give riders alerts while they are traveling on the bus much earlier while avoiding the problem of giving the alert too early. If TAD is expanded in capabilities to alert the user as they approaching their boarding stop, simple geofence-based detection should be sufficient for this service since the user will be traveling via modes at lower speeds (e.g. walking, biking) and the window for successful alert delivery is much larger than when the user is actively traveling on a bus.

Future versions of TAD could also examine direct support to the transit rider in case they miss their bus stop and exit the vehicle at an incorrect stop. Currently, the server-side route deviation algorithm should detect when the rider is outside the area of the route that they are traveling. In this case, a text-message and email alert would be sent to the 
caretaker and travel trainer. Future integration with AVL systems could also potentially be able to detect situation where the rider is still in the vicinity of the route but their real-time location no longer matches the bus real-time location and they have not arrived at the correct stop. In other words, the rider has exited the vehicle at the incorrect location but still on the path of the bus route, they were traveling. Additional aid could also be given to the transit rider to help guide them back to their planned destination stop. However, these features should be designed with consultation of travel trainers and special education professionals in order to prevent giving instructions that could be harmful to the transit rider. For example, it may be preferable to simply have the travel trainer contact the transit rider via the cell phone and give them verbal directions based on the rider's location, local environment, the rider's abilities, and the travel trainer's professional judgment. Navigation software will not be able to take all of these issues into account, and therefore may inadvertently direct the user to perform an action (e.g. crossing a street) which could be dangerous to that particular user.

\section{Importance of Bus Stop Accuracy}

A major issue that has been repeatedly encountered during TAD testing is the accuracy of the bus route and stop information obtained from the transit agency through their Google Transit Feed. The most significant problem has been the inaccuracies in geo-coded bus stop locations. Since TAD relies on this information to properly announce the alerts to request a stop, if the bus stop location is inaccurate, in certain situations TAD will not perform well. The difference between geo-coded and true stop location has been observed to be anywhere from 10 to 100 meters, which can negatively impact TAD performance.

Figure 37 illustrates the potential differences between the data being obtained from the Google Transit Feed (Alumni Dr at Laurel bus icon) and the actual geographic location of the bus stop (pushpin marker). This scenario also represents a situation where inaccuracies would negatively affect TAD. Since the bus will approach the stop from the east (right side of image), it will reach the actual stop location before the geo-coded does. Therefore, TAD would alert the rider to request a stop after he/she had already passed his/her destination stop. This circumstance would result in the rider arriving at the next transit stop, which could potentially be a long distance from the intended destination. Additionally, if the rider's trip involves transfers between buses and this stop is one of the transfers, TAD may be impacted for future segments even if the rider exits the vehicle at the proper stop. Since the TAD, software will believe the rider never reached this location; it will not begin tracking the next segment and therefore will not give a notification for that segment.

It should be noted that some bus stop inaccuracies do not affect TAD performance. For example, if the locations in Figure 37 were reversed and the bus would first encounter the geo-coded stop before passing the actual geographic location of the stop, TAD would likely still perform adequately to prompt the rider to get off at the proper stop. The stop request alert would be triggered sooner than intended, but as long as the alert was triggered after the stop before the destination stop was passed the rider would still be able to exit the vehicle at the correct stop. 


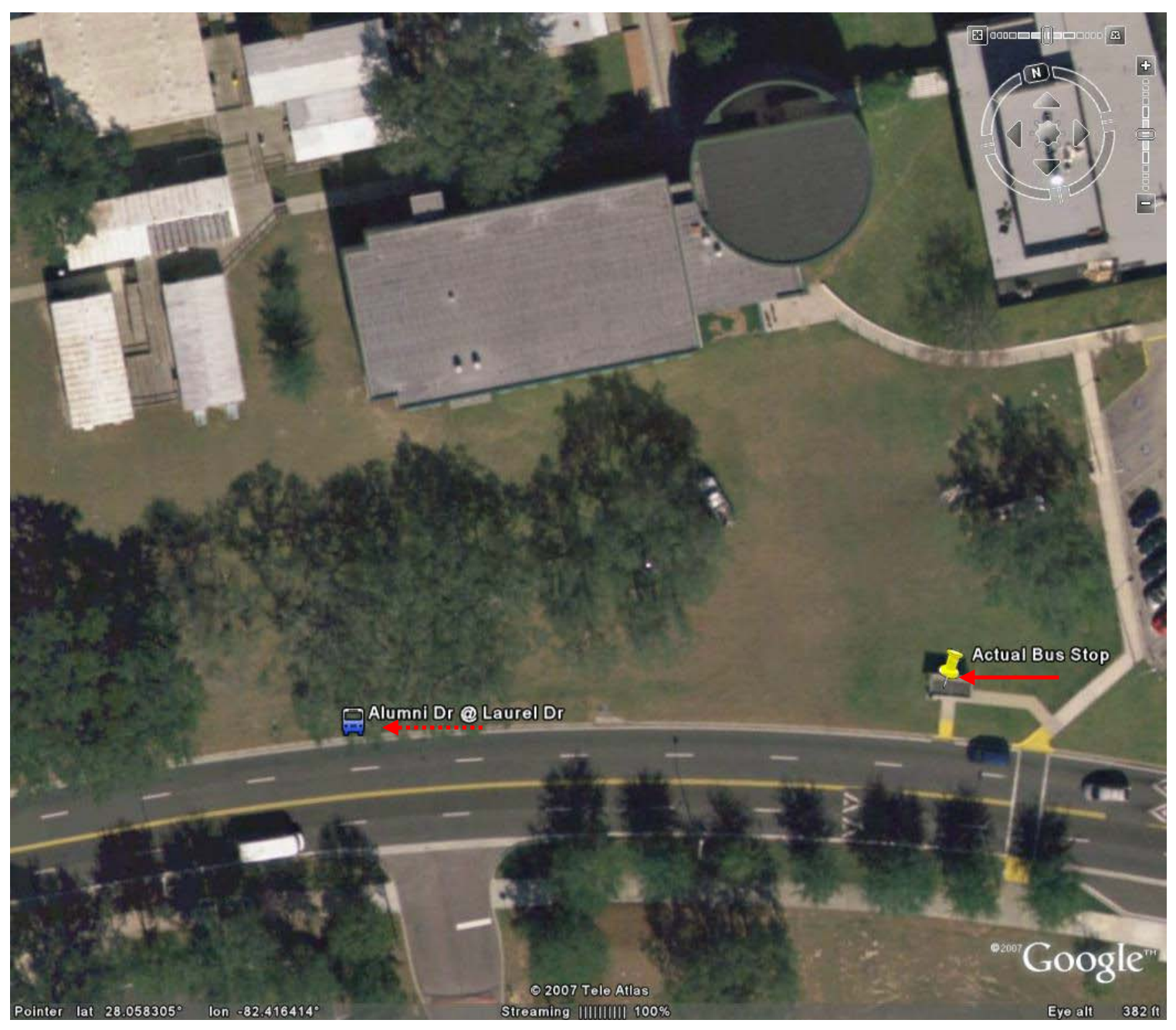

Figure 37 - Illustration of Inaccuracies in Bus Stop Inventory Datasets 


\section{CHAPTER 6 - CONCLUSIONS AND FUTURE RESEARCH}

The initial design, implementation, and field-testing of the TAD software application, running on commercially available GPS-enabled mobile phones and announcing upcoming bus stops to the transit rider has been successful. The device with the proof-of-concept TAD software has been field tested in the Tampa area on HART transit bus routes with very promising results. However, several improvements remain to be researched, designed, tested, and implemented.

Several areas of the TAD software system can be improved. For example, improvements to the TAD mobile phone application user interface may help riders be less conspicuous when utilizing TAD. Field test participants stated their preference for a more discreet notification method to alert them of upcoming stops instead of publically announcing the alerts via the device speakerphone. Future versions of TAD could utilize Bluetooth" wireless headsets so that the audio prompt for "Get ready" and "Pull the cord now!" be heard privately through the headsets and not announced out loud.

Another function that could be added to the TAD system is trip inference. It may be possible to automatically predict which transit trip the rider currently wants to take by their real-time position and past travel behavior. This feature could remove the requirement for riders to select their trip from a list of trips displayed on the phone and make the user experience simpler.

Trip planning functionality could also be integrated into the TAD website. Currently, the website user must have knowledge of the bus system routes and schedule to set up a trip for a TAD user. Trip planning software such as Google Transit potentially could be integrated into the TAD system. This software, given a source and destination address, would be able to automatically plan a trip and set up the proper routes and schedules for download by the TAD mobile application.

While for the majority of transit trips, TAD is able to alert the rider at the appropriate time, both bus stop detection and alert triggering algorithms of TAD should be enhanced to avoid giving alerts in very close proximately to the desired stop. The current algorithm provides some alerts in locations that require very fast reaction time by riders to request a stop before the bus passes their destination stop. Advanced bus stop detection algorithms should be able to give the rider notification earlier without giving the alert too soon.

The current requirement to detect the first stop for each segment should be removed to prevent possible failures due to an incorrectly geo-coded starting bus stop location. By removing this requirement, TAD will still alert the rider of his/her approaching destination stop even if the user was never detected as being near their starting stop. To further increase the reliability of TAD, detection of multiple segment ending stops simultaneously may be desirable so that an intermediate failure at a transfer stop that is improperly geocoded will not result in remaining segments of the total trip being unmonitored. TAD would, therefore, function for remaining segments of a trip even if one intermediate 
segment was not properly detected and the transit rider could continue his/her trip past an undetected stop.

Future work also should focus on creating a tool that would allow administrators to move bus stop locations in the database via the user interface. It is likely that many transit agencies will have inaccuracies in their bus stop inventory, so allowing the travel trainer to move the stop to the correct location would ensure that TAD functions correctly for that segment while removing from the TAD system administrators the burden of manually updating datasets. Allowing direct placement by the travel trainer through a website tool reduces errors in communicating information between parties and reduces the potential for human error during direct data manipulations in the database. Once a bus stop is manually moved, automatic updates via the Google Transit Feed should continue to take place, but the manually adjusted bus stops would remain untouched during the update process. In the future, tools such as Google Earth" ${ }^{\mathrm{TM}}$ 's "Streetview," which provides a first-person perspective of the street at the bus stop location, should prove very useful to travel trainers wanting to remotely view the potential destination of a planned trip for a transit rider.

Transit AVL systems also should be studied to see what additional services can be provided to the user, such as estimated time until arrival as well as ensuring that the rider boarded the correct bus. AVL also should be investigated as a potential backup positioning system when the mobile phone cannot calculate the GPS fix based on its embedded GPS hardware. Since AVL utilizes GPS antennas that are located on the exterior of the bus, it may be able to calculate position information in environments where a mobile phone cannot. While lack of an accurate GPS signal does not seem to be a significant problem for newer phones with high-sensitivity assisted GPS technology, AVL may serve as an important backup for older mobile phones with less sensitive GPS. It may also be possible to utilize the AVL to provide location-aware services to transit riders with mobile phones without GPS function. However, the quality of such a service would have to be researched and evaluated.

Further testing with other transit agencies is essential so that the research team can observe the results of TAD functioning on a different transit system. If a transit agency has an accurate and up-to-date bus stop inventory and that data are placed into the Google Transit Feed Specification format, the TAD system should be able to read the data and instantly add that agency into the system.

The task of integrating the TAD into travel training curricula is an open issue that will require input from multiple parties including special education professionals and travel trainers. Guidance for "training the trainers" should be developed to ensure the trainers utilize TAD properly during training sessions. Trainers should also be educated to assess a rider's ability to independently use TAD to complete a trip. Further studies that define the capabilities and skills needed for a rider to use various TAD features are needed with input from parents, trainers, riders, and others to assure the user-friendliness and functionality of the application to riders with specific disabilities. Although field tests with special needs population proved rather challenging logistically, more testing is needed to refine TAD and make it applicable to specific needs. For example, for the hearing impaired, additional 
visual cues on the phone screen can be considered along with the vibration of the phone instead of current audio prompts.

Lastly, since no software system is 100 percent reliable, travel trainers should provide clients with fallback plans in case the TAD software is not able to alert the rider at the appropriate time. Both the tracking feature and the automated route deviation alert of the TAD software, along with general utility features of a cell phone, are designed to aid the travel trainer and/or guardian in case the rider becomes lost. However, in general, with or without TAD's assistance, different scenarios should be prepared and field-tested for a particular rider according to his/her specific needs. Keeping in mind that TAD is designed to be a used as a tool to aid in travel training and to enhance the rider's independence and safety, trainees should have ample opportunities to practice with guardians and trainers so that some level of familiarity and confidence is attained before riding independently. 


\section{References}

(1) Hardin, J. Assessment of Operational Barriers and Impediments to Transit Use: Transit Information and Scheduling for Major Activity Centers, National Center for Transit Research (NCTR), Center for Urban Transportation Research, University of South Florida, 2001.

(2) Cain, A. Design Elements of Effective Transit Information Materials, National Center for Transit Research (NCTR), Center for Urban Transportation Research, University of South Florida, 2004.

(3) Kirasic, K. "Aging and Spatial Behavior in the Elderly Adult”, Cognitive Mapping: Past Present and Future, London, Routledge, 2000.

(4) Wilkniss, S., M. Jones, D. Korol, P. Gold, and C. Manningal, "Age-Related Differences in an Ecologically-Based Study of Route Learning”, Psychological Aging, Vol. 12, Issue 2, 1997, pp. 372-375.

(5) Hunt, W., Orientation and Wayfinding: A Review, Arlington, Office of Naval Research, 1999.

(6) U.S. Administration on Aging. http://www.aoa.gov/ (accessed February 11, 2008).

(7) Aging States Project, a collaborative effort of the Association of State and Territorial Chronic Disease Program Directors and the National Association of State Units on Aging.

(8) Bailey, L., Aging Americans: Stranded Without Options, Surface Transportation Policy Project, 2004.

(9) Balog, J., Guidebook for Attracting Paratransit Patrons to Fixed-Route Service, Transit Cooperative Research Program, Report 24, Transportation Research Board of the National Resource Council, National Academy Press, Washington DC, 1997.

(10) Transportation Research Board, Communicating with Persons with Disabilities in a Multimodal Transit Environment - A Synthesis of Transit Practices TCRP Synthesis, Report 37, Transportation Research Board of the National Resource Council, National Academy Press, Washington DC, 2001.

(11) Public Transportation Factbook, American Public Transportation Association, 2004.

(12) Wade, T.K., and J.C. Troy, "Mobile Phones as a New Memory Aid: A Preliminary Investigation Using Case Studies”, Brain Injury, Vol 15, No 4, 2001, pp 305-320.

(13) O’Connell, M., C. Mateer, and K. Kerns "Prosthetic Systems for Addressing Problems with Initiation: Guidelines for Selection, Training, and Measuring Efficacy”, NeuroRehabilitation, Vol 18, No 9, 2003, pp 20.

(14) Humanware. Trekker device specification. http://www.humanware.ca/web/en/p_DA_Trekker.asp (accessed February 11, 2008).

(15) Braddock, D., M.C. Rizzolo, M. Thompson, and R. Bell, "Emerging Technologies and Cognitive Disability”, Journal of Special Education Technology, Vol 19, No 4, 2004, pp 49-56.

(16) Fischer, G. and J. Sullivan Jr., "Human-Centered Public Transportation Systems for Persons with Cognitive Disabilities - Challenges and Insights for Participatory Design”, Proceedings of the Participatory Design Conference, Malmo University, Sweden, 2002.

(17) Fischer, G., "Distributed Cognition: A Conceptual Framework for Design-for-all”, Proceedings of HCI International, C. Stephanidis (eds.), Lawrence Erlbaum Associates, Mahwah, NJ and Crete, Greece, 2003. 
(18) Fischer, G. and J. Sullivan Jr., Mobile Architectures and Prototypes to Assist Persons with Cognitive Disabilities using Public Transportation, Cognitive Levers Project, University of Colorado, 2001.

(19) Neff, T. (2003). “Project a Beacon for Disabled”, Daily Camera-Section B, July 5, 2003, http://www.agentsheets.com/about_us/pressmaterial/documents/Cameraarticle2003.pdf (accessed July 31, 2003).

(20) Carmien, S., M. Dawe, G. Fischer, A. Gorman, A. Kintsch, J. Sullivan Jr., Transportation Systems and People with Cognitive Disabilities, Center for LifeLong Learning and Design at the University of Colorado at Boulder, 2005.

(21) Liao, L., D. Fox, and H. Kautz, "Learning and Inferring Transportation Routines”, Paper presented at Nineteenth National Conference on Artificial Intelligence, San Jose, CA, 2004.

(22) Patterson, D., L. Liao, G. Krzysztof, M. Collier, N. Livic, K. Olson, S. Wang, D. Fox, and H. Kautz, Opportunity Knocks: A System to Provide Cognitive Assistance with Transportation Services, UbiComp, 2004, pp 433-450.

(23) Groce, M., Travel Training for Youth with Disabilities: An Introduction to Travel Training, National Dissemination Center for Children With Disabilities, 1996, http://old.nichcy.org/pubs/transum/ts9txt.htm (accessed February 11, 2008).

(24) Wolf-Branigin, K., T. Haenftling, and S. Green, "Getting Down to Business with Bus Familiarization, Travel Instruction and Orientation and Mobility Services", Proceedings of the 2005 Bus and Paratransit Conference, Columbus, OH, 2005.

(25) Newbigging, E.D., and J.W. Laskey, "Riding the Bus: Teaching an Adult with a Brain Injury to Use a Transit System to Travel Independently to and from Work", Brain Injury, Vol 10, 1995, pp 543-550.

(26) Association of Travel Instruction. http://www.travelinstruction.org (accessed February 11, 2008).

(27) Sohlberg, M., and C. Mateer, Cognitive Rehabilitation: An Integrative Neuropsychological Approach, Guilford Press, New York, 2001.

(28) Wilson, B., H.C. Emslie, K. Quirk, and J.J. Evans, "Reducing Everyday Memory and Planning Problems by Means of a Paging System: A Randomized Control Crossover Study”, Journal of Neurology, Neurosurgery, and Psychiatry with Practical Neurology, Vol 70, 2001, pp 477-482.

(29) Yasuda, K., T. Misu, B. Beckman, O. Watanabe, Y. Ozawa, and T. Nakamura, "Use of an IC Recorder as a Voice Output Memory Aid for Patients with Prospective Memory Impairment”, Neuropsychological Rehabilitation, Vol 12, No 2, 2002, pp 155-166.

(30) Van Den Broek, M., J. Downes, Z. Johnson, B. Dayus, and N. Hilton, "Evaluation of an Electronic Memory Aid in the Neuropsychological Rehabilitation of Prospective Memory Deficits”, Brain Injury, Vol 14, No 5, 2000, pp 455-462.

(31) Yasuda, K., B. Beckman, M. Yoneda, H. Yoneda, A. Iwamoto, and T. Nakamura, "Successful Guidance by Automatic Output of Music and Verbal Messages for Daily Behavioural Disturbances of Three Individuals with Dementia”, Neuropsychological Rehabilitation, Vol 16, No 1, 2006, pp 66-82.

(32) Sohlberg, M., S. Fickas, P.F. Hung, and A. Fortier, “A Comparison of Four Prompt Modes for Route Finding for Community Travelers with Severe Cognitive Impairments”, Brain Injury, Vol 2, No 5, 2007, pp 531-538. 
(33) Lee, J., B. Caven, S. Haake, and T. Brown, "Speech-Based Interaction with InVehicle Computers: The Effect of Speech Based Email on Driver's Attention to the Roadway”, Human Fact, Vol 43, 2001, pp 613-640.

(34) McCallum, M., J. Campbell, J. Richman, and J. Brown, "Speech Recognition and InVehicle Telematics Devices: Potential Reductions in Driver Distraction", International Journal of Speech Technology, Vol 7, 2004, pp 25-33.

(35) Parush, A., "Speech-Based Interaction in Multitask Conditions: Impact of Prompt Modality”, Human Fact, Vol 47, 2005, pp 591-597.

(36) ABI Research, "GPS-Enabled Location-Based Services (LBS) Subscribers Will Total 315 Million in Five Years”, ABI Research, 2006, http://www.abiresearch.com/abiprdisplay.jsp?pressid=731 (accessed September 27, 2006).

(37) ABI Research, "Personal Locator Services to Reach More than 20 Million North American Consumers by 2011”, ABI Research, 2006, http://www.abiresearch.com/abiprdisplay.jsp?pressid=766 (accessed November 28, 2006).

(38) ABI Research, "GPS Devices and Systems Will Generate Revenues of \$240 Billion by 2013”, ABI Research, London, 2008.

(39) Sterling, T., "GPS Market at Turning Point with Sliding Prices, Demand Off”, Associated Press-USA Today, April 25, 2008, http://www.usatoday.com/tech/products/2008-04-25-1442319346_x.htm (accessed September 11, 2008).

(40) Winters, P., R. Perez, M. Labrador, N. Georggi, and S. Barbeau, Traveling Smart: Increasing Transit Ridership through Automated Collection (TRAC) of Individual Travel Behavior Data and Personalized Feedback, National Center for Transit Research, University of South Florida, 2005.

(41) Aguilar, D., S. Barbeau, M. Labrador, A. Perez, R. Perez, and P. Winters, Quantifying the Position Accuracy of Real-time Multi-Modal Transportation Behavior Data Collected using GPS-Enabled Mobile Phones, Transportation Research Record, 2007.

(42) Winters, P., S. Barbeau, and N. Georggi, Smart Phone Applications to Influence Travel Behavior (TRAC-IT Phase 3), National Center for Transit Research, University of South Florida, 2008, http://www.nctr.usf.edu/pdf/77709.pdf (accessed June 26, 2008).

(43) Witte, T., and A. Wilson, “Accuracy of Non-Differential GPS for the Determination of Speed over Ground”, Journal of Biomechanics, Vol 37, No 12, 2004, pp 1891-8.

(44) Federal Communications Commission (FCC), Enhanced 911 - Wireless Services. http://www.fcc.gov/911/enhanced/ (accessed February 11, 2008).

(45) Sun Microsystems, Inc. The Java ME Platform - the Most Ubiquitous Application Platform for Mobile Devices. http://java.sun.com/javame/ (accessed February 11, 2008).

(46) Sun Microsystems, Inc. Java Specification Request (JSR) 179: Location API for J2ME ${ }^{\mathrm{TM}}$. http://jcp.org/en/jsr/detail?id=179 (accessed February 11, 2008).

(47) Sun Microsystems, Inc. Java Specification Request (JSR) 293: Location API 2.0. http://jcp.org/en/jsr/detail?id=293 (accessed February 11, 2008).

(48) Aguilar, D., S. Barbeau, R. Perez, M. Labrador, and P. Winters, “A Comparison of Fix Times and Estimated Accuracies in Application Programming Interfaces (APIs) 
for GPS Enabled Mobile Phones", Proceedings of the 11th World Conference on Transport Research, Berkeley, CA, 2007.

(49) Barbeau, S., M. Labrador, P. Winters, R. Pérez, and N. Georggi, "Location API 2.0 for J2ME - A New Standard in Location for Java-Enabled Mobile Phones”, Computer Communications, Vol 31, No 6, 2008,

(50) Palm. Palm Developer Network. https://pdn.palm.com/regac/pdn/index.jsp (accessed February 11, 2008).

(51) Research In Motion, Inc. Blackberry - BlackBerry Developer Program. http://na.blackberry.com/eng/developers/ (accessed February 11, 2008).

(52) Netbeans, "Netbeans Integrated Development Environment", http://www.netbeans.org (accessed February 11, 2008).

(53) Eclipse. Eclipse - An Open Development Platform. http://www.eclipse.org/ (accessed February 11, 2008).

(54) Sun Microsystem, Inc. Sun Java Wireless Toolkit for CLDC (formerly known as J2ME Wireless Toolkit). http://java.sun.com/products/sjwtoolkit/ (accessed February 11, 2008).

(55) Sprint Nextel Corporation. Overview of Sprint Location Based Services, 2006. http://developer.sprint.com/site/global/develop/technologies/location_based_serv/p_l bs.jsp (accessed February 11, 2008).

(56) Sun Microsystems, Inc. JSR118: Mobile Information Device Profile 2.0. http://jcp.org/en/jsr/detail?id=118 (accessed February 11, 2008).

(57) Information Sciences Institute, "Request for Comments (RFC) 793 - Transmission Control Protocol DARPA Internet Program Protocol Specification”, Information Sciences Institute, 1981.

(58) Postel, J., "Request for Comments (RFC) 768 - The User Datagram Protocol”, 1980, http://www.javvin.com/protocolUDP.html (accessed February 11, 2008).

(59) Sun Microsystems, Inc. JSR172: J2ME Web Services Specification. http://jcp.org/en/jsr/detail?id=172 (accessed February 11, 2008).

(60) W3C. Simple Object Access Protocol v1.2. http://www.w3.org/TR/soap/ (accessed February 11, 2008).

(61) Sprint. Sprint Business - Sprint Mobile Broadband Coverage. http://www.sprint.com/business/products/products/evdoCoverage2.jsp?map=Tampa FL\&mrkt=Tampa/St.\%20Petersburg,\%20Fl (accessed February 11, 2008).

(62) Qualcomm. Qualcomm Technology and Solutions - Location Based Services. http://www.qualcomm.com/products_services/mobile_content_services/location/gps one.html (accessed September 11, 2008).

(63) AT\&T. devCentral | Location-based Services (LBS). http://developer.att.com/developer/index.jsp?page=toolsTechSection\&id=7000080 (accessed February 11, 2008).

(64) Qualcomm. FAQ - Does BREW support multi-threading? https://brewx.qualcomm.com/bws/content/gi/common/appseng/en/developerfaqs/doc s/creatingapps/coding/codinge.html (accessed February 11, 2008).

(65) Verizon Wireless. Verizon Wireless to Introduce Any Apps, Any Device Option for Customers in 2008. Press release, Basking Ridge, NJ, 11/27/2007. http://news.vzw.com/news/2007/11/pr2007-11-27.html (accessed February 11, 2008). 
(66) Reed, B., “What Does Verizon's Open-Access Network Option Mean for You?” Network World, 2007, http://www.networkworld.com/news/2007/112807-verizonanalysis.html?page=1 (accessed February 11, 2008).

(67) AFP. Verizon, AT\&T Win FCC Auction, Google Wins Open Spectrum. http://afp.google.com/article/ALeqM5iMbsPSv2vatAVvbz_8n0xU3Mfvnw (accessed March 2008).

(68) Google. Google Web Toolkit - Build AJAX apps in the Java Language. http://code.google.com/webtoolkit/ (accessed February 11, 2008).

(69) PostGIS. PostGIS Home. http://www.postgis.org/ (accessed April 30, 2008).

(70) Sun Microsystems. Glassfish - Open Source Application Server. https://glassfish.dev.java.net/ (accessed April 30, 2008).

(71) Google. Google Transit Feed Specification. http://code.google.com/transit/spec/transit_feed_specification.html (accessed November 1, 2007).

(72) Hillsborough Area Regional Transit (HART). Travel Training Program. http://www.hartline.org/ride_guide/travel_training/index.htm (accessed February 11, 2008).

(73) Hillsborough Area Regional Transit (HART), Hart Wave Newsletter, 2007, pp 3. 


\section{Appendices}

Appendix A - Additional TAD Testing Results on Hillsborough Area Regional Transit (HART) System

Appendix B - Participant Consent Forms Used in Field Tests 


\section{Appendix A - Additional TAD Testing Results on Hillsborough Area Regional Transit (HART) System}

Legend:

$$
\begin{aligned}
& \text { = "Get Ready" Command } \\
& \text { X = Actual Bus Stop Location (if different from GTF stop location) }
\end{aligned}
$$

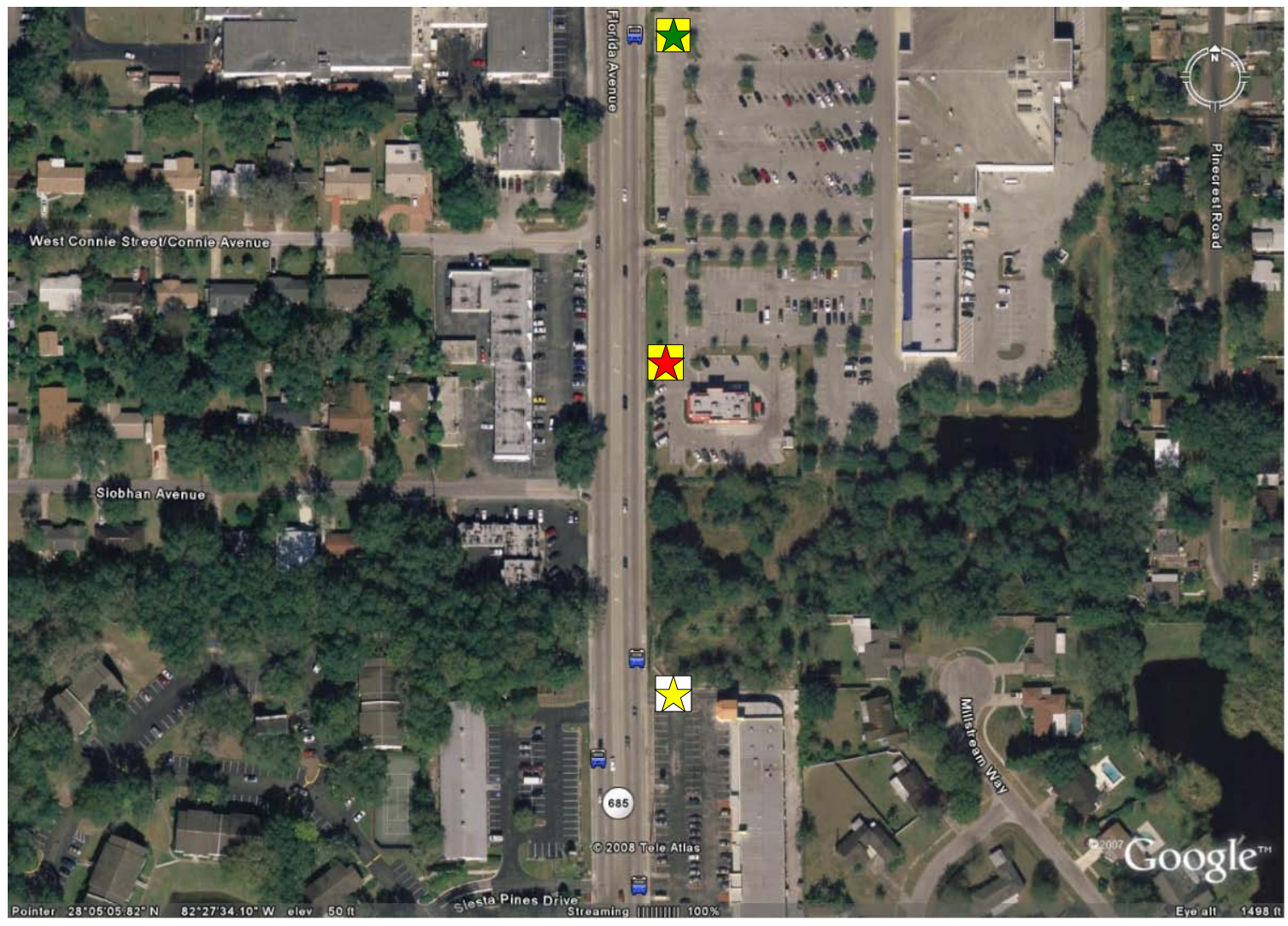

Route 83-East

N. Florida Avenue and Bearss Avenue 


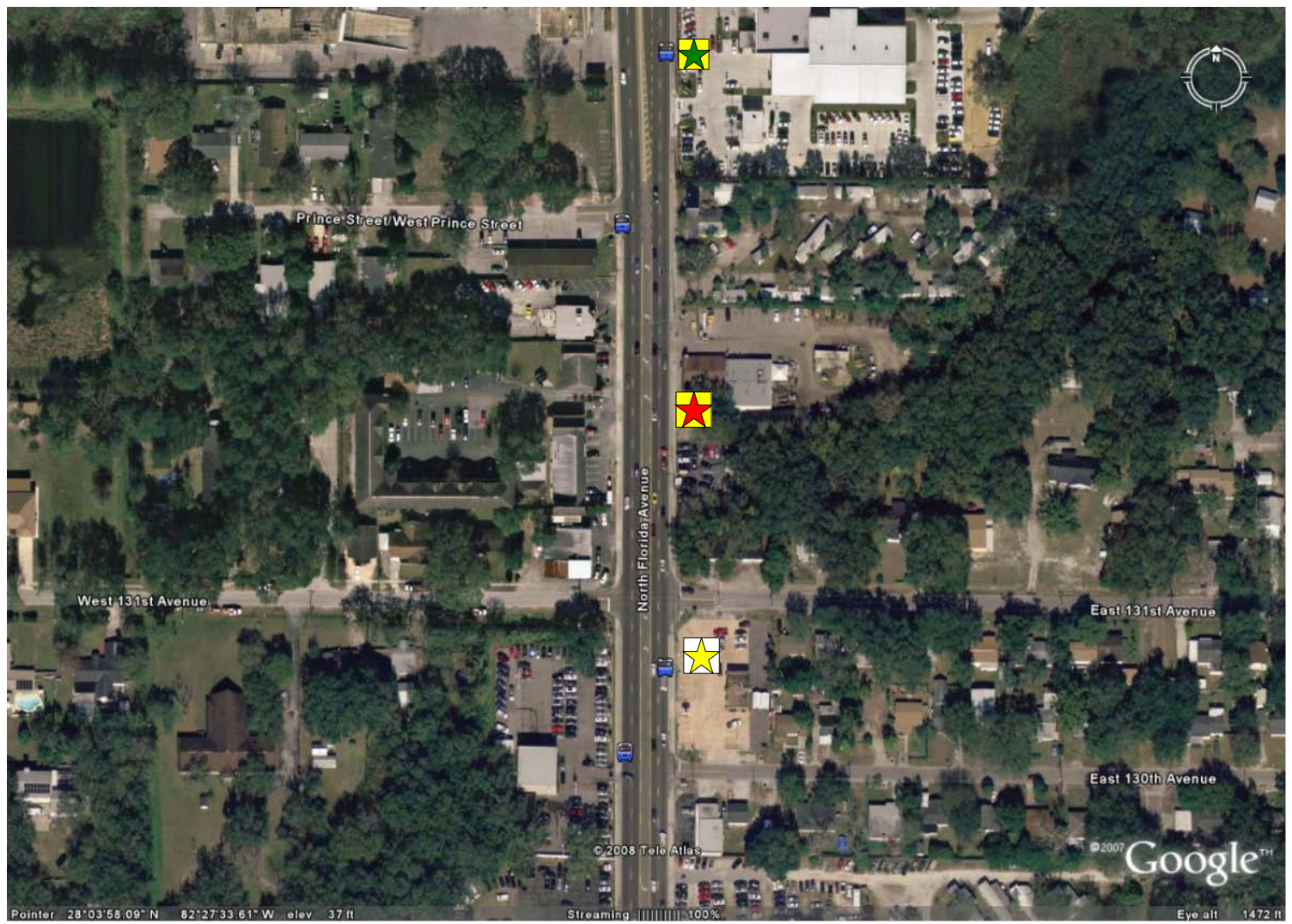

Route 1-North

N. Florida Avenue and Prince Street

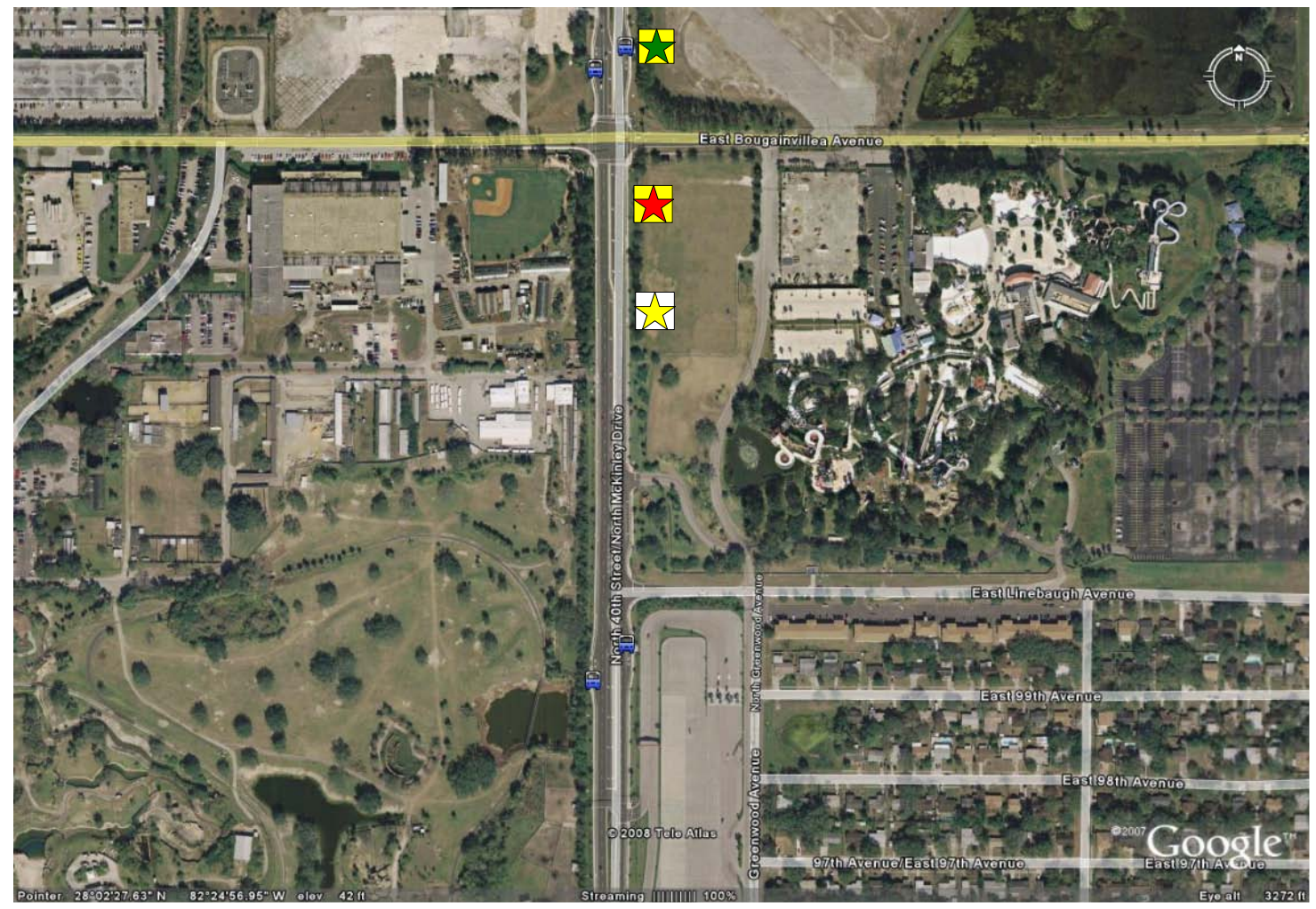

Route 5-North

N. McKinley Drive and E. Bougainvillea Avenue 


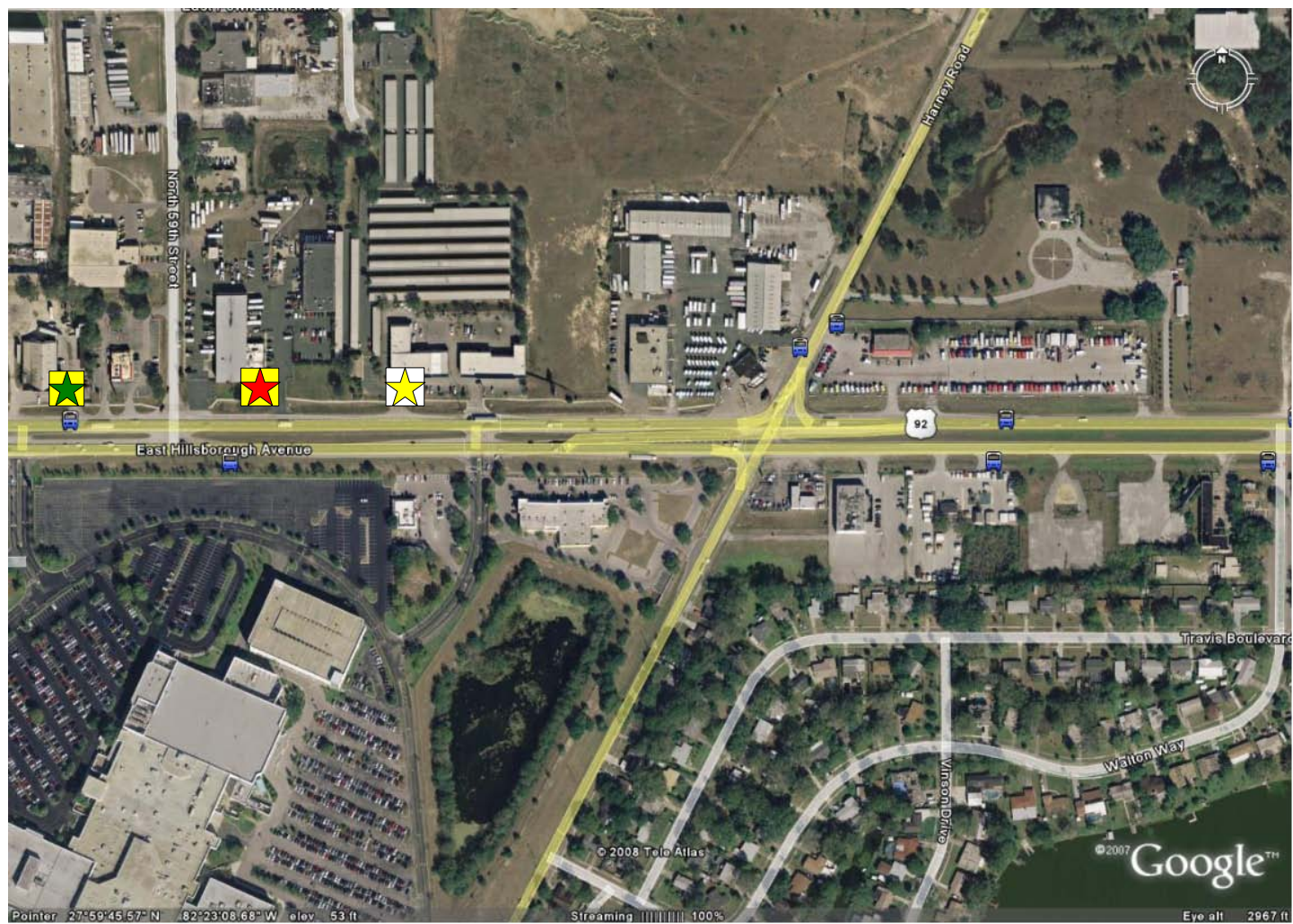

Route 15-East

Hillsborough Avenue and $59^{\text {th }}$ Street

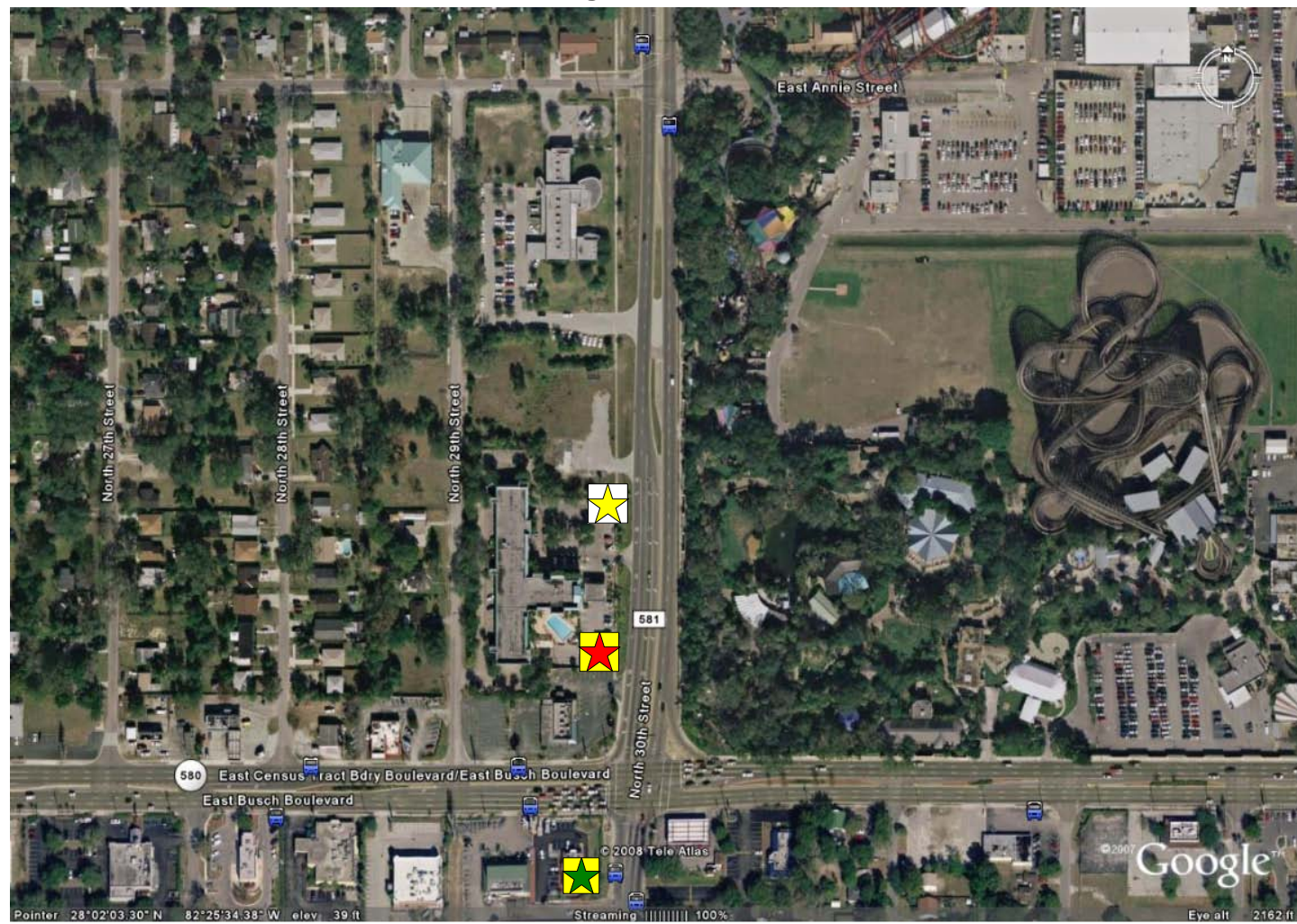

Route 18-South

N. $30^{\text {th }}$ Street and Busch Boulevard 


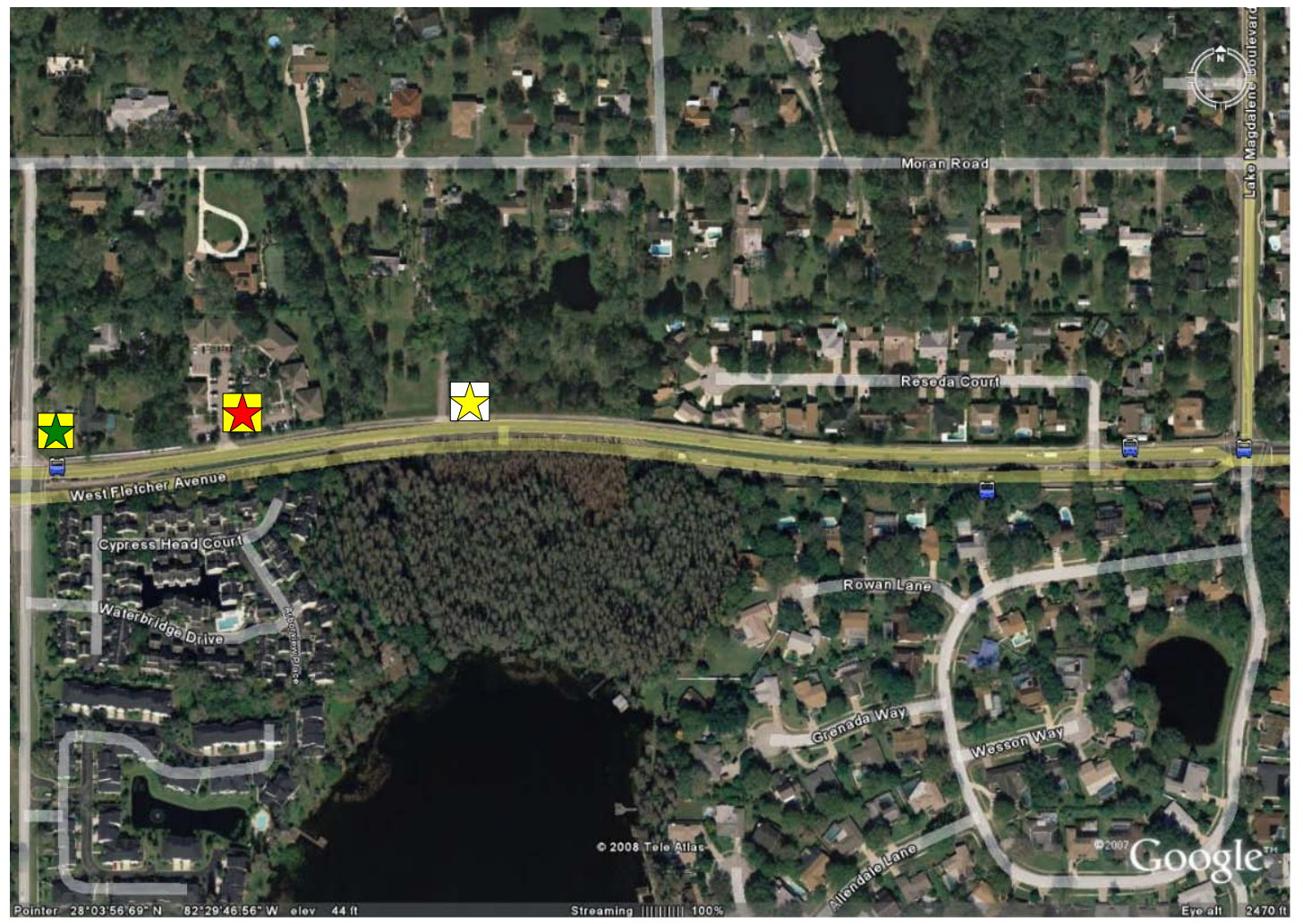

Route 33-West

Fletcher Avenue and Orange Grove Drive

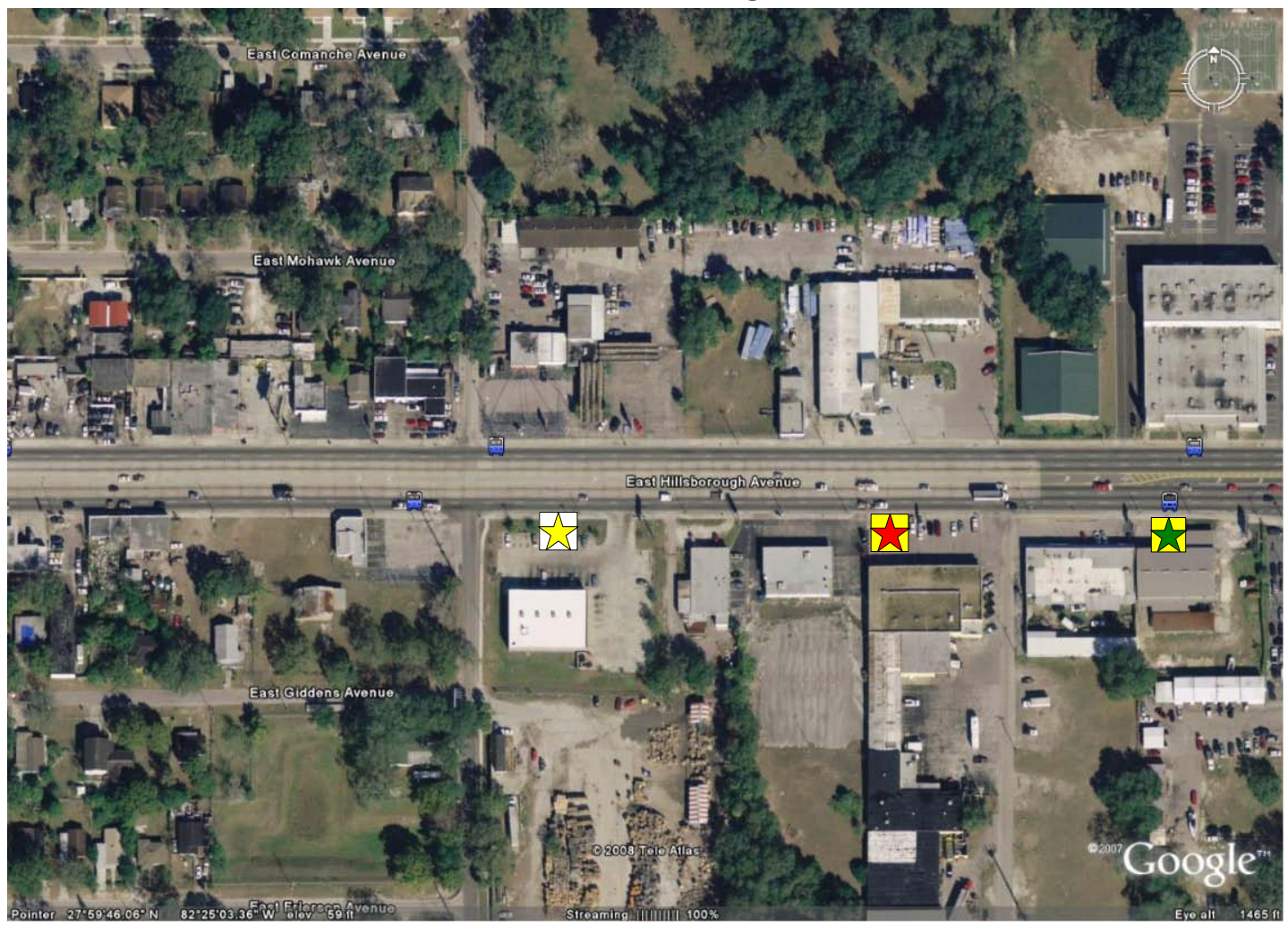

Route 34-East

Hillsborough Avenue and $40^{\text {th }}$ Street 


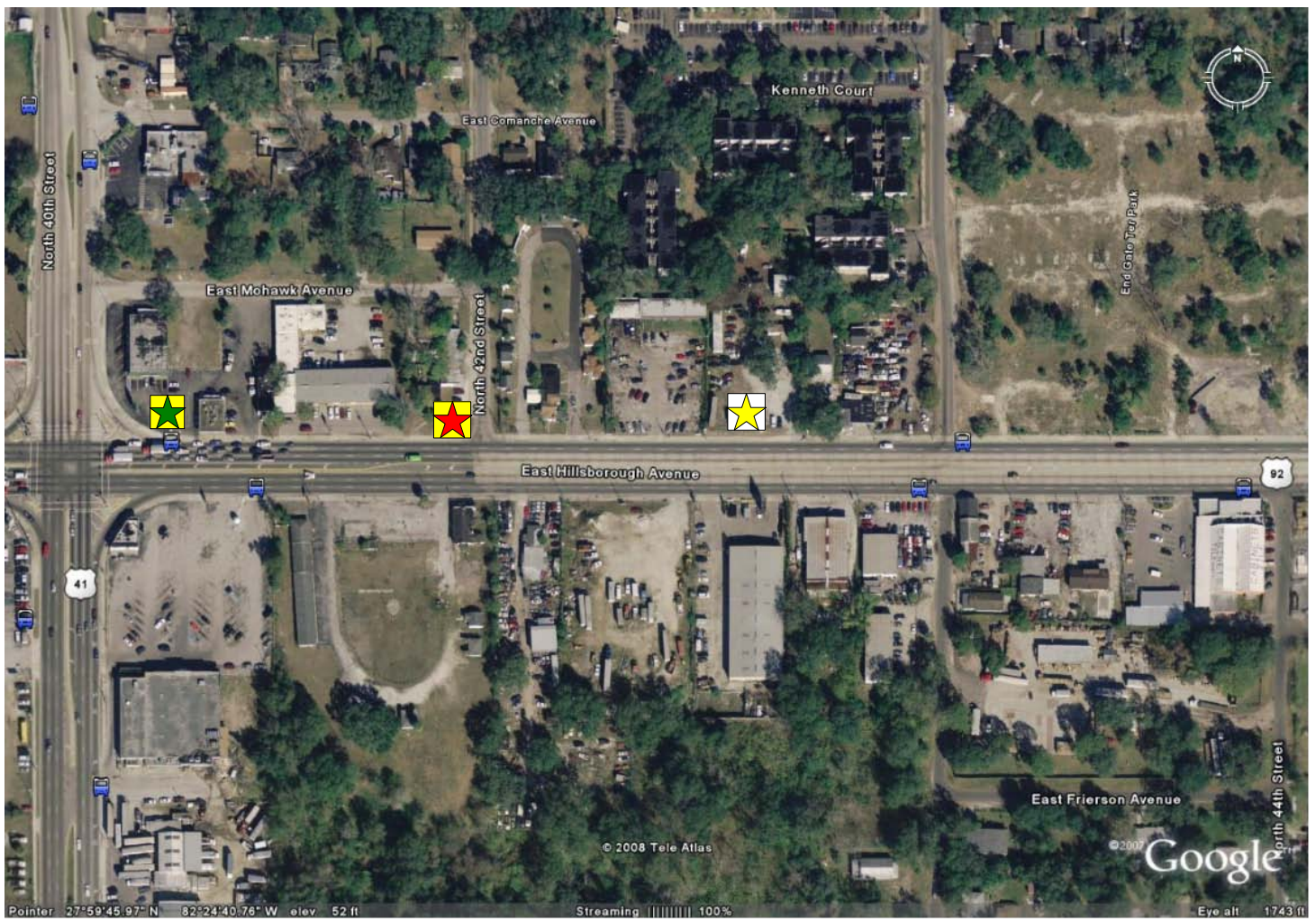

Route 34-West

Hillsborough Avenue and $40^{\text {th }}$ Street

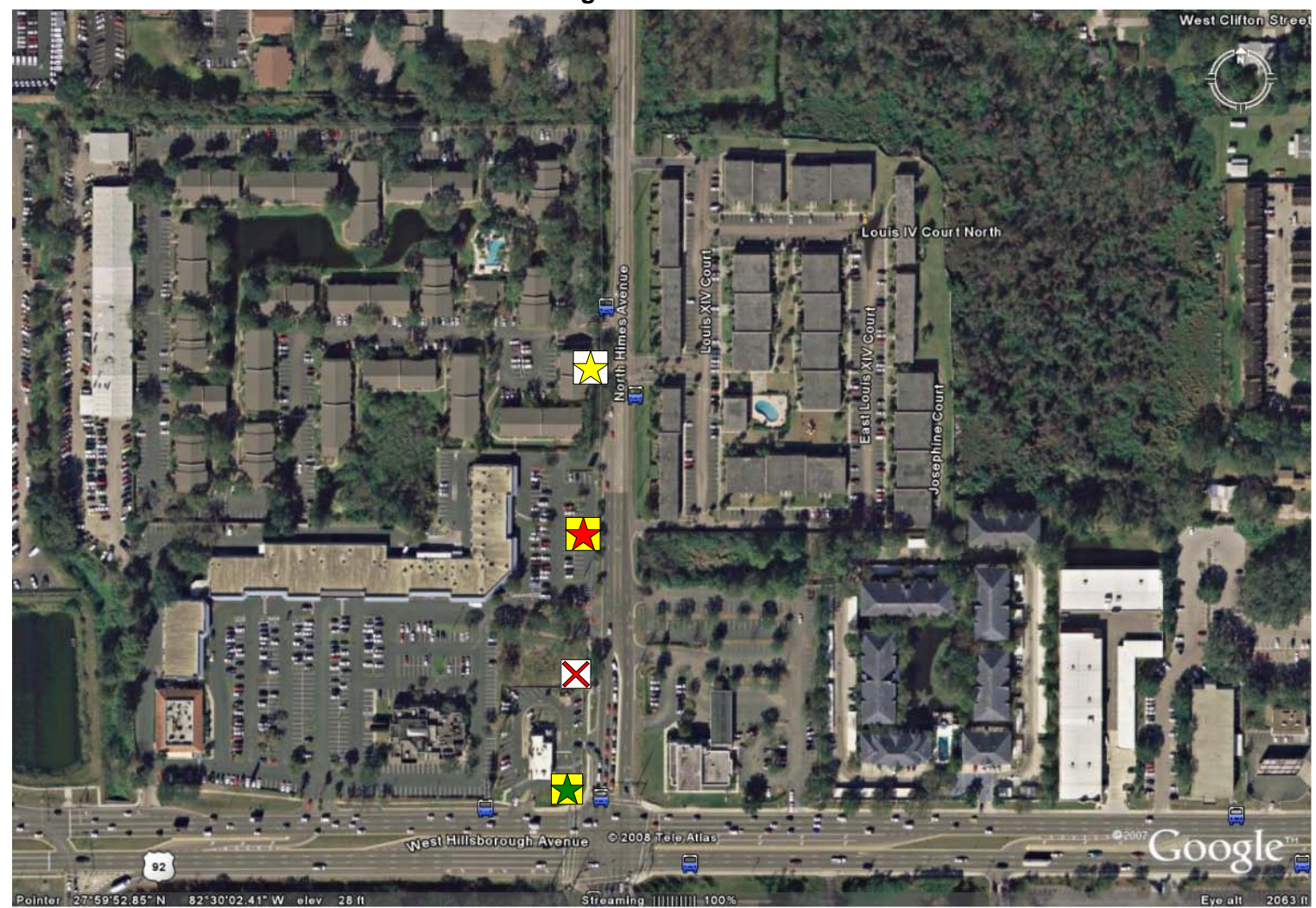

Route 36-South

Himes Avenue and Hillsborough Avenue 


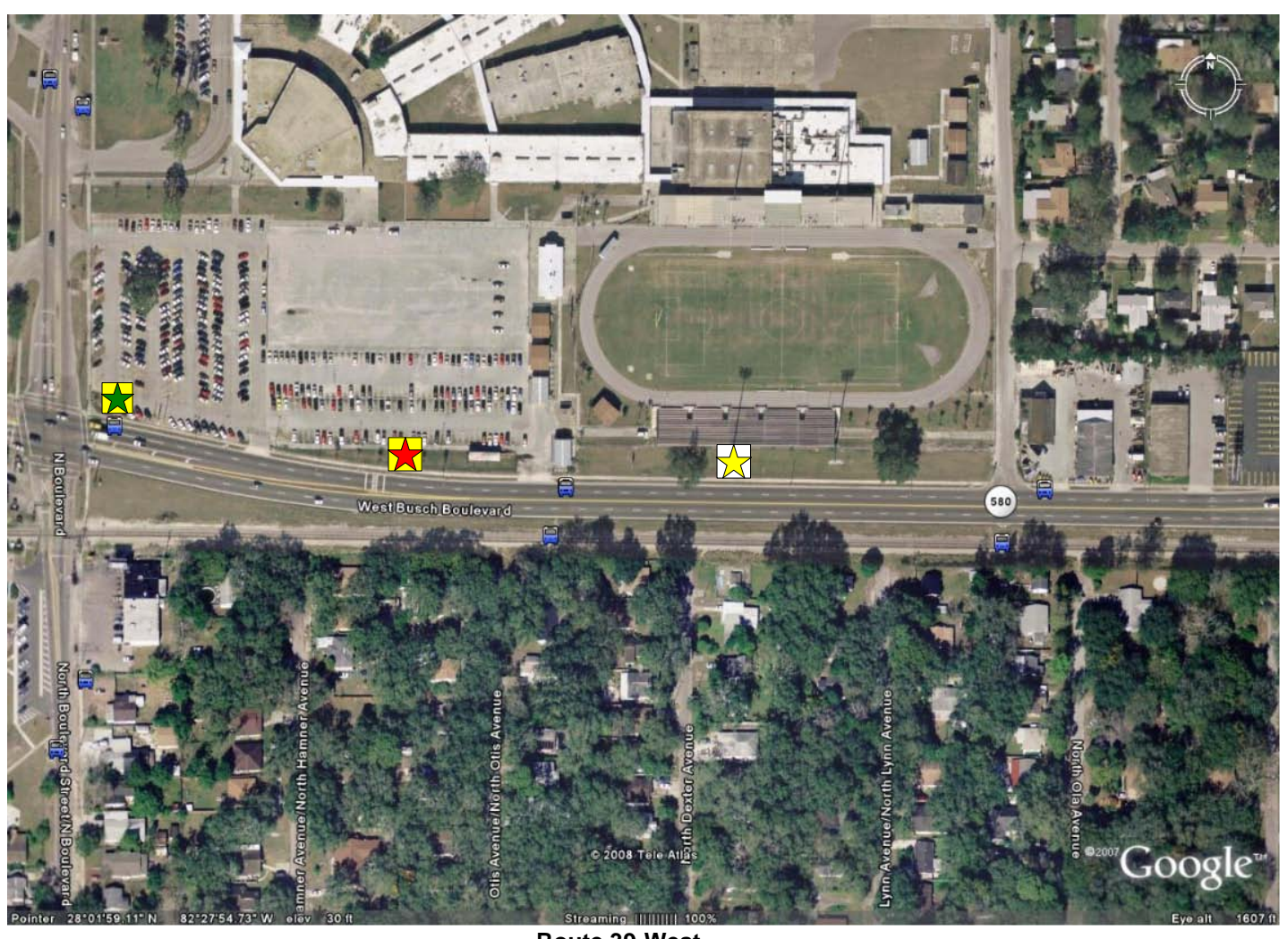

Busch Boulevard and N. Boulevard

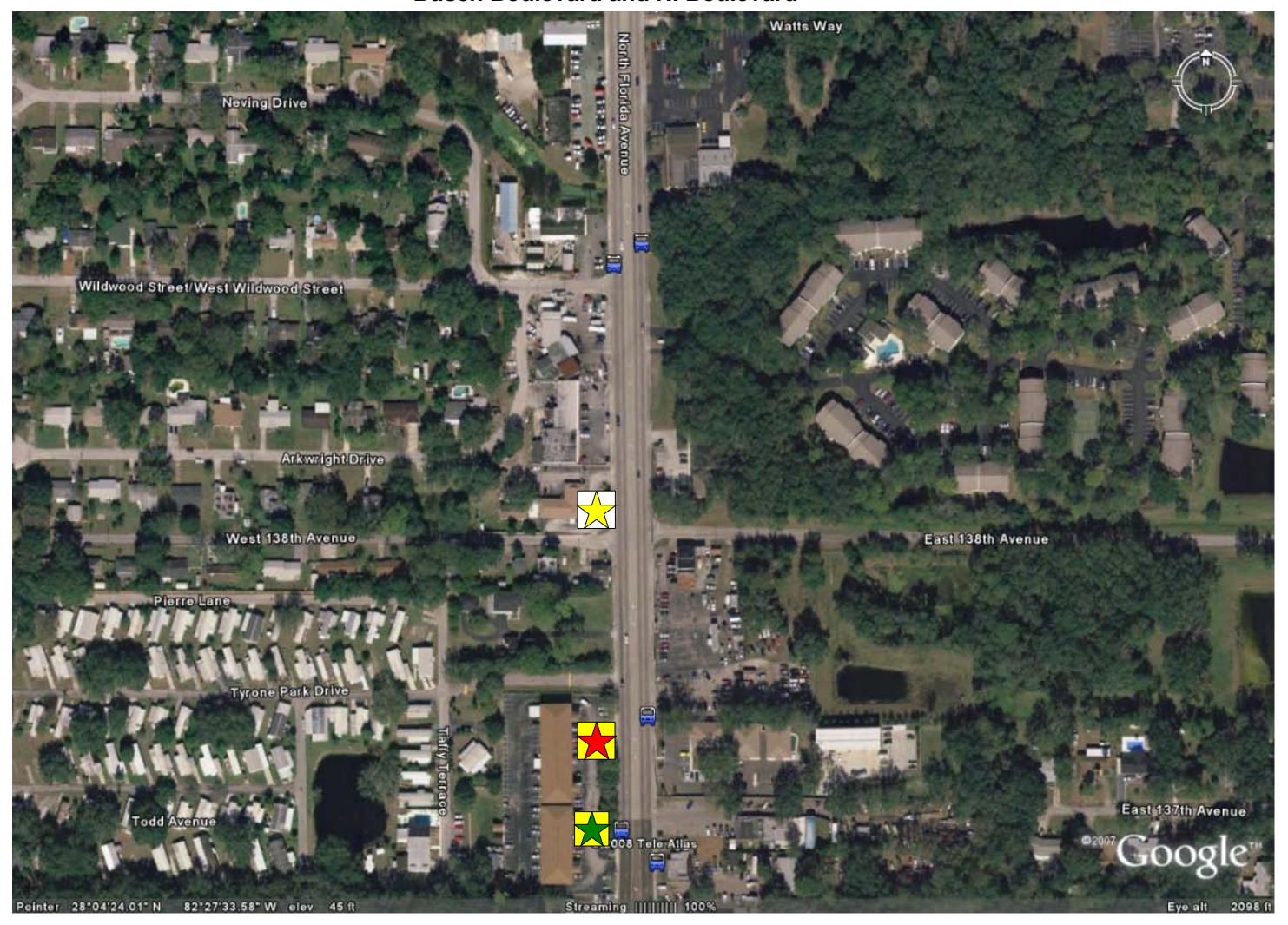

Route 83-S

N. Florida Avenue and $135^{\text {th }}$ Avenue

Comment: Alert too close to bus stop 


\section{Appendix B - Participant Consent Forms Used in Field Tests}

Consent of Proxy

University of South Florida

Information for People Who Give Proxy

Consent to Take Part in Research Studies

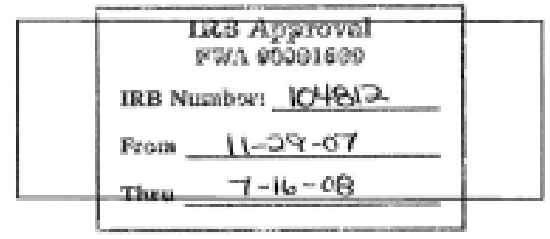

Title of research study: Travel Assistant Device (TAD) to Aid Transit Riders

Person in charge of study: Sean J. Barbeau

Study staff who can act on behalf of the person in charge: Phil Winters, Rafael Perez, Miguel Labrador, or Nevine Georggi

Where the study will take place: USF campus and surrounding Tampa Bay Area

Who is paying for it: Florida Department of Transportation \& National Center for Transit Research at the Center for Urban Transportation Research, University of South Florida

\section{Finding the best person to give consent by proxy}

Under certain circumstances, someone can give consent for another person to take part in this research study. This person is the "subject by proxy." The proxy can make choices for the subject, if the subject is not able to make choices for him/her self.

Someone can give consent for another person to take part in this study. This person is "the Subject by Proxy." This person can decide for the subject, if the subject is not able to make the decision. A proxy can be any of the people listed in A.

A. Look at the list and write Proxy in the space next to the description of the person who will give consent for the person. If there is a person with a higher authority, write in the space why that person is not available, willing, or able to act as proxy. Here is an example:

Health Care Surrogate: No one was named

Spouse:

Spouse has died

Adult Child:

Unable to reach by phone after several tries 


\section{Parent: $\quad \underline{\text { PROXY }}$}

(1) Health Care Surrogate named by person:

(2) A guardian of the person, appointed by the court. He/she must be authorized to give consent to medical treatment:

(3) The person's spouse:

(4) An adult child of the person. If the person has more than one adult child, a majority of the adult children who live near enough to be asked:

(5) A parent of the person:

(6) The adult sibling of the person. If the person has more than one sibling, a majority of the adult siblings who live near enough to know what is going on:

(7) An adult relative of the person who has shown special care and concern for the person. This adult relative has kept regular contact with the person. He/she knows how the person feels about things, what the person likes to do, what the person's health is like, what the person believes and thinks is right

(8) A close friend of the person:

(9) A clinical social worker licensed pursuant to Chapter 491 , or who is a graduate of a court-approved guardianship program. Such a proxy must be selected by the provider's bioethics committee and must not be employed by the provider. If the provider does not have a bioethics committee, then such a proxy may be chosen through an arrangement with the bioethics committee of another provider. The proxy will be notified that, upon request, the provider shall make available a second physician, not involving in the patient's care to assist the proxy in evaluating treatment. Decisions to withhold or withdraw life-prolonging procedures will be reviewed by the facility's bioethics committee. Documentation of efforts to locate proxies from prior classes must be recorded in the patient record.

\section{Proxy's Statement of Consent:}

I understand that I am being asked to give permission for to participate in this research study. My decision is based on what I believe the person would choose for him/herself and what I believe is now best for the person, based on the information I have been provided. 
The remainder of this form is written as if you, as the proxy, are being asked to participate in this research study.

You are being asked to participate because you are enrolled in either the Successful Transition After Graduation for Exception Students (STAGES) at USF or Hillsborough Area Regional Transit (HART)'s travel training program. Both of these programs are designed to increase your level of independence, including the ability to travel independently using public transit (ex. buses). We want to see if a cell phone with Travel Assistant Device (TAD) software can be used to give you "coaching" while riding public transit and also to see if giving you access to the TAD increases your ability to travel safely and independently using public transit.

\section{General Information about the Research Study}

The purpose of this research study is to

1. Determine if software installed on a cell phone (TAD) can "coach" transit riders in a way similar to a travel trainer while riding public transit.

2. Determine if access to a TAD can increase your ability to travel safely and independently

\section{Plan of Study}

Upon your consent, you will be asked to carry a cell phone with the TAD software for two round trips using the bus. A travel trainer will accompany you on these trips and teach you how to ride the bus system safety and also how to use the TAD. Before using the TAD, we will ask you several questions that will take around 1 hour to complete. These questions will be about your travel habits before you use the TAD. You will be supervised by the travel trainer assigned to you, who will also teach you how to use the TAD and how it can help you travel safely using public transportation. After traveling for two round trips, you may be able to travel on additional trips independently for up to two months, if the travel trainer and your parent/guardian believe that it is safe for you to travel independently with the TAD and you want to travel on additional trips. The length of your participation, including while you are carrying the TAD and interviews with the research team, will be up to two months. If you do not wish to participate in the TAD study and do not wish to carry a cell phone, you are still eligible to be taught how to ride public transportation as is normally performed under the STAGES and travel trainer programs.

The TAD system in the cell phone will record your trip start and ends, route, travel time, date/time of day and travel distance for each trip. TAD will also give you reminders about when you are supposed to pull the "stop" cord to get off the bus. The travel trainer will instruct you how to best use these reminders to get off at the correct bus stop.

We will contact you periodically by email or phone to make sure no problems have been encountered and answer any questions you may have.

After you have finished traveling on the bus and using TAD, we will meet with you (approximately 1 hour) to review your travel habits and gauge the effectiveness of the TAD in contributing to your travel independence. This may include discussing: 
- the experience associated with participating in the project

- the accuracy and quality of the information provided by the TAD mobile phone unit

- the impact of the TAD on your quality of life

- the number and type of trips taken while using the TAD

This project is funded by the Florida Department of Transportation and U.S. Department of Transportation under grants to the National Center for Transit Research at the University of South Florida.

\section{Payment for Participation}

You will not be paid for your participation in this study.

\section{Benefits of Being a Part of this Research Study}

Based on the expert opinion of the travel trainer and the approval of your parent/guardian, you may be able to travel independently while carrying the Travel Assistant Device with you. If deemed safe by the travel trainer, the TAD may be able to provide you with reminders for when to stop the bus and get off at the correct bus stop. This feature could prevent you from accidentally becoming lost or missing your bus stop. Also, the TAD includes features to track your current location on a map while traveling, which can be viewed by the travel trainer or your parents/caretaker through a web page. TAD will also monitor your trip and will try to automatically alert the travel trainer if you miss a bus stop or get lost. If you're lost, you can also use the speed-dial feature on the cell phone to call your travel trainer or parents/caretaker.

By taking part in this research study, you will also increase our overall knowledge of the technology behind the TAD mobile phone and the potential for it to be used by many other people in the future.

\section{Risks of Being a Part of this Research Study}

You will face the same risks while carrying the TAD mobile phone and riding public transportation by yourself as you would when not carrying the TAD and riding public transportation, including the risk of getting lost or getting off at the incorrect bus stop. There is a certain amount of risk to your safety when traveling alone, as there is for anyone who travels by themselves. Always be aware of your surroundings and follow the instructions of the travel trainer. There also exists a chance that the TAD could stop working while you are traveling, or could malfunction and give you incorrect advice such as telling you to get off at the wrong bus stop. A travel trainer will travel with you for the two round trips you will take to help reduce any risk to you. You will only travel by yourself if you choose to travel on additional trips and the travel trainer and your parent/guardian approve of this additional travel. If this situation occurs, follow the advice and training that the travel trainer has taught you. We have extensively tested the TAD cell phone and, with the expert opinions of the STAGES teacher and travel trainer, have determined that the risk of the TAD not working or giving wrong information to you is small compared to the benefits that you would receive by carrying the TAD, including increased independence. 
In the efforts to protect your safety, you will be coached by a travel trainer as is a normal part of the STAGES and travel training programs, and this person will train you on how to use public transportation (the bus) as well as how to use the TAD as a reminder for the skills that you will learn, such as getting off at the correct bus stop. Based on the travel trainer's expert opinion, you will only be allowed to travel independently and carry the TAD if the travel trainer believes that it is safe for you to do so and your parents/guardians approve. You can also use the speed dial numbers programmed into the phone to call your travel trainer or parent/caretaker in case of emergency. The TAD also includes a built-in GPS tracking function that will allow us to determine your location if you get lost. The TAD system will also attempt to monitor your travel progress and automatically alert us if it believes that you are lost. Based on these protective features, we believe that while there is a risk in taking part in this study, the above features will keep you reasonably safe while traveling with the TAD.

If you do not feel comfortable or safe riding public transportation with the TAD after receiving training on how to use the TAD, you SHOULD NOT continue with the TAD study and should withdraw from the TAD program. If you withdraw from the TAD study, you will still receive the same amount of travel training as you would have if you had not chosen to be trained on how to use the TAD mobile phone. There is no penalty for choosing to stop carrying the TAD mobile phone.

\section{Confidentiality of Your Records}

Completed informed consent forms and travel information forms will remain with researchers at all times during data collection. They will be kept on file in secure offices at CUTR during analysis and storage. Data will be stored on password-protected computers. Documents will be stored in a lockable research office. Data will be retained for the life of the project and comply with contractual requirements.

The results of this study may be published. The published results will not include your name. However, the inclusion of travel patterns or particular experiences in the published results in a tabular and/or map format and the accuracy of the tracking feature of the TAD mobile phone could permit others to identify a particular household or even individual and link them with dates, times, and locations visited.

Your privacy and research records will be kept confidential to the extent of the law. Authorized research personnel, employees of the Department of Health and Human Services, and the USF Institutional Review Board and its staff, and any other individuals acting on behalf of USF, may inspect the records from this research project.

\section{Volunteering to Be Part of this Research Study}

Your decision to participate in this research study is completely voluntary. You are free to participate in this research study or to withdraw at any time. There will be no penalty if you stop taking part in the study. If you choose to stop carrying the TAD mobile phone at any time, you will still receive the same amount of travel training that you have received if you had never carried the TAD. 


\section{Questions and Contacts}

- If you have any questions about this research study, contact Sean Barbeau at 813974-7208 or barbeau@cutr.usf.edu.

- If you have questions about your rights as a person who is taking part in a research study, you may contact the Division of Research Compliance of the University of South Florida at (813) 974-5638.

\section{Consent to Take Part in This Research Study}

By signing this form I agree that:

- I have fully read or have had read and explained to me this informed consent form describing this research project.

- I have had the opportunity to question one of the persons in charge of this research and have received satisfactory answers.

- I understand that I am being asked to participate in research. I understand the risks and benefits, and I freely give my consent to participate in the research project outlined in this form, under the conditions indicated in it.

- I have been given a signed copy of this informed consent form, which is mine to keep.

Signature of Participant

Printed Name of Participant

Date

\section{Investigator Statement:}

I certify that participants have been provided with an informed consent form that has been approved by the University of South Florida's Institutional Review Board and that explains the nature, demands, risks, and benefits involved in participating in this study. I further certify that a phone number has been provided in the event of additional questions.

\footnotetext{
$\overline{\text { Signature of Investigator }} \quad \overline{\text { Printed Name of Investigator }} \overline{\text { Date }}$
} 
Travel Assistant Device Appendix B Consent to Take Part in this Research Study

\section{Consent to Take Part in this Research Study}

It's up to you. You can decide if you want to take part in this study.

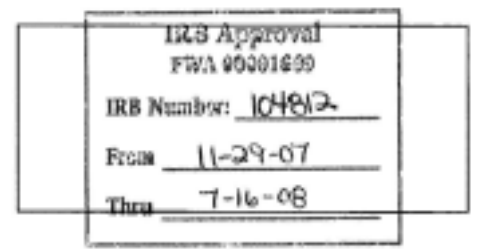

I freely give my consent to take part in this study. I understand that this is research. I have received a copy of this consent form.

\author{
Signature of Proxy \\ for Person taking part in study
}

[Optional] Signature of Witness
Printed Name of Proxy for

Person taking part in study

Printed Name of Witness
Date

Date

\section{Determination of the Person's Ability to Give Consent}

A. I am [the person's name for whom proxy consent is being given]'s [doctor, counselor, therapist, etc.]. I have examined this individual and have found that he/she is unable to give informed consent to take part in the research study.

Signature of Person Attesting to Limited/Diminished Autonomy of Subject

Printed Name of Person Attesting to Limited/Diminished Autonomy of Subject

[OR]

B. I am a physician licensed in the State of Florida. I agree that this person is unable to give consent.

Signature of Physician

Printed Name of Physician 


\section{Statement of Person Obtaining Informed Consent}

I have carefully explained to the person taking part in the study what he or she can expect.

The person who is giving consent to take part in this study

- Understands the language that is used.

- Reads well enough to understand this form. Or is able to hear and understand when the form is read to him or her.

- Does not have any problems that could make it hard to understand what it means to take part in this study.

- Is not taking drugs that make it hard to understand what is being explained.

To the best of my knowledge, when this person signs this form, he or she understands:

- What the study is about.

- What needs to be done.

- What the potential benefits might be.

- What the known risks might be.

- That taking part in the study is voluntary.

$\overline{\text { Signature of Person Obtaining Informed Consent }} \quad$ Date

Printed Name of Person Obtaining Informed Consent

(Optional) Signature of Witness

Date

Printed Name of Witness 

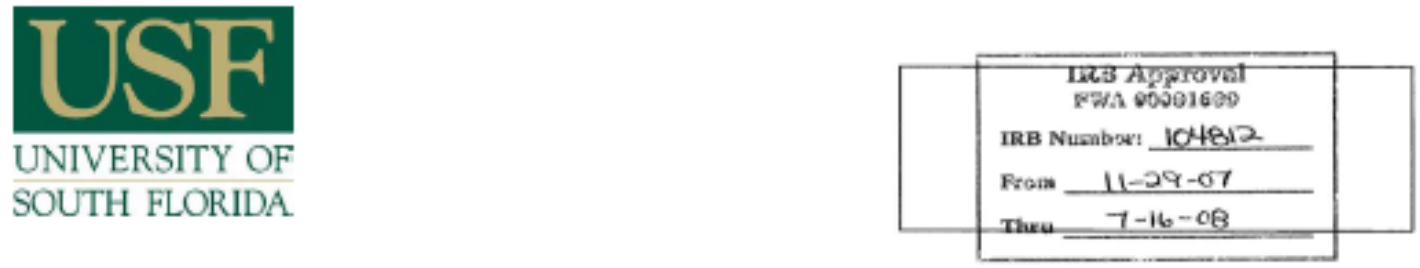

\title{
Assent to Participate in Research
}

\author{
University of South Florida
}

Information for Individuals who cannot provide Informed Consent

Title of Study: $\quad$ Travel Assistant Device (TAD) to Aid Transit Riders

\section{WHY AM I BEING ASKED TO TAKE PART IN THIS RESEARCH?}

You are being asked to take part in a research study about using cell phones to help you travel on the bus. You are being asked to take part in this research study because you are a student in the STAGES program at USF or the HART Travel Training program. If you take part in this study, you will be one of about 6 people in this study.

\section{WHO IS DOING THE STUDY?}

The person in charge of this study is Sean Barbeau of the Center for Urban Transportation Research (CUTR). He is being guided in this research by Phil Winters and Rafael Perez. Other people who you may see while you are in the study are other members of the STAGES or HART Travel Training program. Gigi Gonzalez from STAGES and Mark Sheppard from HART will also help guide you in this study.

\section{WHAT IS THE PURPOSE OF THIS STUDY?}

By doing this study, we hope to learn if we can use cell phones to give you directions for when to get off the bus as well as track where you are in case you get lost. Also, we want to see if the cell phone helps you learn how to use the bus more quickly than if you did not have the cell phone.

\section{WHERE IS THE STUDY GOING TO TAKE PLACE AND HOW LONG WILL IT LAST?}

The study will be take place at and around the USF Tampa area, including some bus routes in Tampa. You will be asked to come to USF 2 times during the study for interviews. Each of those visits will take about 1 hour. The total amount of time you will be interviewed for this study is 2 hours over the next 10 months. You will also be asked to carry a cell phone with you while you ride the bus with a travel trainer for two round trips. The travel trainer will teach you how to ride the bus and how to use TAD on a particular bus route. After completing these two trips, if you want you may be able to travel independently and use the TAD, if approved by the travel trainer and your parent/guardian for up to 2 months. 


\section{WHAT WILL I BE ASKED TO DO?}

You will be asked to carry a cell phone with you while you learn how to travel on the bus for two round trips. Since you are a STAGES student or in the HART travel training program, you would normally be trained how to ride the bus. As part of the research of this study, the cell phone will give you reminders for when to get off the bus. Your travel trainer will also teach you how to use this cell phone correctly. This cell phone will also let us know where you are so we can find you if you get lost while traveling. Before you carry the cell phone, we will interview you and ask you questions about how you get to places now and problems that you think might keep you from traveling by yourself on the bus. After you carry the cell phone, we will interview you and ask you if you liked to carry the cell phone and if it gave you useful reminders for when to get off the bus. You can also tell us anything that you thought was difficult about using the cell phone. After you travel on the two trips with the travel trainer, if you want to you may be able to ride by yourself while using the TAD, if approved by the travel trainer and your parent/guardian for a period of up to two months.

\section{WHAT THINGS MIGHT HAPPEN THAT ARE NOT PLEASANT?}

Although we have made every effort to try and make sure this doesn't happen, you may get lost while riding the bus or get off at the wrong bus stop. Also, the cell phone could stop working and not provide you with reminders to get off the bus. The travel trainer will accompany you on the two round trips to prevent this from happening, and, if you ride independently, the travel trainer will teach you what to do if these things happen. The cell phone will try and let us know where you are so if you are lost we can find you.

In addition to the things that we have already talked about, you may experience something bad that we do not know about at this time.

\section{WILL SOMETHING GOOD HAPPEN IF I TAKE PART IN THIS STUDY?}

We cannot promise you that anything good will happen if you decide to take part in this study. However, there is a chance that you will be able to ride the bus by yourself after completing the travel training program and if you carry the Travel Assistant Device cell phone and it is approved by the travel trainer and your parent/guardian.

\section{DO I HAVE TO TAKE PART IN THE STUDY?}

You should talk with your parents or anyone else that you trust about taking part in this study. If you do not want to take part in the study, that is your decision. You should take part in this study because you really want to volunteer.

If you do not think you want to take part in this study, you should talk this over with your parents or travel trainer or teacher and decide together.

\section{IF I DON'T WANT TO TAKE PART IN THE STUDY, WHAT WILL HAPPEN?}


If you do not want to take part in the study, you can still be taught how to ride the bus as would normally happen as part of the STAGES and Travel Training programs. However, you will not be given a cell phone, will not receive reminders for when to get off the bus from your cell phone and your cell phone will not tell us where you are at all times.

\section{WILL I RECEIVE ANY REWARDS FOR TAKING PART IN THE STUDY?}

You will not receive any reward for taking part in this study.

\section{WHO WILL SEE THE INFORMATION I GIVE?}

We will share your information with your parents and/or travel trainer and/or special education teacher so that they can better help you. The information may also be provided to other people so they can examine the benefits of the Travel Assistant Device, but we will remove your name and locations that you visit from the information so that they won't know who you are.

\section{CAN I CHANGE MY MIND AND QUIT?}

If you decide to take part in the study you still have the right to change your mind later. No one will think badly of you if you decide to quit. Also, the people who are running this study may need for you to stop. If this happens, they will tell you why.

\section{WHAT IF I HAVE QUESTIONS?}

You can ask questions about this study at any time. You can talk with your parents or other adults, including your STAGES teacher or travel trainer, that you trust about this study. You can talk with the person who is asking you to volunteer. If you think of other questions later, you can ask them.

\section{Assent to Participate}

I understand what the person running this study is asking me to do. I have thought about this and agree to take part in this study.

Name of person agreeing to take part in the study

Date

Name of person providing information to subject

Date

IRB\# 104812 


\section{Informed Consent}

Social and Behavioral Sciences

University of South Florida

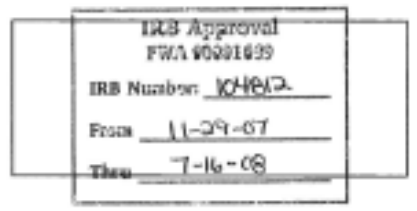

\section{Information for People Who Take Part in Research Studies}

The following information is being presented to help you decide whether or not you want to take part in a minimal risk research study. Please read this carefully. If you do not understand anything, ask the person in charge of the study.

Title of Study: Travel Assistant Device (TAD) to Aid Transit Riders

Principal Investigator: Sean J. Barbeau, Center for Urban Transportation Research, USF

Study Location(s): USF campus and Tampa Bay Area

You are being asked to participate because you are enrolled in either the Successful Transition After Graduation for Exception Students (STAGES) at USF or Hillsborough Area Regional Transit (HART)'s travel training program. Both of these programs are designed to increase your level of independence, including the ability to travel independently using public transit (e.g. buses). We want to see if a cell phone with Travel Assistant Device (TAD) software can be used to give you "coaching" while riding public transit and also to see if giving you access to the TAD increases your ability to travel safely and independently using public transit.

\section{General Information about the Research Study}

The purpose of this research study is to:

- Determine if software installed on a cell phone (TAD) can "coach" transit riders in a way similar to a travel trainer while riding public transit.

- Determine if access to a TAD can increase your ability to travel safely and independently

\section{Plan of Study}

Upon your consent, you will be asked to carry a cell phone with the TAD software for two round trips using the bus. A travel trainer will accompany you on these trips and teach you how to ride the bus system safety and also how to use the TAD. Before using the TAD, we will ask you several questions that will take around 1 hour to complete. These questions will be about your travel habits before you use the TAD. You will be supervised by the travel trainer assigned to you, who will also teach you how to use the TAD and how it can help you travel safely using public transportation. After traveling for two round trips, you may be able to travel on additional trips independently for up to two months, if the travel trainer and your parent/guardian believe that it is safe for you to travel independently with the TAD and you want to travel on additional trips. The length of your participation, including while you are carrying the TAD and interviews with the research team, will be up to two months. If you do not wish to participate in the TAD study and do not wish to carry a cell phone, you are still eligible to be taught how to ride public transportation as is normally performed under the STAGES and travel trainer programs. 
The TAD system in the cell phone will record your trip start and ends, route, travel time, date/time of day and travel distance for each trip. TAD will also give you reminders about when you are supposed to pull the "stop" cord to get off the bus. The travel trainer will instruct you how to best use these reminders to get off at the correct bus stop.

We will contact you periodically by email or phone to make sure no problems have been encountered and answer any questions you may have.

After you have finished traveling on the bus and using TAD, we will meet with you (approximately 1 hour) to review your travel habits and gauge the effectiveness of the TAD in contributing to your travel independence. This may include discussing:

- The experience associated with participating in the project,

- The accuracy and quality of the information provided by the TAD mobile phone unit,

- The impact of the TAD on your quality of life,

- The number and type of trips taken while using the TAD.

This project is funded by the Florida Department of Transportation and U.S. Department of Transportation under grants to the National Center for Transit Research at the University of South Florida.

\section{Payment for Participation}

You will not be paid for your participation in this study.

\section{Benefits of Being a Part of this Research Study}

Based on the expert opinion of the travel trainer and the approval of your parent/guardian, you may be able to travel independently while carrying the Travel Assistant Device with you. If deemed safe by the travel trainer, the TAD may be able to provide you with reminders for when to stop the bus and get off at the correct bus stop. This feature could prevent you from accidentally becoming lost or missing your bus stop. Also, the TAD includes features to keep you safe while traveling by tracking your current location on a map, which can be viewed by the travel trainer or your parents/caretaker through a web page. TAD will also monitor your trip and will try to automatically alert the travel trainer if you miss a bus stop or get lost. If you're lost, you can also use the speeddial feature on the cell phone to call your travel trainer or parents/caretaker.

By taking part in this research study, you will also increase our overall knowledge of the technology behind the TAD mobile phone and the potential for it to be used by many other people in the future.

\section{Risks of Being a Part of this Research Study}

You will face the same risks while carrying the TAD mobile phone and riding public transportation by yourself as you would when not carrying the TAD and riding public transportation, including the risk of getting lost or getting off at the incorrect bus stop. A travel trainer will travel with you for the two round trips you will take to help reduce any risk to you. You will only travel by yourself if you choose to travel on additional trips and the travel trainer and your parent/guardian approve of this additional travel. There is a certain amount of risk to your safety when traveling alone, as there is for anyone who travels by themselves. Always be aware of your surroundings and follow the instructions of the travel trainer. There also exists a chance that the TAD could stop working while you are traveling, or could malfunction and give you incorrect advice such as telling you to get off at the wrong bus stop. If this situation occurs, follow the advice and training that the travel trainer has taught you. We have extensively tested the TAD cell phone and, with the expert opinions of the STAGES teacher and travel trainer, have determined that the risk of the TAD not working or giving

IRB\# 104812 
wrong information to you is small compared to the benefits that you would receive by carrying the TAD, including increased independence.

In the efforts to protect your safety, you will be coached by a travel trainer as is a normal part of the STAGES and travel training programs, and this person will train you on how to use public transportation (the bus) as well as how to use the TAD as a reminder for the skills that you will learn, such as getting off at the correct bus stop. Based on the travel trainer's expert opinion, you will only be allowed to travel independently and carry the TAD if the travel trainer believes that it is safe for you to do so and your parents/guardians approve. You can also use the speed dial numbers programmed into the phone to call your travel trainer or parent/caretaker in case of emergency. The TAD also includes a built-in GPS tracking function that will allow us to determine your location if you get lost while traveling. The TAD system will also attempt to monitor your travel progress and automatically alert us if it believes that you are lost. Based on these protective features, we believe that while there is a risk in taking part in this study, the above features will keep you reasonably safe while traveling with the TAD.

If you do not feel comfortable or safe riding public transportation with the TAD after receiving training on how to use the TAD, you SHOULD NOT continue with the TAD study and should withdraw from the TAD program. If you withdraw from the TAD study, you will still receive the same amount of travel training as you would have if you had not chosen to be trained on how to use the TAD mobile phone. There is no penalty for choosing to stop carrying the TAD mobile phone.

\section{Confidentiality of Your Records}

Completed informed consent forms and travel information forms will remain with researchers at all times during data collection. They will be kept on file in secure offices at CUTR during analysis and storage. Data will be stored on password-protected computers. Documents will be stored in a lockable research office. Data will be retained for the life of the project and comply with contractual requirements.

The results of this study may be published. The published results will not include your name. However, the inclusion of travel patterns or particular experiences in the published results in a tabular and/or map format and the accuracy of the tracking feature of the TAD mobile phone could permit others to identify a particular household or even individual and link them with dates, times, and locations visited.

Your privacy and research records will be kept confidential to the extent of the law. Authorized research personnel, employees of the Department of Health and Human Services, and the USF Institutional Review Board and its staff, and any other individuals acting on behalf of USF, may inspect the records from this research project.

\section{Volunteering to Be Part of this Research Study}

Your decision to participate in this research study is completely voluntary. You are free to participate in this research study or to withdraw at any time. There will be no penalty if you stop taking part in the study. If you choose to stop carrying the TAD mobile phone at any time, you will still receive the same amount of travel training that you have received if you had never carried the TAD. 


\section{Questions and Contacts}

- If you have any questions about this research study, contact Sean Barbeau at 813-9747208 or barbeau@cutr.usf.edu.

- If you have questions about your rights as a person who is taking part in a research study, you may contact the Division of Research Compliance of the University of South Florida at (813) $974-5638$.

\section{Consent to Take Part in This Research Study}

By signing this form I agree that:

- I have fully read or have had read and explained to me this informed consent form describing this research project.

- I have had the opportunity to question one of the persons in charge of this research and have received satisfactory answers.

- I understand that I am being asked to participate in research. I understand the risks and benefits, and I freely give my consent to participate in the research project outlined in this form, under the conditions indicated in it.

- I have been given a signed copy of this informed consent form, which is mine to keep.

Signature of Participant

Printed Name of Participant

Date

\section{Investigator Statement:}

I certify that participants have been provided with an informed consent form that has been approved by the University of South Florida's Institutional Review Board and that explains the nature, demands, risks, and benefits involved in participating in this study. I further certify that a phone number has been provided in the event of additional questions. 


\section{Parental Informed Consent}

Social and Behavioral Sciences

University of South Florida

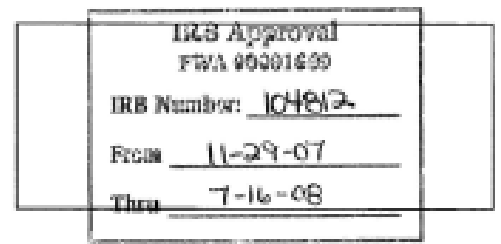

Information for Parents

Who are being asked to allow their dependant to take part in a research study

Researchers at the University of South Florida (USF) study many topics. We want to see if cell phones can help individuals with cognitive disabilities use public transit. To do this, we need the help of people who agree to take part in a research study.

Title of research study: Travel Assistant Device (TAD) to Aid Transit Riders

Person in charge of study: Sean Barbeau

Study staff who can act on behalf of the person in charge: Phil Winters, Rafael Perez, Miguel Labrador, and Nevine Georggi

Where the study will be done: In and around the USF Tampa area

Who is paying for it: The Florida Department of Transportation and the National Center for Urban Transportation Research

\section{Should your child take part in this study?}

This form tells you about this research study. You can decide if you want your child to take part in it. They do not have to take part. Reading this form can help you decide.

Before you decide:

- Read this form.

- Talk about this study with the person in charge of the study or the person explaining the study.

- You can have someone with you when you talk about the study. Find out what the study is about.

You can ask questions:

- You may have questions this form does not answer. If you do, ask the person in charge of the study or study staff as you go along.

- You don't have to guess at things you don't understand. Ask the people doing the study to explain things in a way you can understand.

After you read this form, you can:

- Take your time to think about it.

- Have a friend or family member read it.

- Talk it over with someone you trust.

It's up to you. If you choose to let your child be in the study, then you can sign the form. If you do not want your child to take part in this study, do not sign the form.

IRB\# 104812 


\section{Why is this research being done?}

The purpose of this study is to find out if GPS-enabled cell phones can be used to help individuals with cognitive disabilities use public transit by providing them with reminders for tasks like getting off the bus at the correct time. These phones will also track their position so we will know where they are if they get lost while traveling.

\section{Why is your child being asked to take part?}

We are asking your child to take part in this study because they are a student in the STAGES program at USF or are enrolled in the HART Travel Training program.

\section{How long will your child be asked to stay in the study?}

Your child will be asked to spend up to the amount of time necessary to complete two round trips via public transportation, which is not expected to exceed 2 month. in this study,. He/she will be asked to carry the cell phone with him/her as they he/she travels on two round trips using public transportation. If your child elects, he/she may carry it for a longer period of time up to two months as he/she regularly rides public transportation upon the approval of your child, you, and the travel trainer.

\section{How often will your child need to come for study visits?}

A study visit is one you have with the person in charge of the study or study staff. Your child will need to come for 2 study visits to complete two interviews. Additionally, they will be asked to ride public transportation on two round trips.

- Your child will come for one visit towards the beginning of the study, before they are given the cell phone, so they can tell us about their current travel experiences and any questions or concerns that they might have with riding the bus. Your child will come for one visit towards the end of the study after they have carried the cell phone so they can tell us about their experiences with carrying the phone and the reminders that it provided to them. They will also be asked to carry the cell phone while riding on two round trips using public transportation.

Most study visits will take about 1 hour.

On two visits (one before your child carries the cell phone, and one after your child carries the cell phone), the person in charge of the study or staff will:

- Interview your child (a copy of an interview script is attached).

On the remaining visits, the person in charge of the study or staff will:

- Accompany your child while they travel on a round trip using public transportation.

How many other people will take part?

About 5 other people will take part in this study at USF.

What other choices do you have if you decide not let your child to take part? 
If you decide not to let your child take part in this study, that is okay. They are still eligible to receive the same travel training under the STAGES or travel training program that they would receive if this study was not taking place.

\section{How do you get started?}

If you decide to let your child take part in this study, you will need to sign this consent form. Then, we will interview you and your child. After this happens, your child will be given a cell phone and will go through the travel training program with the travel trainer teaching your child how to ride public transportation, and how the cell phone can help them do this.

\section{What will happen during this study?}

Your child will be trained on how to use public transportation as they would have normally if this study was not taking place. As part of this study, your child will be given a GPS-enabled cell phone that will attempt to give them reminders (i.e. audible, visual, or vibration alerts) for when to get off the bus. The cell phone will also track the movements of your child so we know where they are if they become lost while traveling. As part of this study your child will also be taught how to use the cell phone by the travel trainer as part of their travel training.

\section{Here is what your child will need to do during this study}

You child will need to carry a GPS-enabled cell phone (provided by us) with them while they are learning how to ride public transportation. They will be instructed by the travel trainer how to use the cell phone to receive reminders for when to get off the bus. Your child will also be interviewed twice, once before using the cell phone and once after using the cell phone. At the end of the study, you will have to return the cell phone to us.

\section{Will you or your child be paid for taking part in this study?}

We will not pay you or your child for the time you volunteer in this study.

\section{What will it cost you to let your child take part in this study?}

It will not cost you anything to take part in the study.

The study will pay the costs of:

- the cell phone

- cell phone service

The cell phone must be returned at the end of the study period.

What are the potential benefits to your child if you let him/her take part in this study?

The potential benefits to your child are:

- being able to ride public transportation independently

- increasing the frequency that your child gets off at the correct bus stop because the cell phone provides reminders to them

- contributing to your child's safety by tracking the location of the cell phone while they are traveling independently

What are the risks if your child takes part in this study? 
There may be these risks:

- Risk to your child's safety when traveling independently, as there is for any individual traveling independently. A travel trainer will accompany your child on the two round trips that will be traveled via public transportation to help prevent risks to your child's safety. Your child will only travel independently if they elect to do so after completing the two round trips accompanied by a travel trainer, and approval is given by the travel trainer and you.

- Risk to your child's safety while using public transportation, as there is for any individual using public transportation. A travel trainer will accompany your child on the two round trips that will be traveled via public transportation to help prevent risks to your child's safety. Your child will only travel independently on additional trips if they elect to do so after completing the two round trips accompanied by a travel trainer, and approval is given by the travel trainer and you.

- Risk of your child becoming lost while traveling on public transportation. A travel trainer will accompany your child on the two round trips that will be traveled via public transportation to help prevent this from occurring. Your child will only travel independently on additional trips if they elect to do so after completing the two round trips accompanied by a travel trainer, and approval is given by the travel trainer and you.

- Risk of your child getting off at the wrong bus stop. A travel trainer will accompany your child on the two round trips that will be traveled via public transportation to help prevent this from occurning. Your child will only travel independently on additional trips if they elect to do so after completing the two round trips accompanied by a travel trainer, and approval is given by the travel trainer and you.

If your child has any of these problems, call the person in charge of this study right away at (813) 974-7208.

If the potential risks bother or worry you, or if you have other problems, call the person in charge of this study at (813) 974-7208.

\section{What if your child gets sick or hurt while he/she is in the study?}

\section{If you need emergency care:}

- Call 911 or go to the nearest hospital right away.

- USF does not provide emergency care.

- Call the person in charge of this study as soon as you can. They will need to know that your child is hurt or ill. Call Sean Barbeau at (813) 974-7208 or Phil Winters at (813) 974-9811.

If it is not an emergency, and your child gets hurt or sick:

- Go to your regular doctor.

If your child is harmed because he/she takes part in the study:

- We will pay the medical costs if your child was harmed because our staff did something they should not have done.

- Florida law limits how much USF is able to pay. USF cannot pay for lost wages, disability, or discomfort. Read Florida Statute 768.28 to find out how much USF is able to pay. You can get a copy of the law by calling USF Research Compliance at (813) $974-5638$.

- Call the USF Self Insurance Programs (SIP) at (813) 974-8008 and ask them to look into what happened.

Affiliate Statement [if applicable, insert your Institution-approved injury statement here.] 
Sponsor Statement [if applicable, insert here.]

Conflict of Interest Statement [if applicable, insert here.]

What will we do to keep your child's study records from being seen by others?

Federal law requires us to keep your child's study records private.

We will keep all data and records in a locked office at USF and all electronic data in a secured database.

However, certain people may need to see your child's study records. By law, anyone who looks at your child's records must keep them confidential. The only people who will be allowed to see these records are:

- The study staff.

- People who make sure that we are doing the study in the right way. They also make sure that we protect your rights and safety:

- USF Institutional Review Board (IRB)

- United States Department of Health and Human Services (DHHS)

- The Florida Department of Transportation and the National Center for Transit research have paid for this study. They may look at the study records to make sure the study is done in the right way

- We may publish what we find out from this study. If we do, we will not use your child's name.

- Because of the nature of this study, travel behavior patterns will be recorded by the cell phone. While this information will be kept confidential, there is a small risk that someone with advanced knowledge of your child's transportation patterns could identify them from these characteristics (i.e. street names, bus routes, street grid patterns, relationship to location of USF or other landmarks on a map, etc.). If findings from this study are published, your address will not be used and artificial names will be substituted for real street names.

What happens if you decide not to let your child take part in this study?

You should only let your child take part in this study if both of you want to take part. If your child does not want to take part in this study, they are still eligible for the same travel training that they would normally have under the STAGES and HART programs.

If you decide not to let your child take part:

- You and your child won't be in trouble or lose any rights either of you normally have.

- You and your child will still get the same services you would normally have.

- You and your child can still get your travel training through the STAGES and HART programs.

What if you let your child join the study and then later decide you want to stop? If you decide you want to stop taking part in the study, tell the study staff as soon as you can.

- We will tell you how to stop safely. We will tell you if there are any dangers if you stop 
suddenly.

- If you decide to stop, you can go on getting your regular travel training through the STAGES and HART programs.

- However, you will have to turn in the cell phone and your child will no longer have access to it.

\section{Are there reasons we might take your child out of the study later on?}

Even if you want your child to stay in the study, there may be reasons we will need to take him/her out of it. Your child may be taken out of this study:

- If the sponsor stops the study

- If you or your child are not coming for your study visits when scheduled

- If the travel trainer, STAGES teacher, or study staff member decides that it is not safe for your child to travel using public transportation or use the cell phone while traveling.

- If the travel trainer, STAGES teacher, or study staff member decides that it is not in your child's best interest to continue with the study.

You can get the answers to your questions.

If you have any questions about this study, call Sean Barbeau at (813) 974-7208.

If you have questions about your rights as a person who is taking part in a study, call USF Research Compliance at (813) 974-5638.

\section{Consent for Child to Take Part in this Research Study}

It's up to you. You can decide if you want your child to take part in this study.

I freely give my consent to let my child take part in this study. I understand that this is research. I have received a copy of this consent form.

Signature of Parent of child taking part in study

Signature of Witness

$$
\text { Printed Name of Parent }
$$

Date
Date

\section{Statement of Person Obtaining Informed Consent}

I have carefully explained to the person taking part in the study what he or she can expect.

The person who is giving consent to take part in this study

- Understands the language that is used.

- Reads well enough to understand this form. Or is able to hear and understand when the form is read to him or her.

- Does not have any problems that could make it hard to understand what it means to take

IRB\# 104812 
part in this study.

- Is not taking drugs that make it hard to understand what is being explained.

To the best of my knowledge, when this person signs this form, he or she understands:

- What the study is about.

- What needs to be done.

- What the potential benefits might be.

- What the known risks might be.

- That taking part in the study is voluntary.

Signature of Investigator Printed Name of Investigator Date Or authorized research investigator designated by the Principal Investigator

Signature of Witness

Printed Name of Witness

Date

\section{Child's Assent Statement}

Sean Barbeau has explained to me this research study called "Travel Assistant Device (TAD) to Aid Transit Riders".

I agree to take part in this study.

Signature of Child taking part in study

Signature of Parent of child taking part in study

Signature of person obtaining consent

Signature of Witness

\section{Printed Name of Child}

Printed Name of Parent

Printed Name of person obtaining consent

Printed Name of Witness

\section{Date}

Date

Date

Date

If child is unable to give assent, please explain the reasons here: 
Travel Assistant Device Appendix B Parental Informed Consent

Signature of Parent of child taking part in study

Signature of person

obtaining consent

Signature of Witness
Printed Name of Parent

Printed Name of person obtaining consent

Printed Name of Witness
Date

Date

Date 


\section{Informed Consent}

Social and Behavioral Sciences

University of South Florida

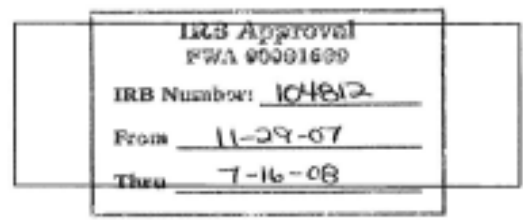

\section{Information for People Who Take Part in Research Studies}

The following information is being presented to help you decide whether or not you want to take part in a minimal risk research study. Please read this carefully. If you do not understand anything, ask the person in charge of the study.

Title of Study: Travel Assistant Device (TAD) to Aid Transit Riders

Principal Investigator: Sean J. Barbeau, Center for Urban Transportation Research, USF

Study Location(s): USF campus and Tampa Bay Area

You are being asked to participate because your child or dependant is a member of the Successful Transition After Graduation for Exceptional Students (STAGES) program at USF or is a client or Hillsborough Area Regional Transit (HART)'s Travel Training program. We want to see if a cell phone with Travel Assistant Device (TAD) software can be used to give individuals with special needs "coaching" while riding public transit and also to see if giving individuals with special needs access to the TAD increases their ability to travel safely and independently using public transit. We want your feedback and input in the design, development, and testing of the TAD device to make sure that the TAD can adequately meet the challenges that an individual with cognitive disabilities will face when they are using public transit. You have personal and/or professional experiences, including the relationship with your child or dependant that may give insight to this problem.

\section{General Information about the Research Study}

The purpose of this research study is to:

- Determine if software installed on a cell phone (TAD) can "coach" transit riders in a way similar to a travel trainer while riding public transit.

- Determine if access to a TAD can increase individuals with special needs' ability to travel safely and independently

\section{Plan of Study}

Upon your consent, you will be interviewed both before and after your child/dependant carries the TAD and rides the bus. Each interview will last approximately 1 hour. You will be asked questions about your child's use of the TAD, and potential benefits or drawbacks to the use of the device. You will also be also questions about your opinion of your child's level of independence before and after carrying the TAD, as well as the amount of trips that they take via the bus.

IRB\# 104812 
This project is funded by the Florida Department of Transportation and U.S. Department of Transportation under grants to the National Center for Transit Research at the University of South Florida.

\section{Payment for Participation}

You will not be paid for your participation in this study.

\section{Benefits of Being a Part of this Research Study}

You will receive no direct benefit of participating in this study. Individuals with special needs may benefit from this study by being able to travel independently by carrying the Travel Assistant Device. The TAD may be able to provide these individuals with reminders for when to stop the bus and get off at the correct bus stop. This feature could prevent these individuals from accidentally becoming lost or missing their bus stop. Also, the TAD includes features to keep individuals safe while traveling by tracking their current location on a map, which can be viewed by the travel trainer or their parents/caretaker through a web page. TAD will also monitor the individual's trips and will try to automatically alert the travel trainer if they miss a bus stop or get lost. If they're lost, they can use the speed-dial feature on the cell phone to call the travel trainer or their parents/caretaker.

By taking part in this research study, you will also increase our overall knowledge of the technology behind the TAD mobile phone and the potential for it to be used by many other people in the future.

\section{Risks of Being a Part of this Research Study}

There are no known risks to you as a result of participating in this research study.

If you do not feel comfortable being interviewed about your child/dependant's use of the TAD, you SHOULD NOT continue to function as a study participant and should withdraw from the TAD program. There is no penalty for you to leave the study at any time.

\section{Confidentiality of Your Records}

Completed informed consent forms and comments/feedback given in an advisory role will remain with researchers at all times during data collection. They will be kept on file in secure offices at CUTR during analysis and storage. Data will be stored on password-protected computers. Documents will be stored in a lockable research office. Data will be retained for the life of the project and comply with contractual requirements.

The results of this study may be published. The published results will not include your name as a participant in this project unless you give permission. Comments/suggestions provided by you during the course of the study will only be published with your permission and can be published anonymously. Your privacy and research records will be kept confidential to the extent of the law. Authorized research personnel, employees of the Department of Health and Human Services, and the USF Institutional Review Board and its staff, and any other individuals acting on behalf of USF, may inspect the records from this research project.

\section{Volunteering to Be Part of this Research Study}

Your decision to participate in this research study is completely voluntary. You are free to participate in this research study or to withdraw at any time. There will be no penalty if you stop taking part in the study. 


\section{Questions and Contacts}

- If you have any questions about this research study, contact Sean Barbeau at 813-9747208 or barbeau@cutr.usf.edu.

- If you have questions about your rights as a person who is taking part in a research study, you may contact the Division of Research Compliance of the University of South Florida at (813) $974-5638$.

\section{Consent to Take Part in This Research Study}

By signing this form I agree that:

- I have fully read or have had read and explained to me this informed consent form describing this research project.

- I have had the opportunity to question one of the persons in charge of this research and have received satisfactory answers.

- I understand that I am being asked to participate in research. I understand the risks and benefits, and I freely give my consent to participate in the research project outlined in this form, under the conditions indicated in it.

- I have been given a signed copy of this informed consent form, which is mine to keep.

Signature of Participant

$$
\text { Printed Name of Participant }
$$

Date

\section{Investigator Statement:}

I certify that participants have been provided with an informed consent form that has been approved by the University of South Florida's Institutional Review Board and that explains the nature, demands, risks, and benefits involved in participating in this study. I further certify that a phone number has been provided in the event of additional questions.

Signature of Investigator

Printed Name of Investigator

Date 